\title{
Validação de metodologia de avaliação da função pulmonar em pacientes submetidos à laringectomia total
}

\begin{abstract}
Tese apresentada à Faculdade de Medicina da Universidade de São Paulo para obtenção do título de Doutor em Ciências.
\end{abstract}

Programa de Clínica Cirúrgica

Orientador: Prof. Dr. Rogério Aparecido Dedivitis Coorientador: Dr. João Marcos Salge

São Paulo 
Dados Internacionais de Catalogação na Publicação (CIP)

Preparada pela Biblioteca da

Faculdade de Medicina da Universidade de São Paulo

Oreprodução autorizada pelo autor

\section{Castro, Mario Augusto Ferrari de}

Validação de metodologia de avaliação da função pulmonar em pacientes submetidos à laringectomia total / Mario Augusto Ferrari de Castro. -- São Paulo, 2015.

Tese(doutorado)--Faculdade de Medicina da Universidade de São Paulo.

Programa de Clínica Cirúrgica.

Orientador: Rogério Aparecido Dedivitis.

Coorientador: João Marcos Salge.

Descritores: 1.Testes de função respiratória 2.Espirometria 3.Pletismografia 4.Laringectomia 5.Neoplasias laríngeas 6.Carcinoma de células escamosas

USP/FM/DBD-315/15 
Para as três gerações que inspiram minha caminhada:

Minha mãe (in memorian), minha esposa e meus filhos. 
"Porque se chamava homem Também se chamavam sonhos E sonhos não envelhecem Em meio a tantos gases lacrimogêneos Ficam calmos, calmos, calmos..."

Flavio Venturini, "Clube da esquina II"

Determinação + Resiliência $=$ Objetivo 


\section{AGRADECIMENTOS}

A todos os pacientes, alvo desse estudo, agradeço sua disponibilidade, mesmo sem benefícios imediatos, espero sinceramente que nossos resultados possam melhorar de alguma maneira a qualidade de vida de todos.

A minha esposa Andréa e meus filhos Enzo e Mateus, por entender a necessidade da minha ausência para a realização desse trabalho e por darem-me motivos para seguir em frente todos os dias.

Ao Prof. Dr. Rogério A. Dedivitis, meu orientador, chefe, amigo e irmão agradeço os ensinamentos de vida diários, pelo exemplo de profissionalismo e por despertar em mim a vontade de ir mais além, sempre.

Ao Prof. Dr. Lenine Garcia Brandão, Professor Titular do Departamento de Cirurgia de Cabeça e Pescoço da Faculdade de Medicina da USP, por permitir que esse projeto se tornasse realidade.

Ao Prof. Dr. Cláudio Roberto Cernea, Coordenador da Comissão Assessora de Pesquisa, pela oportunidade, amizade e atenção dispensada.

Ao Dr. João Marcos Salge por dispor de seu tempo para a interpretação e avaliação de todos os exames, pela amizade cativada e pela gentileza para comigo.

À Dra. Lica Arakawa-Sugueno pela disponibilidade constante na realização da avaliação dos pacientes e pela grande amiga que se tornou.

Ao Dr. André Vicente Guimarães, agradeço pela atenção, amizade e pela generosidade constante para auxiliar e ensinar.

Ao Dr. Carlos Eduardo Molinari Nardi, pela parceria diária, pela cumplicidade e pelo prazer de ser um grande amigo para todas as horas.

À Dra. Silvia Miguéis Picado Petrarolha pelo auxílio em nossa rotina diária, tornando possível minha ausência na realização dos exames. 
À Ft. Viviane Alves pela auxílio na realização dos exames, agradeço seu profissionalismo e carinho no trato com os pacientes, motivo de exemplo para muitos profissionais.

Ao Dr. José Luiz Boechat Paione, Diretor Técnico do Hospital Ana Costa e Dr. Jorge Tadeu, Diretor Clínico da Irmandade da Santa Casa da Misericórdia de Santos, pelo exemplo de probidade, seriedade e pela valorização que dão às boas iniciativas, estimulando-as.

Às secretárias do Departamento de Cirurgia de Cabeça e Pescoço, Ana Aparecida Justino Oliveira e Francisca Cathia de Oliveira, ao Sr. Maurício Gonçalves Leite; às secretárias Eliane F. Monico Gazetto e Márcia Sueli da S. Bento do Curso de Pós-Graduação de Clínica Cirúrgica pela permanente disponibilidade.

À Athos Medical, por meio do Sr. José Cruz, pela doação dos bocais.

À Profa. Jocely Picado pelo auxílio na tradução do abstract.

À Dra Ines Nishimoto pelo auxílio e orientação na avaliação estatística.

À Sra. Valéria Vilhena e toda equipe da Divisão de Biblioteca e Documentação da Faculdade de Medicina da USP pela elaboração da ficha catalográfica.

À minha irmã, Dra. Maria Claudia Ferrari de Castro, meus queridos sogros e meu pai pelo apoio incondicional.

A todos que, mesmo injustamente não citados, não deixarão de ser reconhecidos.

A Deus por tudo. 


\section{LISTA DE FIGURAS}

Figura 1 - Dispositivo adesivo extratraqueal ............................................. 20

Figura 2 - Dispositivo extratraqueal fixado ............................................... 20

Figura 3 - Espirômetro conectado ……………................................... 22

Figura 4 - Aparelho de pletismografia …………………........................ 22 


\section{LISTA DE TABELAS}

Tabela 1 - Características demográficas, etilismo e tabagismo.................... 31

Tabela 2 - Classificação da amostra por estádio oncológico......................... 32

Tabela 3 - Estratificação da amostra segundo a Escala de dispnéia............. 32

Tabela 4 - Medidas funcionais respiratórias................................................ 33

Tabela 5 - Frequência dos padrões respiratórios....................................... 34

Tabela 6 - Características demográficas, etilismo e tabagismo de acordo com os padrões respiratórios, segundo agrupamentos.............................. 34

Tabela 7 - Escala de dispnéia de acordo com padrões respiratórios, segundo grupamentos

Tabela 8 - Características demográficas casos x controles. 36

Tabela 9 - Média e desvio padrão dos parâmetros de reprodutibilidade casos $\mathrm{x}$ controles

Tabela 10 - Frequência e porcentagem de exames rejeitados para cada parâmetro de reprodutibilidade avaliado casos $x$ controles.

Tabela 11 - Frequência e porcentagem de exames rejeitados agrupados por manobra e total de exames rejeitados por pelo menos uma manobra casos $x$ controles. 


\section{LISTA DE ABREVIAÇÕES}

DPOC - Doença pulmonar obstrutiva crônica

$V_{E F}$ - Volume expiratório forçado no primeiro segundo

CVF - Capacidade vital forçada

VC - Volume corrente

CPT - Capacidade pulmonar total

VR - Volume residual

VGT - Volume gasoso torácico

CRF - Capacidade residual funcional

Raw - Resistência das vias aéreas

Gaw - Condutância das vias aéreas

sGaw - Condutância específica das vias aéreas

CO - Monóxido de carbono

$\mathrm{CO}_{2}$ - Dióxido de carbono

DLCOunc - Capacidade de difusão do monóxido de carbono

V_ext_obs - Volume retroextrapolado valor absoluto

V_ext_CVF_\% - Volume retroextrapolado (porcentagem da CVF)

T_Exp_obs - $\quad$ Tempo de Expiração

Delta_CVF - Variabilidade da CVF

Delta_VEF1 - Variabilidade do VEF1

Switch-In - Erro de Switch in na Pletismografia

Reprod_VGT - Varibilidade da manobra de VGT

IVC/SVC - Capacidade vital inspiratória em relação á Capacidade Vital lenta na manobra de Difusão 
BHT - Breath Holding Time

n_BHT_9_11 - Número de Manobras de Difusão com BHT entre 9-11 s

Delta_DLCO_abs - Variabilidade da Difusão valor absoluto

Delta_DLCO_\% - Variabilidade da Difusão valor em porcentagem

DP - Desvio padrão 


\section{RESUMO}

Castro MAF. Validação de metodologia de avaliação da função pulmonar em pacientes submetidos a laringectomia total [Tese]. São Paulo: Faculdade de Medicina, Universidade de São Paulo; 2015.

Introdução: Pacientes com câncer de laringe costumam apresentar histórico de tabagismo. Nos pacientes submetidos à tratamento cirúrgico, as complicações pulmonares podem levar à morte no período pós-operatório. Um método com dispositivo extratraqueal padronizado, simples e de baixo custo para a avaliação pulmonar dos pacientes laringectomizados seria muito útil. Objetivo: Validar a metodologia para a avaliação pulmonar em pacientes submetidos à laringectomia total por meio da aplicação de um dispositivo extratraqueal adesivo. Métodos: Participaram deste estudo transversal 50 pacientes submetidos à laringectomia total há pelo menos seis meses como modalidade de tratamento para o câncer de laringe em acompanhamento no Serviço de Cirurgia de Cabeça e Pescoço do Hospital das Clínicas da Faculdade de Medicina da Universidade de São Paulo. Por meio da anamnese e do prontuário dos pacientes foram obtidos dados demográficos, tabagismo, a presença de doenças respiratórias nos últimos 30 dias, dados acerca do tumor e sobre o tratamento realizado. Os testes de função pulmonar foram utilizados para caracterizar a presença de limitação funcional respiratória e o padrão funcional do paciente laringectomizado. Na intenção de avaliar a reprodutibilidade dos exames realizados, foram utilizados parâmetros com respectivos critérios de aceitação dos exames. Os critérios de reprodutibilidade são indicadores de exatidão. Foi feita a comparação desses parâmetros com 50 exames realizados em pacientes não laringectomizados, no mesmo período com o mesmo equipamento, pareados para idade e gênero. Resultados: Em todos os casos de nosso estudo, uma vedação aérea foi mantida durante todo o procedimento com o uso do dispositivo extratraqueal adesivo. Após a realização dos testes de função pulmonar, encontramos que $44 \%$ dos pacientes apresentavam um padrão respiratório normal e 56\% alterado. Comparando a frequência e porcentagem dos exames rejeitados entre os laringectomizados e o grupo controle, dos nove parâmetros avaliados, cinco foram exatamente iguais, três apresentaram frequência de rejeição maior no grupo controle e somente um mostrou uma maior frequência de exames rejeitados no grupo dos pacientes submetidos à laringectomia total. $\mathrm{O}$ total de exames rejeitados foi maior no grupo controle $(72 \%)$ do que no grupo dos laringectomizados (46\%). Conclusões: A maioria dos pacientes submetidos à laringectomia total apresenta função pulmonar alterada, de caráter obstrutivo, na maioria das vezes, devido ao histórico de tabagismo. A metodologia para a avaliação da função pulmonar por meio do uso do dispositivo extra-traqueal proposto é confiável, precisa e reprodutível.

Descritores: testes de função respiratória; espirometria; pletismografia; laringectomia; neoplasias laríngeas; carcinoma de células escamosas. 


\section{ABSTRACT}

Castro MAF. Validation of the methodology for the assessment of the pulmonary function in patients submitted to total laryngectomy [Thesis]. São Paulo: Faculdade de Medicina, Universidade de São Paulo; 2015.

Introduction: Laryngeal cancer patients usually have a smoking history. In patients submitted to laryngectomy, pulmonary complications may lead to death in the postoperative phase. A simple and low-cost method with a standardized extra-tracheal device for the pulmonary assessment of laryngectomized patients would be very useful. Objective: Validate the methodology for pulmonary assessment in patients submitted to total laryngectomy through the application of an adhesive extratracheal device. Methods: This transversal study included 50 patients who had been submitted to total laryngectomy at least six months prior to this investigation, as choice of treatment for laryngeal cancer while followed by the Head and Neck Service from Hospital das Clínicas, São Paulo University. Through anamnesis and patients medical records the following information was collected: demographic data, smoking habits, the presence of respiratory diseases in the last 30 days, as well as information about the tumor and the performed treatment. Pulmonary tests were used to characterize the presence of respiratory functional limitation as well as laryngectomized patient's functional standards. Aiming at evaluating the reproducibility of the performed tests, parameters were used with the respective criteria for the acceptance of the tests. The reproducibility criteria are indicators of accuracy. A comparison of these parameters was made with 50 tests performed in non-laryngectomized patients, in the same period with the same equipment, paired up according to age and gender. Results: In all cases of our study, an air-tight seal was maintained through the entire procedure with the use of the adhesive extratracheal device. After the performance of pulmonary function tests, $44 \%$ of patients presented a normal respiratory standard whereas $56 \%$ had an altered one. When comparing the frequency and percentage of the rejected tests between laryngectomized and control group, out of nine assessed parameters, five were exactly the same, three presented a greater rejection frequency in the control group and only one showed a greater frequency of rejected tests in the group of patients submitted to total laryngectomy. The total of rejected tests was greater in the control group (72\%) when compared to the laryngectomized one $(46 \%)$. Conclusions: Most patients submitted to total laryngectomy present altered pulmonary function, of the obstructive type most of the times, due to a smoking history. The methodology for the assessment of the pulmonary function by using the extra-tracheal proposed device is reliable, accurate and reproducible.

Descriptors: respiratory function tests; spirometry; plethysmography; laryngectomy; laryngeal neoplasias; squamous cell carcinoma.

Essa tese está de acordo com as seguintes normas, em vigor no momento desta publicação: 
Referências: adaptado de International Committee of Medical Journals Editors (Vancouver).

Universidade de São Paulo. Faculdade de Medicina. Divisão de Biblioteca e Documentação. Guia de apresentação de dissertações, teses e monografias. Elaborado por Anneliese Carneiro da Cunha,

Maria Julia de A. L. Freddi, Maria F. Crestana, Marinalva de Souza Aragão, Suely Campos Cardoso, Valéria Vilhena. $3^{a}$ ed. São Paulo: Divisão de Biblioteca e Documentação; 2011.

Abreviaturas dos títulos dos periódicos de acordo com List of Journals Indexed in Index Medicus. 


\section{SUMÁRIO}

Lista de figuras

Lista de tabelas

Lista de abreviações

Resumo

Abstract

Sumário

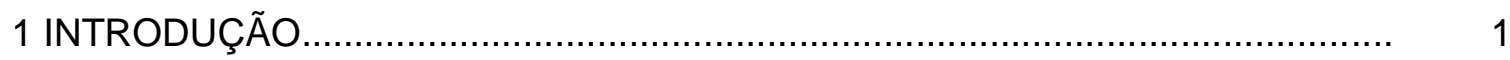

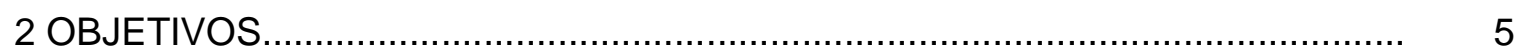

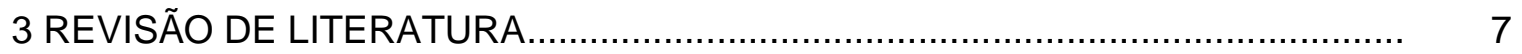

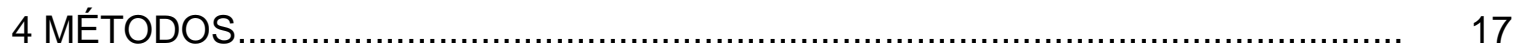

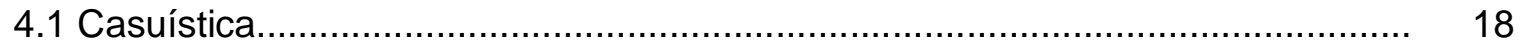

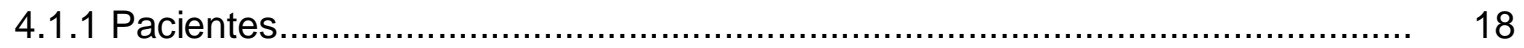

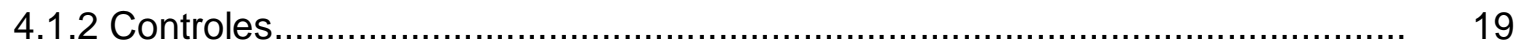

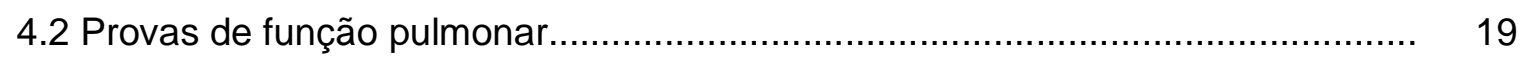

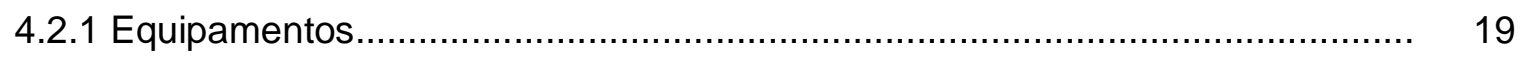

4.2.1.1 Dispositivo adesivo extratraqueal.......................................................... 19

4.2.1.2 Aparelho de pletismografia..................................................................... 21

4.2.2 Manobra de capacidade vital.................................................................... 22

4.2.3 Medidas de volumes pulmonares............................................................... 24

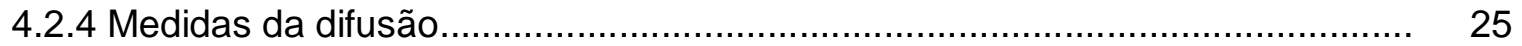

4.2.5 Medida da resistência das vias aéreas.......................................................... 25

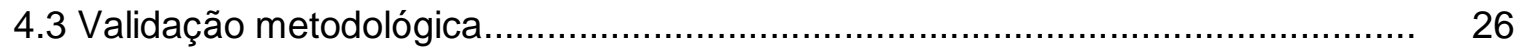

4.4 Análise estatística............................................................................................ 28

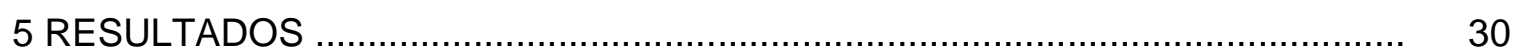

6 DISCUSSÃO

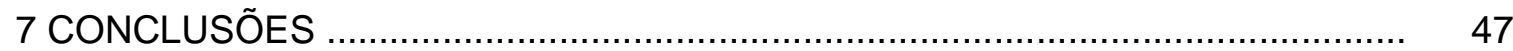

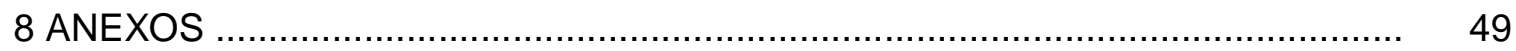

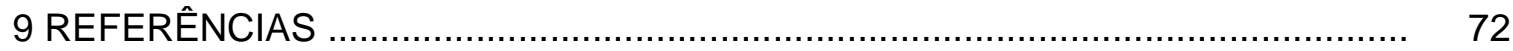

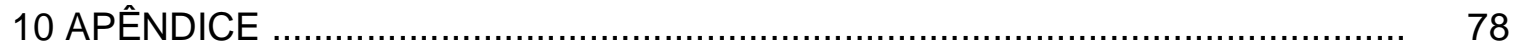


1 INTRODUÇÃO 


\section{INTRODUÇÃO}

Muitos pacientes com câncer de cabeça e pescoço, mais especificamente aqueles com câncer de laringe, apresentam histórico de tabagismo. Dentre as opções para seu tratamento, incluem-se as laringectomias total e parciais e o tratamento não cirúrgico. Nos pacientes submetidos à cirurgia, as complicações pulmonares podem levar ao óbito no período pós-operatório. Devido a dificuldades técnicas, a avaliação da função pulmonar raramente é realizada em pacientes laringectomizados ${ }^{1}$. Muitos desses indivíduos sofrem de doenças pulmonares obstrutivas crônicas (DPOC) ${ }^{2}$, que foram encontradas em $81 \%$ dos pacientes laringectomizados ${ }^{3}$.

Em função do tabagismo anterior à laringectomia e das condições não fisiológicas das vias aéreas, o estado pós-laringectomia apresenta várias alterações na função pulmonar, refletidas pela soma das mudanças ventilatórias. $O$ ar respirado através do traqueostoma após a laringectomia total não passa pelo condicionamento natural do trato respiratório superior, ocorrendo, portanto, redução na filtração de partículas sólidas transmitidas pelo ar, bem como aerossóis. Além disso, o ar inalado não passa por umidificação nem por aquecimento. Comparando com a respiração através do trato respiratório superior, o paciente traqueostomizado tem uma redução aerodinâmica na resistência ao fluxo aéreo durante a inspiração e a expiração, o que pode ter um efeito negativo na ventilação pulmonar periférica (colabamento alveolar) em função de uma alteração do ponto de igual pressão (ponto no qual a pressão intrapleural e a pressão alveolar são iguais) ${ }^{4-7}$.

Além dos possíveis sintomas relacionados ao câncer, existem várias desvantagens para o sistema respiratório no estado pós-laringectomia. Um dos 
fatores prognósticos mais importantes na sobrevida de pacientes laringectomizados é a deterioração progressiva de sua função pulmonar ${ }^{5,8}$. Entretanto, são escassas as informações objetivas acerca das condições respiratórias em laringectomizados, obtidas em laboratórios para avaliação da função pulmonar, ${ }^{2,5,9-11}$.

A influência da remoção da laringe, bem como a consequente diminuição do espaço morto ventilatório, somente pode ser avaliada quando valores espirométricos pré e pós-operatórios são mensurados. Os dados sobre esse tópico são contraditórios ${ }^{12-14}$. Uma estimativa confiável da função pulmonar pode ser muito útil em pacientes laringectomizados para evitar complicações em intervenções cirúrgicas, para avaliar os resultados do tratamento e até mesmo para propósitos preventivos $^{15}$.

Tradicionalmente, uma cânula traqueal com balonete conectada ao espirômetro tem sido usada para avaliação da função pulmonar nesses pacientes $^{5,12,16}$. Entretanto, o uso de uma cânula é problemático por algumas razões. Em primeiro lugar, a inserção da cânula geralmente é uma experiência desconfortável para o paciente e leva à tosse que, por vezes, pode durar vários minutos $^{15}$. Além disso, devido ao decréscimo no diâmetro real da traqueia, seu uso é considerado uma influência negativa nos resultados dos testes de expiração e inspiração forçada. Máscaras traqueais colocadas manualmente sobre o traqueostoma também têm sido usadas para o mesmo propósito, porém, muitas vezes, permite o vazamento de $\operatorname{ar}^{2}$. Dispositivos extratraqueais são usados por alguns autores na tentativa de evitar tais problemas $^{9-11}$.

Um método com dispositivo extratraqueal confortável, que não apresentasse vazamentos, padronizado e simples de ser utilizado seria muito útil para a avaliação pulmonar dos pacientes laringectomizados. Poucos trabalhos constantes na 
literatura avaliaram a reprodutibilidade e acurácia de tal metodologia e mais raros ainda, utilizaram tal metodologia para avaliar a função pulmonar em pacientes laringectomizados ${ }^{17}$. 
2 OBJETIVOS 


\section{OBJETIVOS}

1. Caracterizar a presença de distúrbios funcionais respiratórios e o padrão funcional do paciente laringectomizado.

2. Validar a metodologia para a avaliação pulmonar em pacientes submetidos à laringectomia total por meio da aplicação de um dispositivo extratraqueal adesivo. 
3 REVISÃO DE LITERATURA 


\section{REVISÃO DE LITERATURA}

Desde o trabalho de Heyden ${ }^{13}$, em 1950, a avaliação da função respiratória em pacientes laringectomizados tem sido avaliado por vários autores. Devido às dificuldades técnicas para a realização de tal avaliação, a literatura nesse tópico é controversa.

Um dos primeiros trabalhos que utilizou a investigação espirométrica para avaliar doenças pulmonares obstrutivas em laringectomizados é o de Torjussen ${ }^{4}$, em 1968. Dando sequência a essa mesma linha de pesquisa, Shim et al. ${ }^{18}$ realizaram, em 1972, estudos sobre a função pulmonar de pacientes com obstrução em vias aéreas superiores determinando que, desde que a resistência das vias aéreas é dominada pelo calibre da parte mais estreita da árvore brônquica, sua medida é particularmente sensível ao estreitamento da traqueia e laringe. Lesões traumáticas e corpos estranhos em grandes vias aéreas também ocasionam aumento da resistência, acompanhada de aumento do trabalho respiratório. O fluxo aéreo na traqueia e grandes brônquios é essencialmente turbulento e a obstrução acentua essa turbulência.

Harris et al. ${ }^{12}$ foram os primeiros a notar que a influência da remoção da laringe propriamente dita e a consequente redução no espaço morto ventilatório só podia ser avaliada quando os valores espirométricos pré e pós-operatórios estavam disponíveis. Esses autores utilizaram uma cânula introduzida na traqueia conectada a um espirômetro para a avaliação da função pulmonar.

Usuil $^{19}$ avaliou a função ventilatória em pacientes laringectomizados, verificando que a curva de fluxo-volume expiratório máximo, quando avaliada juntamente com a curva volume de fechamento, pode dar informações importantes sobre a característica obstrutiva em pacientes laringectomizados. O padrão da 
curva de fluxo-volume foi semelhante ao encontrado em pacientes com bronquite crônica. Essas anormalidades podem ser revertidas, pelo menos parcialmente, por inalação de broncodilatador. Dessa maneira, concluiu-se que os pacientes laringectomizados apresentam anormalidades ventilatórias.

Najwer et al. $^{20}$, avaliando 35 homens antes e depois da ressecção de tumores de laringe, determinaram que a deficiência ventilatória pulmonar resultante depende da extensão da infiltração neoplásica e sua localização, mas depende principalmente do grau de estreitamento do lúmen da laringe.

Um dos primeiros trabalhos que descreve o uso de máscaras sobre o traqueostoma para a avaliação da função pulmonar em laringectomizados foi o de Togawa et al. ${ }^{2}$. Concluiu-se que a falta da função das vias aéreas superiores após laringectomia cria efeitos desfavoráveis sobre o trato respiratório inferior. Para tanto, foram realizados testes de função respiratória em 13 pacientes laringectomizados, os quais evidenciaram mudanças obstrutivas nos pulmões. Apesar de apresentar uma grande variação, a resistência pulmonar foi definitivamente menor do que o normal devido à falta da resistência das vias aéreas superiores. A complacência dinâmica manteve-se dentro do normal, quando foi utilizada uma máscara sobre o traqueostoma. $\mathrm{O}$ valor foi menor do que o normal quando medido através de uma cânula com cuff. A diferença entre as complacências estáticas e dinâmicas foi maior do que em pacientes não laringectomizados, o que podem indicar a evidência da distribuição desigual do ar nos pulmões. Assim, avaliação pulmonar regular é recomendada para os pacientes laringectomizados. Essa avaliação continua sendo fundamental para um tratamento adequado de alterações pulmonares após a laringectomia total, parcial ou 
protocolos de preservação de órgão, visto que grande parte desses pacientes apresenta doenças pulmonares obstrutivas crônicas.

Ferri et al. $^{21}$ realizaram espirometria em pacientes com câncer de laringe antes e depois da laringectomia total, colocando um bocal posicionado sobre a abertura traqueal. Os parâmetros considerados foram os índices de dinâmicos respiratórios. Cinquenta pacientes foram submetidos à espirometria antes da laringectomia para fins de avaliação pré-anestésica. De acordo com os resultados obtidos, os pacientes podiam ser divididos em três grupos. O primeiro grupo é composto por 10 indivíduos, em quem nenhuma melhora foi observada nos valores e, na verdade, alguns pioraram. O segundo grupo é composto por 20 pacientes em quem os valores espirométricos permaneceram mais ou menos constantes. $O$ terceiro grupo é composto por 20 pacientes que apresentaram uma significativa melhora de seus índices respiratórios.

Gregor et al. ${ }^{11}$ avaliaram 39 laringectomizados entre 6 meses e 18 anos depois da operação. Foram medidos os diâmetros do traqueostoma e, além de um exame geral completo, foram realizados testes de função respiratória, incluindo gasometria. A maioria dos pacientes apresentou função respiratória pior que o esperado para a idade. O estudo sugere que tal deficiência é devida a doenças pulmonares e cardiovasculares intercorrentes, ao invés de fatores anatômicos relacionados às mudanças na via aérea superior. Não houve correlação entre tamanho ou área secional transversal do traqueostoma e a função respiratória.

A função pulmonar de 31 tabagistas com câncer de laringe foi avaliada por Todisco et al. ${ }^{5}$ antes e durante o primeiro ano após laringectomia total $(n=21)$ e após o laringectomia parcial $(n=10)$. Dois deles morreram devido a recidivas do câncer e um por complicações broncopulmonares. Os dados da avaliação da 
função pulmonar pré-operatória foram consistentes com doença pulmonar obstrutiva crônica coexistente na maioria dos pacientes, provavelmente devido ao tabagismo. Comparando os grupos, não foram observadas diferenças nos valores pré e pós-operatório nos 10 pacientes submetidos à laringectomia parcial. Pelo contrário, os laringectomizados totais mostraram progressiva diminuição da obstrução brônquica e infecção bacteriológica da traqueia durante o primeiro ano após a operação. Pacientes submetidos ou a serem submetidos à laringectomia total precisam de uma avaliação completa de pré e pós-operatória da função pulmonar.

Davidson et al. ${ }^{9}$ descreveram em um dispositivo simples que pode ser usado para conectar um paciente traqueostomizado a um equipamento de espirometria. Comparando a função pulmonar de nove pacientes após laringectomia com nove pacientes não laringectomizados apresentando graus semelhantes de obstrução do fluxo de ar, encontrou-se que a taxa do pico de fluxo foi significativamente menor do que o $\mathrm{VEF}_{1}$ previsto nos pacientes com traqueostomia.

Um estudo comparativo com avaliação clínica, parâmetros radiológicos e espirometria foi publicado por Duran et al. ${ }^{14}$. Foram avaliados 30 laringectomizados. As conclusões elencadas foram: há uma fraca correlação clínico-funcional em pacientes com doença obstrutiva; pelo contrário, há uma boa correlação radiológica e funcional em pacientes que sofrem de doença restritiva; e os laringectomizados demonstraram maior deterioração funcional que o esperado para sua idade e gênero. A explicação para isso são as doenças intercorrentes e infecções após a remoção da laringe.

Gardner et al. ${ }^{10}$ avaliaram a respiração durante exercício em pacientes laringectomizados usando um dispositivo extratraqueal. Foi realizada uma 
comparação do padrão respiratório em repouso e durante um ciclo de exercício constante com taxas de trabalho de 30, 60 e $90 \mathrm{~W}$ em sete homens laringectomizados e 13 controles normais. $\mathrm{O}$ ar inspirado era úmido e enriquecido com $35 \%$ de $\mathrm{O}_{2}$. Pico de fluxo, volume e tempos para os ciclos de inspiratórios e expiratório e ventilação por minuto foram calculados em pelo menos 40 respirações em repouso e durante os últimos dois minutos dos períodos de cinco minutos em cada taxa de trabalho. Durante a transição do repouso para o exercício e com ritmo crescente de trabalho em ambos os grupos, houve aumento na taxa respiratória e progressivo encurtamento do tempo expiratório. Concluiu-se que a remoção da laringe em ambiente levemente hiperoxigenado tem efeitos apenas sutis e, portanto, insignificantes na respiração durante exercício moderado. Além disso, as vias aéreas superiores podem modular o fluxo expiratório, mas não alteram o tempo expiratório durante o exercício.

Ackerstaff et al..$^{15}$ utilizaram um bocal de silicone colado ao redor do estoma para a realização de espirometria em oito pacientes laringectomizados e concluíram que uma estimativa confiável da função pulmonar é útil em todo tipo de pacientes para evitar complicações em intervenções cirúrgicas, para avaliar os efeitos da terapia.

Pacientes submetidos a cirurgia de cabeça e pescoço estão predispostos a distúrbios da função pulmonar no pós-operatório após ressecção cirúrgica extensa, imobilização ou deformidade na parede torácica devido a vários procedimentos de reconstrução. Um estudo clínico prospectivo em pacientes submetidos á cirurgia de cabeça e pescoço foi conduzido por $\operatorname{Tan}{ }^{16}$ para avaliar a utilização da espirometria para melhorar a função pulmonar pós-operatória. Um adaptador foi inicialmente concebido para permitir que os pacientes com cânulas de traqueostomia pudessem 
utilizar os espirômetros. A melhora significativa da função pulmonar e falta de complicações confirmou que a utilização da espirometria em pós-operatório de cirurgia de cabeça e pescoço deve ser incentivada.

Ackerstaff et al. ${ }^{7}$ avaliaram a função pulmonar em 58 pacientes laringectomizados em consultas ambulatoriais de rotina através de um dispositivo extratraqueal. Em um seguimento tardio após laringectomia, os valores expiratórios da função pulmonar são significativamente menores do que o previsto. Das várias queixas respiratórias subjetivas, apenas uma maior frequência de tosse foi estatisticamente significativa quando associada a valores de função pulmonar diminuída $(p<0,01)$. A idade do paciente teve uma influência significativa na função pulmonar. Apesar de um declínio relativo à idade na função pulmonar ser um fenômeno bem documentado, efeitos adversos adicionais ocorreram no grupo com mais de 65 anos. O tratamento com broncodilatador apresentou melhora significante em vários parâmetros de função pulmonar em um subgrupo de 18 pacientes. Os autores concluíram que, após a laringectomia total, anormalidades significativas na função pulmonar devem ser previstas e que esses distúrbios parecem ser mais pronunciados com o aumento da idade.

O estudo de Olszewski et al. ${ }^{22}$ comparou, por meio de espirometria, a função pulmonar em 20 homens laringectomizados e 20 homens saudáveis. Os resultados mostraram que o valor médio da resistência das vias aéreas foi aproximadamente cinco vezes maior nos laringectomizados do que no grupo dos indivíduos saudáveis. A resistência das vias aéreas influencia para uma diminuição considerável do volume máximo de ventilação.

Matsuura et al. ${ }^{1}$ desenvolveram uma máscara traqueal para a realização de espirometria em laringectomizados. Foram estudados oito pacientes com 
laringectomia, incluindo cinco com câncer de laringe e três com câncer de hipofaringe. Gasometria arterial e medições da função pulmonar foram avaliadas antes e após a laringectomia. Não se encontraram alterações estatisticamente significantes na gasometria arterial e $V_{E F}$. Houve diminuição estatisticamente significativa no VC após a laringectomia total. Os autores concluíram que a diminuição no VC foi causada por uma diminuição do espaço morto na via aérea superior, podendo ser esse um bom parâmetro para a avaliação da função pulmonar após a laringectomia.

McRae et al. ${ }^{6}$ determinaram que a resistência fisiológica do fluxo de ar das narinas à traquéia superior é perdida em laringectomizados que podem ter um subsequente declínio na função pulmonar e saturação de oxigênio arterial. Desenvolveram um filtro de estoma com uma resistência aproximada da via aérea superior normal. Os pacientes laringectomizados que utilizaram esse dispositivo demonstram um rápido aumento na saturação de oxigênio dos tecidos sem alterar significativamente a saturação de dióxido de carbono.

Segundo a publicação de Hyatt et al. ${ }^{23}$, há correlação negativa entre a resistência das vias aéreas e os fluxos expiratórios máximos e o $\mathrm{VEF}_{1}$, de modo que, em geral, a espirometria é suficiente para o diagnóstico de obstrução difusa ao fluxo aéreo. Entretanto, em casos individuais, a medida da resistência das vias aéreas pode ser mais sensível.

Um adaptador especial de silicone foi desenvolvido e testado em 1999 por Hess et al. ${ }^{3}$ em 59 pacientes laringectomizados para conectar o estoma ao pletismógrafo. Os autores avaliaram a função pulmonar antes e depois do uso de broncodilatadores. Os resultados mostraram que a obstrução das vias aéreas pulmonares estava presente em $81 \%$ dos pacientes e função pulmonar normal 
estava presente em apenas 11 dos 59 participantes (19\%). Enfisema foi diagnosticado em 14\% dos casos de obstrução de vias aéreas menores e vias aéreas periféricas. Houve melhora da função pulmonar em 12 dos 16 laringectomizados com obstrução das vias aéreas, quando um aerossol broncodilatador foi administrado. Esses resultados sugerem que $42 \%$ dos laringectomizados avaliados podem beneficiar-se do uso de broncodilatadores.

Vazquez et $a l^{8}{ }^{8}$ desenvolveram um método instrumental capaz de realizar o teste de função do ar pulmonar (espirometria) por meio da conexão do bocal do espirômetro ao traqueostoma em 33 homens laringectomizados. Foi desenvovido um adaptador de com um disco de papelão tubo, um adesivo e silicone. Não foram detectados vazamentos de ar nem alta resistência durante os exames.

Em nosso estudo anterior, testamos a precisão e a acurácia de uma metodologia para realização de espirometria em pacientes submetidos a laringectomia total por meio da utilização de um dispositivo extratraqueal. $\mathrm{O}$ dispositivo experimental extratraqueal foi configurado com um adaptador de silicone por meio de um tubo de papelão para a pele ao redor da traqueostomia. Testes de função pulmonar, incluídas medidas de capacidade vital forçada, volume expiratório de forçado em um segundo e índice de Tiffeneau foram realizados em três avaliações consecutivas em 11 pacientes submetidos a laringectomia total. O grupo controle foi constituído de 11 pacientes não laringectomizados avaliados por meio do método de espirometria convencional. O uso do adaptador de silicone e adesivo de pele não apresentou vazamento de ar em nenhum dos casos. A presença de prótese tráqueo-esofágica não alterou os resultados do teste. Os valores obtidos foram iguais em ambos os grupos, indicando a precisão da metodologia proposta. 
O estudo concluiu que, após a laringectomia total, a realização de testes de função pulmonar, com um dispositivo extratraqueal é fácil e confiável ${ }^{17}$. 
4 MÉTODOS 


\section{MÉTODOS}

Esta pesquisa foi aprovada pelo Comitê de Ética em Pesquisa da Faculdade de Medicina da Universidade de São Paulo sob o número 075/14, em 12 de maio de 2014 - Anexo A. Todos os participantes assinaram o Termo de Consentimento Livre e Esclarecido, concordando em participar do estudo - Anexo B.

\subsection{Casuística}

\subsubsection{Pacientes}

Foram incluídos neste estudo transversal 56 pacientes submetidos à laringectomia total há pelo menos seis meses como modalidade de tratamento para o câncer de laringe em acompanhamento no Ambulatório do Grupo de Tumores de Laringe e Hipofaringe do Serviço de Cirurgia de Cabeça e Pescoço do Hospital das Clínicas da Faculdade de Medicina da Universidade de São Paulo. Os pacientes foram arrolados no período de março a junho de 2014.

Os fatores de exclusão foram: doença respiratória nos últimos trinta dias; ausência de condições clínicas no momento da realização dos exames; e incapacidade de realizar qualquer um dos exames do estudo.

Por meio da anamnese e do prontuário dos pacientes, foram obtidos dados demográficos, tais como nome, endereço, telefone, data de nascimento e profissão; tabagismo prévio à cirurgia, eventuais dificuldades respiratórias (escala de dispnéia) e, por fim, a presença de doenças respiratórias nos últimos trinta dias. 
Foram obtidos também os dados acerca do tumor como sítio e estadiamento e sobre o tratamento realizado - Anexo C.

\subsubsection{Controles}

Foram selecionados 50 exames de pacientes (não laringectomizados) que foram submetidos à prova de avaliação funcional pulmonar completa de maneira convencional, com a utilização de bocal, no laboratório de função pulmonar do Hospital das Clínicas da Faculdade de Medicina da Universidade de São Paulo na intenção de formar um grupo controle para avaliar a reprodutibilidade dos exames. A indicação do exame nesses pacientes foi, na maioria dos casos, devido a alterações obstrutivas no padrão respiratório. Os exames do grupo-controle foram realizados pela mesma fisioterapeuta que realizou os exames nos pacientes alvo do estudo, no mesmo período e com os mesmos equipamentos. Os pacientes foram devidamente pareados por gênero e idade.

\subsection{Provas de função pulmonar}

\subsubsection{Equipamentos}

\subsubsection{Dispositivo adesivo extratraqueal}

Devido ao fato dos participantes serem laringectomizados, não havia como realizar os testes de função pulmonar com bocal, portanto, desenvolvemos um dispositivo extratraqueal utilizando um adesivo com adaptador de silicone para 
válvulas do tipo hands-free (Provox ${ }^{\circledR}-$ Atos Medical - Horby, Suécia) para a conexão com o aparelho e realização dos testes de função respiratória ${ }^{17}$ (Figuras 1 e 2). Para evitar que houvesse desconexão, foram colocadas duas voltas de micropore ao redor do adaptado antes de conectar o aparelho ao traqueostoma.

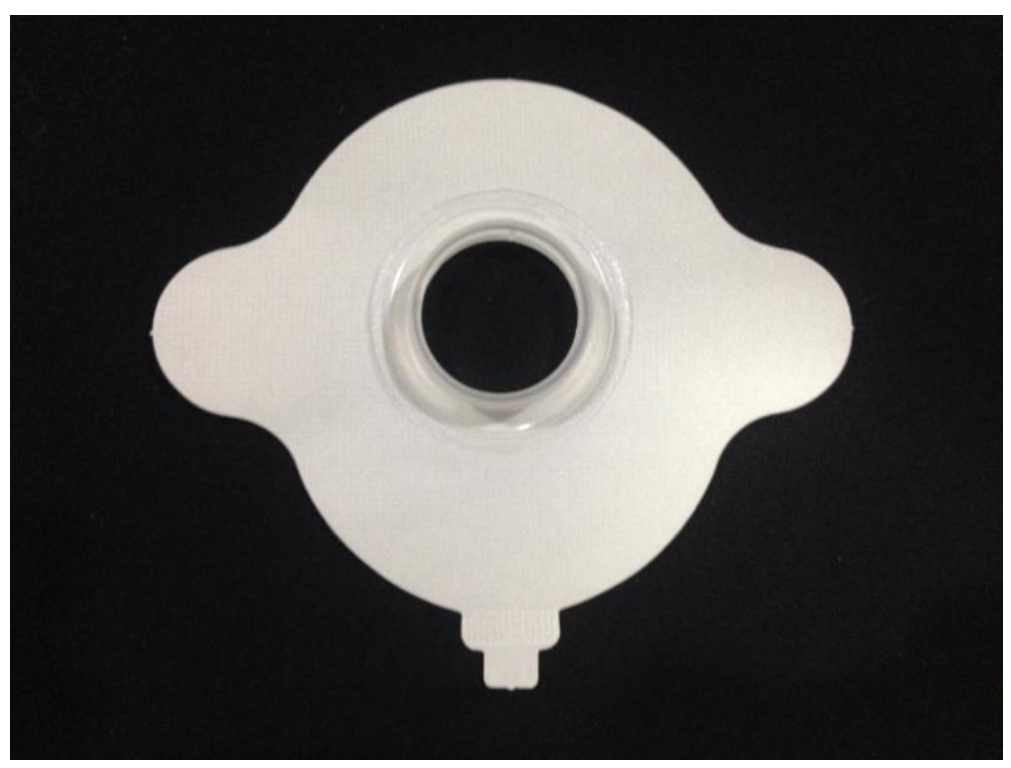

Figura 1 - Dispositivo adesivo extratraqueal

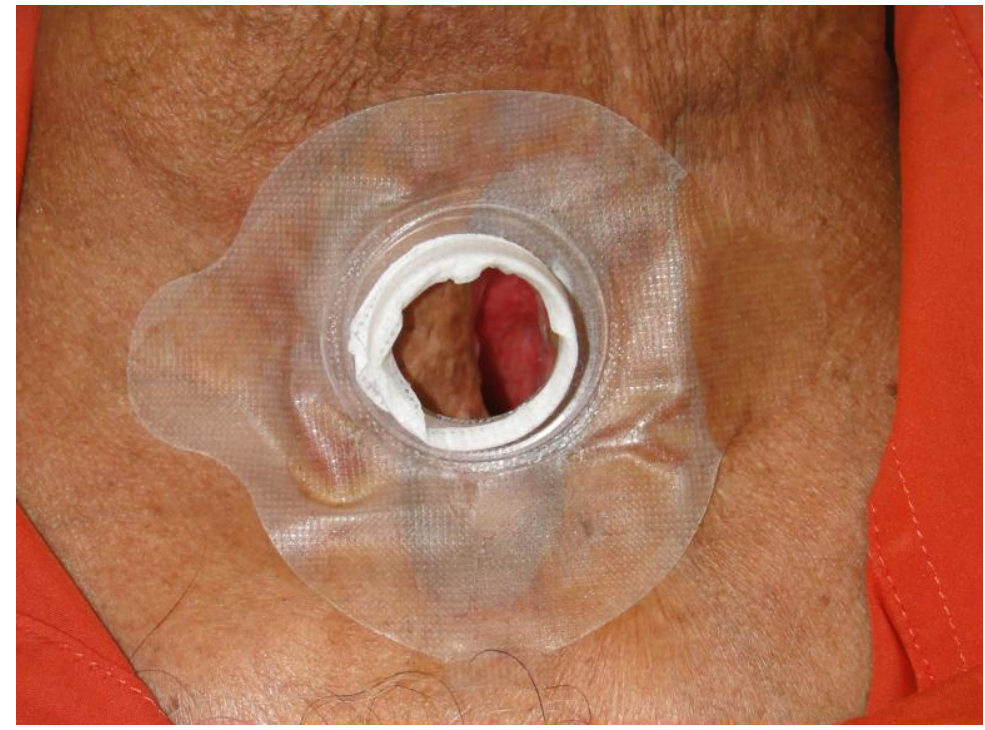

Figura 2 - Dispositivo extratraqueal fixado 


\subsubsection{Aparelho de pletismografia}

A pletismografia de corpo inteiro determina o volume de gás torácico bem como a resistência das vias aéreas.

A medida do volume pulmonar baseia-se na lei de Boyle, que determina que o volume de um gás em temperatura constante varia inversamente com a pressão aplicada.

O pletismógrafo de corpo inteiro é um aparelho composto de um sistema computadorizado acoplado a uma cabine, que deve ser hermeticamente fechada e que possui sensores que captam variações de pressão internas com grande sensibilidade, as quais variam com mudanças no volume do tórax. Essas variações de pressão refletem, portanto, variações de volume pulmonar. Na cabine, há também um pneumotacógrafo com uma válvula solenóide, que permite o registro contínuo e instantâneo do fluxo aéreo. A válvula, comandada do exterior, permite bloquear o fluxo aéreo.

O aparelho utilizado para os testes de função pulmonar foi Elite DX (Medical Graphics Corporation $\AA^{\circledR}$, Saint Paul, MN - EUA) com espirômetro do tipo sensor de fluxo bi-direcional (transdutor diferencial de pressão do tipo "Pilot", com faixa de leitura de $+/-18 \mathrm{~L} / \mathrm{s}$ ), pletismógrafo de corpo inteiro (volume constante $699 \mathrm{~L}$ ), medida da difusão por meio da técnica do monóxido de carbono (leitura das concetrações por cromatrografia gasosa) e medida do volume de fechamento através da técnica de lavagem de Nitrogênio $\left(\mathrm{N}_{2}\right)$ após respiração única de Oxigênio $\left(\mathrm{O}_{2}\right)$ puro (medida direta da concentração de $\mathrm{N}_{2}$ por espectrometria por emissão) (Fig. 3 e 4). Os equipamentos utilizados são validados para os testes realizados e atendem as normas estabelecidas pelas sociedades americana e 
européia de doenças respiratórias (American Thoracic Society e European Respiratory Society $)^{24}$. As rotinas de calibração preconizadas pelos fabricantes dos equipamentos foram seguidas. Todos os testes foram realizados sob supervisão e orientação de técnico habilitado e treinado com experiência na condução de testes de função pulmonar.

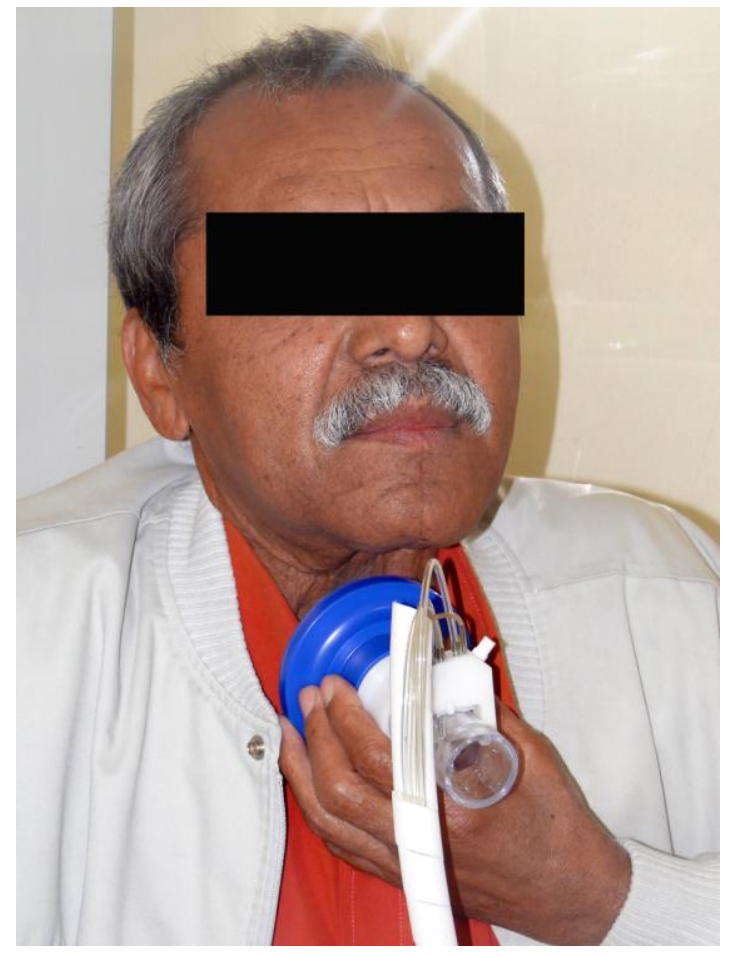

Figura 3 - Espirômetro conectado

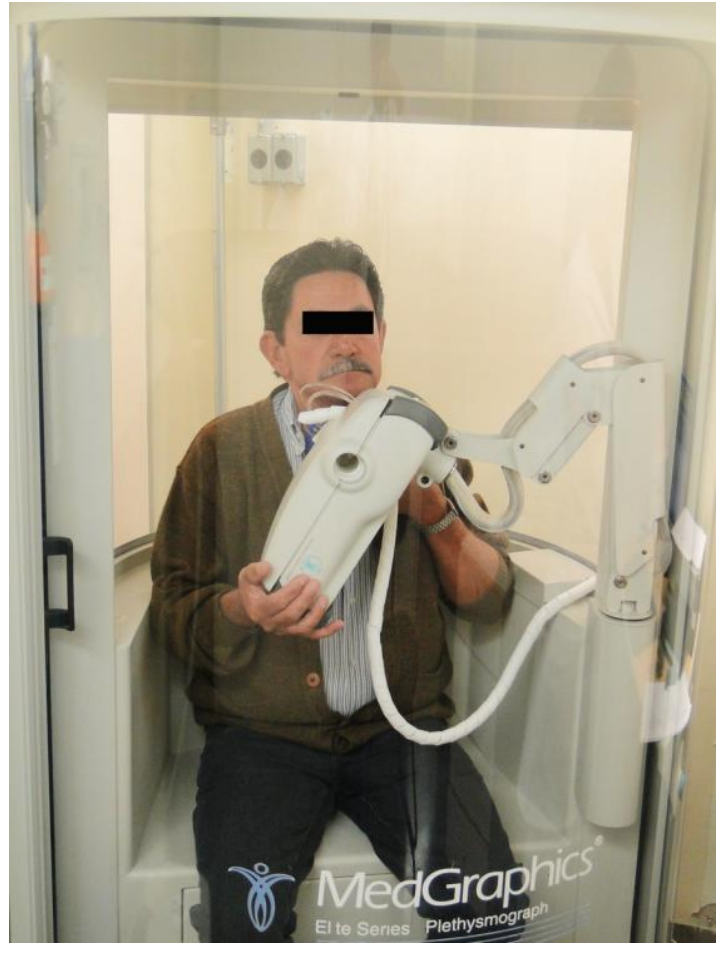

Figura 4 - Aparelho de pletismografia

\subsubsection{Manobra de capacidade vital}

As manobras de capacidade vital forçada (CVF), em que o indivíduo realiza uma expiração forçada, sem hesitação, a partir da capacidade pulmonar total (CPT) até o volume residual (VR), permitiram a obtenção das alças inspiratórias e expiratórias da curva fluxo $\mathrm{X}$ volume. Os indivíduos foram examinados na posição sentada, conectados ao espirômetro por meio de um dispositivo extratraqueal adesivo. Os critérios convencionais de aceitabilidade foram utilizados para a 
seleção das manobras, incluindo a presença de um início de expiração explosivo e sem hesitação, a presença de pico de fluxo nítido e precoce, volume retroextrapolado inferior a 5\% da Capacidade Vital (ou $150 \mathrm{ml}$, o que for correspondente ao maior volume), duração mínima da expiração de seis segundos e/ou a presença de platô de volume nos dois segundos finais. Foram realizadas tentativas repetidas visando a obtenção de três resultados com variabilidade de $V_{E F} F_{1}$ e CVF menor que $150 \mathrm{~mL}$. A realização das manobras, assim como a seleção dos resultados, seguiu os critérios estabelecidos nas Diretrizes para Testes de Função Pulmonar ${ }^{24,25,26}$.

Os valores selecionados de CVF, do $V_{E F}$ e a relação $V E F_{1} / C V F$ foram expressos como porcentagem dos valores normais calculados segundo recomendação da European Respiratory Society ${ }^{27}$. Foi realizada também a manobra de capacidade vital lenta, na qual o indivíduo executa uma expiração completa a partir da insuflação pulmonar máxima, contudo, sem utilizar esforço expiratório máximo. Os resultados dessa manobra foram usados na composição do cálculo dos volumes pulmonares.

Após a realização dos manobras, os exames foram laudados por um especialista em espirometria e classificados como normais, distúrbios ventilatórios obstrutivos sem aprisionamento, distúrbios ventilatórios obstrutivos com aprisionamento e distúrbios ventilatórios restritivos.

Caso não apresentasse alterações, o exame foi laudado como normal.

O exame foi laudado como distúrbio ventilatório obstrutivo quando ocorreu a presença de obstrução, com VEF1 reduzido e CVF normal, com relação VEF1/CVF diminuída.

$\mathrm{Na}$ obstrução, se o aprisionamento de ar elevar muito o volume residual, a capacidade vital pode estar reduzida. Aqui refere-se ao distúrbio obstrutivo com 
capacidade vital reduzida. Quando a CVF se reduz pode levar a uma relação VEF1/CVF normal, nesses casos o exame foi laudado como distúrbio ventilatório obstrutivo com aprisionamento.

Quando o exame apresentou ausência de obstrução e CVF reduzida na presença de causa potencial para restrição, com relação VEF1/CVF normal, o exame foi laudado como distúrbio ventilatório restritivo.

\subsubsection{Medidas de volumes pulmonares}

Para a obtenção dos volumes pulmonares, foi feita a mensuração do volume gasoso torácico (VGT) utilizando a técnica de pletismografia de corpo inteiro, segundo a técnica clássica ${ }^{28,29}$. A partir da capacidade residual funcional (CRF), o indivíduo dentro da cabine fechada executava manobras alternadas de inspiração e expiração de pequena amplitude e alta frequência (entre 60 e 90 oscilações por minuto) contra a válvula do sistema fechada, ao mesmo tempo em que eram registradas as variações de pressão na cabine e na via aérea proximal (junto ao dispositivo fixado ao traqueostoma). A inclinação da relação entre as variações de pressão na via aérea e na cabine foi utilizada para determinação do VGT, que nesse caso, representa a CRF. Foram calculados VR e CPT a partir do VGT, utilizando-se a composição com os valores obtidos na manobra de capacidade vital. Os resultado obtidos foram expressos como porcentagem dos valores calculados normais ${ }^{27}$ e posteriormente ajustadas para a tabela de valores previstos brasileiros de 2008 tanto para o gênero masculino (Apêndice A) como para o gênero feminino (Apêndice B). 


\subsubsection{Medidas da difusão}

A medida da difusão dos pulmões foi utilizada para a caracterização da amostra de pacientes quanto ao acometimento do parênquima pulmonar. Foi utilizada a técnica clássica de respiração única utilizando o monóxido de carbono $(\mathrm{CO})^{28}$, associada às recomendações mais recentemente incorporadas ${ }^{24}$. A manobra foi repetida por, pelo menos, duas e até um máximo de cinco vezes. Os resultados foram expressos como porcentagem de valores previstos brasileiros de 2008 tanto para o gênero masculino (Apêndice A) como para o gênero feminino (Apêndice B).

\subsubsection{Medida da resistência das vias aéreas}

A manobra para medida da resistência das vias aéreas foi realizada pela técnica de pletismografia de corpo inteiro ${ }^{30}$. Dentro da cabine fechada e conectado ao pneumotacógrafo, o indivíduo era solicitado a realizar, a partir da CRF, manobras de respiração rápida (frequência respiratória entre 60 e 90 ciclos por minuto) com sistema inicialmente aberto. Nessa situação, eram registrados o fluxo através da via aérea proximal e a variação de pressão na cabine. Sequencialmente, a válvula do aparelho era fechada, impedindo a geração de fluxo, mantendo-se o esforço alternado (inspiratório e expiratório) com as mesmas amplitude e frequência, agora contra o obturador, enquanto eram registradas as variações de pressão na porção proximal da via aérea e na cabine. A combinação entre os dois tempos da manobra permite a determinação da resistência das vias aéreas (raw). 
Para cada indivíduo, foi relatada a média de pelo menos três manobras com variação inferior a $10 \%$.

A partir da medida da raw foi calculada a condutância das vias aéreas (Gaw=1/raw), assim como a condutância específica das vias aéreas obtida pela sua correção para o volume pulmonar no qual a medida foi realizada (sGaw=Gaw/VTG). Os valores de raw e sGaw foram expressos, respectivamente, em $\mathrm{cmH}_{2} \mathrm{O} / \mathrm{L} / \mathrm{s}$ e $1 / \mathrm{cmH}_{2}$ O.s.

\subsection{Validação metodológica}

$\mathrm{Na}$ intenção de avaliar a reprodutibilidade dos exames realizados, foram utilizados parâmetros com os respectivos critérios de aceitação. Os exames que não atingiram, tais critérios foram rejeitados. Os critérios de reprodutibilidade são indicadores de exatidão ${ }^{31}$.

Os parâmetros utilizados para avaliar a aceitação ou não de determinado exame na avaliação espirométrica foram:

- Volume retro-extrapolado observado (V_ext_obs): é o volume de ar que "escapa" no início da expiração forçada e que não é computado, medido em valor absoluto (ml). O exame foi rejeitado se V_ext_obs $>150 \mathrm{~mL}^{26}$.

- Volume retro-extrapolado \% da CVF (V_ext_CVF_\%): é volume de ar que "escapa" no início da expiração forçada e que não é computado, medido em porcentagem da capacidade vital. O exame foi rejeitado se V_ext_obs $>5 \%$ da $\mathrm{CVF}^{26}$. 
- Tempo de expiração (T_Exp_obs): é a duração da expiração na manobra de capacidade vital forçada medida em segundos. O exame foi rejeitado se T exp < 6 segundos $^{32}$.

- Variabilidade da capacidade vital forçada (Delta_CVF): é a diferença entre o melhor e o segundo melhor valor de CVF da série de manobras aceitáveis realizadas, medido em mililitros. $O$ exame foi rejeitado se Delta CVF $>150 \mathrm{~mL}^{32}$.

- Variabilidade do volume expiratório forçado no $1^{\circ}$ segundo (Delta_VEF 1 ): é a diferença entre o melhor e o segundo melhor valor de $\mathrm{VEF}_{1}$ da série de manobras aceitáveis realizadas, medido em mililitros. O exame foi rejeitado se Delta VEF1 > $150 \mathrm{~mL}^{32}$.

Os parâmetros utilizados para avaliar a aceitação ou não de determinado exame na avaliação da pletismografia (medida de volumes pulmonares) foram:

- Erro de Switch in (Switch-In): é a diferença de volume entre a linha de base da respiração corrente (correspondente à CRF) e o momento em que o obturador foi ocluído na manobra de pletismografia. O exame foi rejeitado se Switch in > $200 \mathrm{~mL}$.

- Variabilidade da manobra de VGT (Reprod_VGT): é a razão ente a diferença do maior menos o menor valor de VGT das manobras aceitáveis sobre a média, expresso em porcentagem ${ }^{34}$. O exame foi rejeitado se a variabilidade TGV > $10 \%{ }^{33}$.

Os parâmetros utilizados para avaliar a aceitação ou não de determinado exame na avaliação da difusão foram:

- Capacidade vital inspiratória em relação à Capacidade Vital lenta na manobra de difusão (IVC/SVC): é a razão entre o volume inspirado na manobra de difusão sobre o volume possível de ser inspirado (que corresponde á capacidade 
vital), expresso em porcentagem. O exame foi rejeitado se relação IVC/SVC < $0,85^{34}$.

- Breath holding time (BHT): é o tempo retenção da mistura gasosa da difusão (CO) no gás alveolar, medido em segundos. O exame foi rejeitado se BHT $<9$ seg ou $>11 \mathrm{seg}^{34}$.

- Número de manobras de difusão válidas com BHT entre 9 e 11 segundos (n_BHT_9_11). O exame foi rejeitado se o número de manobras de difusão com BHT adequado for menor que $2^{34}$.

- Variabilidade da difusão (Delta_DLCO_abs): é a diferença entre o maior e segundo maior valor de difusão em unidades absolutas. O exame foi rejeitado se a variabilidade da DLCO for maior que 3 unidades ${ }^{35}$.

- Variabilidade da difusão (\%) (Delta_DLCO_\%): é a diferença entre o maior e o segundo maior valor de difusão em porcentagem. O exame foi rejeitado se a variabilidade da DLCO for maior que $10 \%{ }^{35}$.

Foi realizada a comparação com 50 exames realizados pela mesma fisioterapeuta em pacientes não laringectomizados (controles), no mesmo período da realização desse estudo, como o mesmo equipamento, pareados para idade e gênero, visando avaliar a aceitação e rejeição dos exames comparativamente com o grupo de laringectomizados (casos) em relação a cada um dos parâmetros de reprodutibilidade avaliados.

\subsection{Análise estatística}

A distribuição de frequências foi utilizada para descrever as variáveis categóricas (numero de casos e percentual) e as medidas de tendência central 
(média e mediana) e de variabilidade (mínimo, máximo e desvio padrão) para as variáveis contínuas ou numéricas.

Para verificar a associação entre as variáveis numéricas de acordo com a interpretação respiratória agrupadas em normal e alterado (obstrutivo sem aprisionamento + obstrutivo com aprisionamento + restritivo) o teste t de Student foi aplicado.

Para comparar variáveis categóricas de acordo com a interpretação respiratória agrupadas em normal e alterado (obstrutivo sem aprisionamento + obstrutivo com aprisionamento + restritivo) o teste de frequências do qui-quadrado foi aplicado e, quando pelo menos uma frequência esperada foi menor do que 5, o teste exato de Fisher foi adotado.

Para a comparação das médias obtidas por meio dos parâmetros e critérios de reprodutibilidade dos exames do grupo de laringectomizados com o grupo controle, foi utilizado o teste $\mathrm{t}$ de Student. Para a comparação da frequência de rejeição dos exames para cada parâmetro foi adotado o teste exato de Fisher e o teste de frequências do qui-quadrado.

O nível de significância de $5 \%$ foi adotado para todos os testes estatísticos

O programa STATA versão $7.0^{36}$, Stata Corporation, Texas - EUA foi utilizado para a realização das análises estatísticas. 
5 RESULTADOS 


\section{RESULTADOS}

Dos 56 participantes deste estudo, seis foram excluídos, três por não conseguirem realizar as manobras solicitadas nos testes e os demais devido à condição cognitiva, que impedia a compreensão das orientações.

A Tabela 1 descreve as características demográficas e o tabagismo (prévio à cirurgia) dos indivíduos laringectomizados avaliados.

Tabela 1. Características demográficas e tabagismo dos laringectomizados.

\begin{tabular}{llc}
\hline Variável & Categoria / Medidas & Freq. $(\%) /$ Medidas \\
\hline \multirow{2}{*}{ Idade (anos) } & Variação & $41-87$ \\
& Mediana & 64,5 \\
& Média (Desvio Padrão) & $64,2(10,3)$ \\
Índice de Massa & Variação & $15,7-32,6$ \\
Corpórea (kg/m $\left.{ }^{2}\right)$ & Mediana & 24,2 \\
& Média (Desvio Padrão) & $24,4(3,8)$ \\
Etnia & Orietais & $1(2)$ \\
& Afrodescendentes & $5(10)$ \\
& Caucasianos & $44(88)$ \\
Gênero & Feminino & $6(12,0)$ \\
& Masculino & $44(88,0)$ \\
Tabagismo & Não tabagista & $6(12,0)$ \\
& Menos que 10 cigarros / dia & $4(8,0)$ \\
& 10 a 20 cigarros / dia & $7(14,0)$ \\
& 21 a 40 cigarros / dia & $4(8,0)$ \\
& Mais que 40 cigarros / dia & $29(58,0)$ \\
& & \\
\hline
\end{tabular}


A classificação dos estádios tumorais dos pacientes e sua frequência está descrita na Tabela 2.

Tabela 2. Classificação da amostra por estádio tumoral (T).

\begin{tabular}{lc}
\hline Estádio tumoral (T) & Freq. (\%) \\
\hline T3 & $15(30)$ \\
T4a & $26(52)$ \\
T4b & $9(18)$ \\
\hline
\end{tabular}

Com relação à Escala de Dispnéia (Medical Research Council) ${ }^{37}$, os participantes foram estratificados segundo a Tabela 3.

Tabela 3. Estratificação da amostra segundo a Escala de dispnéia.

\begin{tabular}{lc}
\hline Escala de dispnéia & Freq. (\%) \\
\hline Somente com exercícios extenuantes & $28(56)$ \\
Ao caminhar depressa no plano ou subir ladeira suave & $19(38)$ \\
Ao andar mais devagar que alguém da mesma idade no plano & $2(4)$ \\
Precisa parar para respirar ao andar uma quadra $(90-120 \mathrm{~m})$ & $1(2)$ \\
\hline
\end{tabular}


As medidas funcionais respiratórias estão descritas na Tabela 4.

Tabela 4. Medidas funcionais respiratórias

\begin{tabular}{|c|c|c|c|}
\hline Variável & Categoria / Medidas & $\begin{array}{l}\text { Valores } \\
\text { absolutos }\end{array}$ & $\begin{array}{c}\text { Valores } \\
\text { Porcentagem }\end{array}$ \\
\hline & Espirometria & & \\
\hline $\begin{array}{l}\text { CVF = Capacidade vital } \\
\text { forçada }\end{array}$ & $\begin{array}{l}\text { Variação } \\
\text { Mediana } \\
\text { Media (Desvio Padrão) }\end{array}$ & $\begin{array}{c}1,7-4,9 \\
3,4 \\
3,3(0,7)\end{array}$ & $\begin{array}{c}52,1-109,6 \\
84,1 \\
83,3(12,6)\end{array}$ \\
\hline $\begin{array}{l}\text { VEF1 = Volume } \\
\text { expiratório forçado em } 1 \\
\text { seg }\end{array}$ & $\begin{array}{l}\text { Variação } \\
\text { Mediana } \\
\text { Media (Desvio Padrão) }\end{array}$ & $\begin{array}{c}1,1-3,5 \\
2,5 \\
2,4(0,6)\end{array}$ & $\begin{array}{c}43,4-106,7 \\
77,5 \\
75,8(15,1)\end{array}$ \\
\hline VEF1/CVF & $\begin{array}{l}\text { Variação } \\
\text { Mediana } \\
\text { Media (Desvio Padrão) } \\
\text { Volumes pulmonares }\end{array}$ & $\begin{array}{c}49-90 \\
71,5 \\
71,4(8,8)\end{array}$ & $\begin{array}{c}66,6-109,5 \\
91,9 \\
91,1(11,1)\end{array}$ \\
\hline VR $=$ Volume residual & $\begin{array}{l}\text { Variação } \\
\text { Mediana } \\
\text { Media (Desvio Padrão) }\end{array}$ & $\begin{array}{c}1,3-4,0 \\
2,4 \\
2,5(0,6)\end{array}$ & $\begin{array}{c}63,3-240,1 \\
112,3 \\
122(32,3)\end{array}$ \\
\hline $\begin{array}{l}\text { CPT = Capacidade } \\
\text { pulmonar total }\end{array}$ & $\begin{array}{l}\text { Variação } \\
\text { Mediana } \\
\text { Media (Desvio Padrão) } \\
\text { Difusão }\end{array}$ & $\begin{array}{l}3,4-8,1 \\
6,0 \\
6,0(1,0)\end{array}$ & $\begin{array}{c}71,39-126,4 \\
98,3 \\
99,2(12,3)\end{array}$ \\
\hline $\begin{array}{l}\text { DLCOunc = Capacidade } \\
\text { de difusão do monóxido } \\
\text { de carbono }\end{array}$ & $\begin{array}{l}\text { Variação } \\
\text { Mediana } \\
\text { Media (Desvio Padrão) } \\
\text { Resistência das vias } \\
\text { aéreas }\end{array}$ & $\begin{array}{c}9,8-34,3 \\
20,6 \\
21,0(6,5)\end{array}$ & $\begin{array}{c}42,1-124,9 \\
75,5 \\
74,3(18,8)\end{array}$ \\
\hline $\begin{array}{l}\text { Sgaw = condutância } \\
\text { específica das vias } \\
\text { aéreas }\end{array}$ & $\begin{array}{l}\text { Variação } \\
\text { Mediana } \\
\text { Media (Desvio Padrão) }\end{array}$ & $\begin{array}{c}0,1-0,5 \\
0,2 \\
0,2(0,1) \\
\end{array}$ & $\begin{array}{c}50-185 \\
105 \\
121,7(52,8) \\
\end{array}$ \\
\hline
\end{tabular}

* Valores em porcentagem do previsto brasileiro 
Os resultados obtidos após a interpretação e classificação dos padrões respiratórios estão descritos na Tabela 5.

Tabela 5. Frequência dos padrões respiratórios.

\begin{tabular}{lc}
\hline Padrão de interpretação & Freq. (\%) \\
\hline Normal & $22(44)$ \\
Obstrutivo sem aprisionamento & $14(28)$ \\
Obstrutivo com aprisionamento & $11(22)$ \\
Restritivo & $3(6)$ \\
\hline
\end{tabular}

O cruzamento das características demográficas, etilismo e tabagismo com os padrões respiratórios, segundo os agrupamentos realizados, bem como avaliação estatística está demonstrado na Tabela 6.

Tabela 6. Características demográficas e tabagismo de acordo com os padrões respiratórios, segundo agrupamentos.

\begin{tabular}{|c|c|c|c|c|}
\hline \multirow[b]{2}{*}{ Variável } & \multirow[b]{2}{*}{ Categoria / Medidas } & \multicolumn{2}{|c|}{ Padrão respiratório } & \multirow[b]{2}{*}{$\mathrm{p}$-valor } \\
\hline & & $\begin{array}{l}\text { Normal } \\
\text { Medida }\end{array}$ & $\begin{array}{l}\text { Alterado } \\
\text { eq. }(\%)\end{array}$ & \\
\hline Idade (anos) & $\begin{array}{l}\text { N } \\
\text { Variação } \\
\text { Mediana } \\
\text { Média (Desvio Padrão) }\end{array}$ & $\begin{array}{c}22 \\
41-83 \\
65,5 \\
65,8(8,9)\end{array}$ & $\begin{array}{c}28 \\
42-87 \\
63,5 \\
62,9(11,2)\end{array}$ & 0,324 \\
\hline Gênero & $\begin{array}{l}\text { Feminino } \\
\text { Masculino }\end{array}$ & $\begin{array}{l}3(50,0) \\
19(43,2)\end{array}$ & $\begin{array}{c}3(50,0) \\
25(56,8)\end{array}$ & 0,999 * \\
\hline Tabagismo & $\begin{array}{l}\text { Não + (<10 cigarros/dia }) \\
\geq 10 \text { cigarros/dia }\end{array}$ & $\begin{array}{c}7(70,0) \\
15(37,5)\end{array}$ & $\begin{array}{c}3(30,0) \\
25(62,5)\end{array}$ & 0,084 * \\
\hline
\end{tabular}


A Tabela 7 demonstra o cruzamento dos resultados da escala de dispnéia com os padrões respiratórios, segundo agrupamento realizado e avaliação estatística.

Tabela 7. Escala de dispnéia de acordo com padrões respiratórios, segundo agrupamentos.

\begin{tabular}{lllll}
\hline Variável & Categoria / Medidas & \multicolumn{2}{c}{$\begin{array}{c}\text { Padrão Respiratório } \\
\text { Normal } \\
\text { Medidas / Freq. }(\%)\end{array}$} & p-valor \\
\hline Escala de & 0 & $15(55,6)$ & $12(44,4)$ & 0,075 \\
Dispnéia & $1+2+3$ & $7(30,4)$ & $16(69,6)$ & \\
\hline
\end{tabular}

p-valor obtido pelo teste o qui-quadrado

Padrão de interpretação respiratório

Alterado = Obstrutivo sem aprisionamento + Obstrutivo com aprisionamento + Restritivo Escala de Dispnéia:

0 - Somente com exercícios extenuantes

1 - Ao caminhar depressa no plano ou subir ladeira suave

2 - Ao andar mais devagar que alguém da mesma idade no plano

3 - Precisa parar para respirar ao andar uma quadra (90 - $120 \mathrm{~m}$ ) 
A Tabela 8 compara as características demográficas e tabagismo do grupo de laringectomizados (tabagismo prévio à cirurgia) com o grupo-controle.

Tabela 8. Características demográficas e tabagismo casos $x$ controles.

\begin{tabular}{|c|c|c|c|}
\hline Variável & Categoria / Medidas & $\begin{array}{c}\text { Casos } \\
\text { Freq. (\%) / Medidas }\end{array}$ & $\begin{array}{c}\text { Controles } \\
\text { Freq. (\%) / Medidas }\end{array}$ \\
\hline Idade (anos) & $\begin{array}{l}\text { Variação } \\
\text { Mediana } \\
\text { Média (Desvio-padrão) }\end{array}$ & $\begin{array}{c}41-87 \\
64,5 \\
64,2(10,3)\end{array}$ & $\begin{array}{c}54-81 \\
63 \\
63,1(5,7)\end{array}$ \\
\hline Etnia & $\begin{array}{l}\text { Orientais } \\
\text { Afrodescendentes } \\
\text { Caucasianos }\end{array}$ & $\begin{array}{c}2(4) \\
12(24) \\
36(72)\end{array}$ & $\begin{array}{c}1(2) \\
5(10) \\
44(88)\end{array}$ \\
\hline $\begin{array}{l}\text { Índice de } \\
\text { Massa } \\
\text { Corpórea } \\
\left(\mathrm{kg} / \mathrm{m}^{2}\right)\end{array}$ & $\begin{array}{l}\text { Variação } \\
\text { Mediana } \\
\text { Média (Desvio-padrão) }\end{array}$ & $\begin{array}{c}15,7-32,6 \\
24,2 \\
24,4(3,8)\end{array}$ & $\begin{array}{c}17,5-40,9 \\
25,5 \\
25,8(5,5)\end{array}$ \\
\hline Gênero & $\begin{array}{l}\text { Feminino } \\
\text { Masculino }\end{array}$ & $\begin{array}{c}6(12,0) \\
44(88,0)\end{array}$ & $\begin{array}{c}6(12,0) \\
44(88,0)\end{array}$ \\
\hline Tabagismo & $\begin{array}{l}\text { Não tabagista } \\
\text { Menos que } 10 \text { cigarros / dia } \\
10 \text { a } 20 \text { cigarros / dia } \\
21 \text { a } 40 \text { cigarros / dia } \\
\text { Mais que } 40 \text { cigarros / dia }\end{array}$ & $\begin{array}{c}6(12,0) \\
4(8,0) \\
7(14,0) \\
4(8,0) \\
29(58,0)\end{array}$ & $\begin{array}{l}8(16,0) \\
5(10,0) \\
7(14,0) \\
6(14,0) \\
24(46,0)\end{array}$ \\
\hline
\end{tabular}


A Tabela 9 compara as médias e respectivos desvios-padrão para cada parâmetro de reprodutibilidade avaliado dos casos $x$ controles.

Tabela 9. Média e desvio-padrão dos parâmetros de reprodutibilidade casos $\mathrm{x}$ controles.

\begin{tabular}{|c|c|c|c|c|}
\hline \multirow[t]{2}{*}{ Parâmetro } & \multirow[t]{2}{*}{ Descrição } & \multirow{2}{*}{$\begin{array}{c}\text { Casos } \\
\text { Média (DP) }\end{array}$} & \multirow{2}{*}{$\begin{array}{l}\text { Controles } \\
\text { Média (DP) }\end{array}$} & \multirow[t]{2}{*}{$\mathrm{p}$} \\
\hline & & & & \\
\hline V_ext_obs & Vol. retro-extrapolado (L) & $0,13(0,05)$ & $0,09(0,05)$ & 0,006 \\
\hline V_ext_CVF_\% & Vol. retro-extrapolado (\% CVF) & $3,87(1,40)$ & $3,57(1,73)$ & 0,348 \\
\hline T_Exp_obs & Tempo de Expiração (s) & $7,06(1,50)$ & $8,60(2,92)$ & 0,001 \\
\hline Delta_CVF & Variabilidade da CVF (L) & $0,05(0,05)$ & $0,04(0,04)$ & 0,369 \\
\hline Delta_VEF 1 & Variabilidade do $\operatorname{VEF}_{1}(\mathrm{~L})$ & $0,05(0,04)$ & $0,03(0,04)$ & 0,020 \\
\hline Switch-In & Erro de Switch-In na pletism. & $36,26(34,27)$ & $35,04(32,78)$ & 0,856 \\
\hline Reprod_VGT & $\begin{array}{l}\text { Variabilidade da manobra de } \\
\text { VGT (\%) }\end{array}$ & $0,03(0,02)$ & $0,05(0,10)$ & 0,094 \\
\hline IVC/SVC & $\begin{array}{l}\text { Capacidade vital inspiratória em } \\
\text { relação à Capacidade Vital lenta } \\
\text { na manobra de Difusão }\end{array}$ & $0,91(0,06)$ & $0,92(0,05)$ & 0,466 \\
\hline BHT & Breath Holding Time (s) & $10,60(0,68)$ & $10,43(0,66)$ & 0,225 \\
\hline n_BHT_9_11 & $\begin{array}{l}\text { Número de Manobras de } \\
\text { Difusão com BHT entre } 9-11 \mathrm{~s}\end{array}$ & $1,56(0,64)$ & $1,62(0,81)$ & 0,663 \\
\hline Delta_DLCO_ab & $\begin{array}{l}\text { Variabilidade da Difusão } \\
\text { (mL/min.mmHg) }\end{array}$ & $1,09(0,78)$ & $1,14(1,02)$ & 0,777 \\
\hline Delta_DLCO_\% & Variabilidade da Difusão (\%) & $5,36(3,89)$ & $9,05(7,02)$ & 0,002 \\
\hline
\end{tabular}


A Tabela 10 compara a frequência e porcentagem de exames rejeitados para cada parâmetro de reprodutibilidade avaliado dos casos $x$ controles.

Tabela 10. Frequência e porcentagem de exames rejeitados para cada parâmetro de reprodutibilidade avaliado casos $x$ controles.

\begin{tabular}{|c|c|c|c|c|}
\hline Parâmetro & Descrição & $\begin{array}{c}\text { Casos } \\
\text { Freq. (\%) }\end{array}$ & $\begin{array}{l}\text { Controles } \\
\text { Freq. (\%) }\end{array}$ & $p$ \\
\hline V_ext_obs & Vol. retro-extrapolado (L) & $5(10)$ & $5(10)$ & 0,999* \\
\hline T_Exp_obs & Tempo de expiração (s) & $11(22)$ & $11(22)$ & $0,999^{\star *}$ \\
\hline Delta_CVF & Variabilidade da CVF (L) & $3(6)$ & $2(6)$ & $0,999^{*}$ \\
\hline Delta_VEF 1 & Variabilidade do $\operatorname{VEF}_{1}(\mathrm{~L})$ & $1(2)$ & $1(2)$ & $0,999^{*}$ \\
\hline Switch-In & Erro de Switch-In na pletism. & $0(0)$ & $0(0)$ & NA \\
\hline Reprod_VGT & $\begin{array}{l}\text { Variabilidade da manobra de } \\
\text { VGT (\%) }\end{array}$ & $0(0)$ & $3(6)$ & NA \\
\hline IVC/SVC & $\begin{array}{l}\text { Capacidade vital inspiratória em } \\
\text { relação à Capacidade Vital lenta } \\
\text { na manobra de difusão }\end{array}$ & $5(10)$ & $5(10)$ & $0,999^{*}$ \\
\hline Delta_DLCO_ab & $\begin{array}{l}\text { Variabilidade da Difusão } \\
(\mathrm{mL} / \mathrm{min} . \mathrm{mmHg})\end{array}$ & $0(0)$ & $2(4)$ & NA \\
\hline Delta_DLCO_\% & Variabilidade da Difusão (\%) & $8(16)$ & $22(44)$ & $0,002^{* *}$ \\
\hline
\end{tabular}


A frequência de exames rejeitados agrupados por manobra e total de exames rejeitados casos $\mathrm{x}$ controles está demonstrado na Tabela 11 .

Tabela 11. Frequência e porcentagem de exames rejeitados agrupados por manobra e total de exames rejeitados por pelo menos uma manobra casos $x$ controles.

\begin{tabular}{lccc}
\hline Manobra & Casos & Controles & $\mathrm{p}$ \\
& Freq. (\%) & Freq. (\%) & \\
\hline Capacidade Vital Forçada & $14(28)$ & $13(26)$ & 0,822 \\
Pletismografia (medida de volumes pulmonares) & $0(0)$ & $3(6)$ & NA \\
Difusão & $12(24)$ & $25(50)$ & 0,007 \\
Total de exames rejeitados (pelo menos 1 manobra) & $23(46)$ & $36(72)$ & 0,008 \\
\hline
\end{tabular}

p-valor obtido pelo teste de frequências do qui-quadrado

NA - Não avaliável 
6 DISCUSSÃO

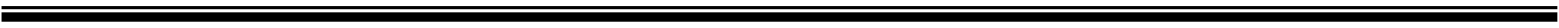




\section{DISCUSSÃO}

Pouca atenção tem sido dada à avaliação da função pulmonar em pacientes submetidos à laringectomia total na literatura. Uma das razões dessa falta de informação deve-se às dificuldades atuais na realização de testes padronizados de avaliação pulmonar nesses pacientes ${ }^{15}$.

Existem vários estudos que concordam que uma alta porcentagem de laringectomizados tem obstrução de vias aéreas e muitos desses poderiam beneficiar-se com tratamento medicamentoso ${ }^{3,5,8}$.

Depois da probabilidade de morrer de um segundo câncer, as doenças pulmonares são a segunda causa de mortalidade em pacientes laringectomizados, o que pode sugerir a realização de espirometria nesses pacientes ${ }^{8}$.

Concordando com Vazquez et al. ${ }^{8}$, acreditamos que a falta de iniciativa em estudar-se a função pulmonar em pacientes laringectomizados não se deve à falta de indicação, mas sim à dificuldade técnica para a realização dos exames.

Alguns autores descrevem o uso de cânulas com cuff na traquéia ${ }^{5,12}$ ou máscaras fixadas manualmente sobre o traqueostoma para conectar o paciente ao equipamento para avaliar a função pulmonar ${ }^{2,11}$. Entretanto, a introdução de uma cânula traqueal é geralmente desconfortável para o paciente e a vedação da máscara por sobre o traqueostoma geralmente apresenta vazamentos.

Dividimos a mesma opinião de Ackerstaff et al. ${ }^{7}$, segundo a qual a presença de uma prótese traqueo-esofágica para emissão vocal, aparentemente não altera os resultados dos exames.

Compartilhando a avaliação de Hess et al. ${ }^{3}$, parece ser crucial não reduzir o diâmetro da luz traqueal durante a mensuração da função pulmonar (como com a 
utilização de cânulas com cuff) para obter dados mais representativos, fato este também enfatizado em outros estudos ${ }^{2,7}$. Alguns estudos descrevem o uso de dispositivos extra-traqueais construídos com um tubo plástico e um balonete de látex para obter vedação aérea na tentativa de evitar esses problemas ${ }^{9}$.

Em todos os casos de nosso estudo, uma vedação aérea foi mantida durante todo o procedimento, incluindo casos nos quais as manobras de expiração forçada foram associadas com alterações de postura devido a movimentos involuntários do tórax e do pescoço ou mesmo durante episódios de tosse. Não foi detectada nenhuma reação alérgica após o uso do adesivo na pele.

Além da comodidade de um dispositivo extra-traqueal, os valores da avaliação da função e dos volumes pulmonares obtidos com o uso de tais dispositivos são mais confiáveis ${ }^{15}$.

Foram descartados seis pacientes dos 56 selecionados, sendo três por não conseguirem realizar as manobras solicitadas. Esse valor (5\%) encontra-se dentro do esperado, uma vez que, pelo senso comum da prática médica, acredita-se que aproximadamente de 2 a $5 \%$ dos pacientes submetidos a testes de avaliação da função pulmonar não conseguem realizar as manobras. Não foi descartado nenhum exame do grupo controle.

Dos 50 pacientes avaliados, 44 eram do gênero masculino e $58 \%$ fumavam mais do que 40 cigarros dia.

De acordo com a Escala de Dispnéia do Medical Research Counciß ${ }^{77}$, 56\% dos pacientes sentiam cansaço somente com exercícios extenuantes e $38 \%$ ao caminhar depressa no plano ou subir ladeira suave. Tal constatação pode relacionar-se à interrupção do tabagismo após a cirurgia, visto que o efeito da cessação do fumo é relativamente imediato ${ }^{38}$. 
Tal escala, quando relacionada ao padrão respiratório, também mostra associação marginalmente significativa, onde $69,6 \%$ dos pacientes que relataram grau de dispnéia 1, 2 ou 3 apresentaram padrão respiratório alterado e $55,6 \%$ dos pacientes que relataram dispneia somente com exercício extenuante eram normais $(p=0,075)$. Apesar de serem muito raros os artigos que relacionem escalas de dispneia em pacientes laringectomizados, Duran et al. ${ }^{14}$ afirmam que a correlação entre padrão respiratório obtido nos testes de função pulmonar e a clínica apresentada por esses pacientes é fraca e Heyden, dentre outros, concordam com nosso estudo ao observar que a laringectomia não influencia a capacidade física dos pacientes. ${ }^{10,13}$

Avaliando a espirometria, vários estudos encontraram valores subnormais em laringectomizados. ${ }^{2,5,9,12}$ Nossos resultados mostraram uma porcentagem, em média, da CVF e VEF 1 abaixo do esperado para o previsto brasileiro, respectivamente $83,3 \%$ e $75,8 \%$. Esses dados confirmam os encontrados por Duran et al. ${ }^{14}$ que encontraram uma diminuição significativa nesses índices.

Em relação aos volumes pulmonares, nesse estudo, o VR mostrou-se, em média, aumentado (122\%) do que o previsto brasileiro exatamente como encontrado no trabalho de Heyden et al..$^{13}$

Os dados obtidos em nosso estudo concordam com os resultados de Vazquez $^{8}$. Esse autor encontrou aumento do volume residual e diminuição do FEV 1 evidenciando, assim, quadro respiratório obstrutivo.

A difusão encontrou-se, em média, diminuída $(74,3 \%)$ e a resistência das vias aéreas aumentada $(121,7 \%)$ em nossos resultados em relação ao previsto brasileiro. 
Após a realização dos testes de função pulmonar, encontramos que $44 \%$ dos pacientes apresentavam um padrão respiratório normal e 56\% alterado distribuídos em 14 pacientes com padrão obstrutivo sem aprisionamento, 11 obstrutivo com aprisionamento e somente três com padrão restritivo. Nossos dados concordam com os encontrados por Duran et al. ${ }^{14}$. Esses autores verificaram, em sua série com 30 pacientes laringectomizados, que 47\% apresentaram função pulmonar normal e 53\% função pulmonar alterada. Já nas séries de Vasquez et al. ${ }^{8}$ e Hess et al. ${ }^{3}$, foram encontrados $81 \%$ de pacientes com função pulmonar de padrão respiratório obstrutivo. Conforme justificado por Ackerstaff et al., talvez, o maior índice de disfunção respiratória encontrada nos pacientes laringectomizados devase ao maior número de possíveis infecções respiratórias em função do traqueostoma ${ }^{7}$.

Em nosso estudo, ao contrário das séries avaliadas por Ackerstaff et al. ${ }^{7}$, a idade não apresentou influência significativa em relação ao padrão de interpretação respiratório.

De todos os pacientes que fumavam mais de 10 cigarros/dia, $62,5 \%$ apresentaram padrão respiratório alterado e $70 \%$ dos que não fumavam ou fumavam menos que 10 cigarros/dia apresentaram padrão respiratório normal. Entretanto, essa associação foi marginalmente significativa $(p=0,084)$. As demais variáveis não apresentaram associação com os padrões respiratórios ( $p>0,05)$.

Os dados demográficos do grupo-controle eleito para a comparação com os exames dos pacientes laringectomizados mostrou-se similar em relação a esse último, visto que foram propositalmente pareados para idade e gênero, as médias e medianas tanto para idade e índice de massa corpórea foram muito próximas, a 
separação entre gênero feminino (seis) e masculino (44) foi igual em ambos os grupos e a distribuição pela carga tabágica também mostrou-se muito parecida.

A comparação das médias dos parâmetros de reprodutibilidade não apresentou diferença significativa entre os grupos, exceto nos critérios de volume retro-extrapolado (valor absoluto), tempo de expiração observado, variabilidade do $V_{E F}$ e a variabilidade da difusão em porcentagem. $O$ fato de não haver diferença entre os grupos na maioria dos parâmetros sustenta a hipótese de que os exames apresentam reprodutibilidade similar. Em todos os parâmetros que apresentaram diferença estatística, os valores das médias de ambos os grupos sempre foram dentro do critério de aceitação do exame, portanto, a diferença apresentada não acarretou nenhum distúrbio nos critérios de reprodutibilidade, não apresentando, por conseguinte, impacto na aceitação dos exames.

De maneira geral, os participantes tanto do grupo controle como os indivíduos laringectomizados, necessitaram aproximadamente o mesmo número de manobras para a realização dos exames, porém, no presente estudo, não foi controlado o número de manobras necessárias para a realização do exame nem o tempo necessário. Assim, não há como inferir precisamente se foram necessárias mais manobras para a obtenção de um exame adequado no grupo dos laringectomizados ou mesmo se esse levou mais tempo do que os exames do grupo-controle. No entanto, acreditamos que tal fator não seja indutor de viés, visto que os pacientes pertencentes ao grupo-controle, na sua maioria doentes crônicos (motivo pelo qual foi indicado o exame), talvez fossem mais "treinados" na execução das manobras, por já terem sido submetidos à realização de exames de função pulmonar por várias vezes. 
Comparando a frequência e porcentagem dos exames rejeitados entre os laringectomizados e o grupo-controle, dos nove parâmetros avaliados, somente a variabilidade da difusão em porcentagem apresentou diferença estatísticamente significante, nesse caso a frequência de exames rejeitados no grupo-controle (44\%) foi maior que nos pacientes laringectomizados (16\%). Estes dados confirmam novamente a hipótese que os exames apresentam reprodutibilidade similar.

Agrupados por manobra, somente na capacidade vital forçada a frequência de exames rejeitados foi maior no grupo dos laringectomizados (28\%) quando comparado ao controle (26\%), porém não apresentou significância estatística. O total de exames rejeitados foi maior no grupo-controle (72\%) do que no grupo dos laringectomizados (46\%). Esse dado demonstra que, em linhas gerais, o exame realizado com o dispositivo extratraqueal proposto apresenta uma reprodutibilidade ao menos similar ao exame realizado de maneira convencional em pacientes que não foram submetidos à laringectomia total.

Nossos resultados concordam com o estudo realizado por Hess et al. ${ }^{3}$, indicando que talvez seja preciso reavaliar o papel do exame de função pulmonar no acompanhamento de pacientes submetidos à laringectomia total levando em conta a disponibilidade, precisão e facilidade do uso do dispositivo aqui avaliado para avaliação da função pulmonar.

Uma vez que determinamos a reprodutibilidade desse método para avaliação da função pulmonar em pacientes submetidos a laringectomia total, como perspectivas futuras, acreditamos que um estudo que avaliasse a função pulmonar do mesmo paciente antes e depois da laringectomia total seria de grande valia para melhor caracterização desses pacientes, principalmente no período póslaringectomia. 
7 CONCLUSÕES 


\section{CONCLUSÕES}

1. A maioria dos pacientes submetidos à laringectomia total apresenta função pulmonar alterada, de caráter obstrutivo, na maioria das vezes, devido ao histórico de tabagismo.

2. A metodologia para a avaliação da função pulmonar por meio do uso do dispositivo extra-traqueal proposto é confiável e reprodutível, não se mostrando diferente da avaliação convencional em indivíduos não laringectomizados. 
8 ANEXOS 


\section{ANEXOS}

Anexo A - Aprovação pelo Comitê de Ética em Pesquisa da Faculdade de Medicina da Universidade de São Paulo sob o número 075/14, em 12 de maio de 2014.

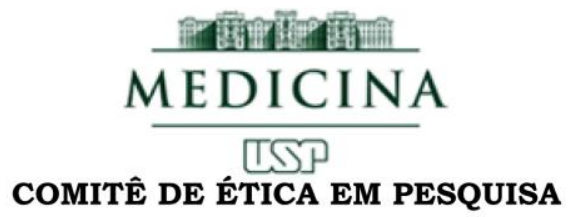

\section{APROVAÇÃO}

O Comitê de Ética em Pesquisa da Faculdade de Medicina da Universidade de São Paulo, em 12/05/2014, APROVOU ad referendum o Protocolo de Pesquisa no o75/14 intitulado: “AVALIAÇÃO DA FUNÇÃO PULMONAR E VOCAL APÓS TRATAMENTO DO CÂNCER DE LARINGE” apresentado pelo Departamento de CIRURGIA

Cabe ao pesquisador elaborar e apresentar ao CEPFMUSP, os relatórios parciais e final sobre a pesquisa (Resolução do Conselho Nacional de Saúde no 466/12).

Pesquisador (a) Responsável: Rogério Aparecido Dedivitis Pesquisador (a) Executante: Mario Augusto Ferrari de Castro

CEP-FMUSP, 12 de Maio de 2014.

$$
\text { Pllamin. }
$$

Prof. Dr. Roger Chammas Coordenador Comitê de Ética em Pesquisa 
Anexo B - Termo de Consentimento Livre e Esclarecido.

HOSPITAL DAS CLÍNICAS DA FACULDADE DE MEDICINA DA UNIVERSIDADE DE SÃO PAULO-HCFMUSP

TERMO DE CONSENTIMENTO LIVRE E ESCLARECIDO PARA OS PACIENTES

DADOS DE IDENTIFICAÇÃO DO PARTICIPANTE DA PESQUISA OU RESPONSÁVEL LEGAL

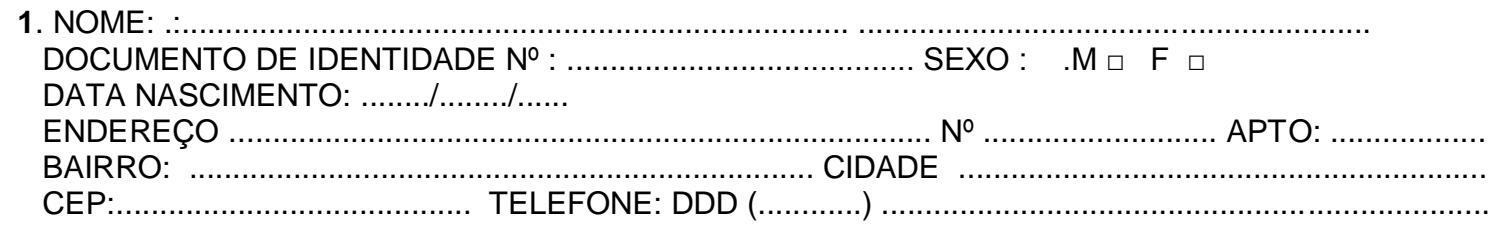

2. RESPONSÁVEL LEGAL

NATUREZA (grau de parentesco, tutor, curador etc.)

DOCUMENTO DE IDENTIDADE :.

DATA NASCIMENTO.: .....................

ENDEREÇO:

BAIRRO:

CEP: SEXO: M $\mathrm{F} \square$ № APTO: TELEFONE: DDD ( CIDADE

\section{DADOS SOBRE A PESQUISA}

1. TÍTULO DO PROTOCOLO DE PESQUISA - Avaliação da função pulmonar em pacientes submetidos a laringectomia total.

2. PESQUISADOR : Prof. Dr. Rogério Aparecido Dedivitis CARGO/FUNÇÃO: Docente INSCRIÇÃO CONSELHO REGIONAL CRM: 65803

UNIDADE DO HCFMUSP: Cirurgia de Cabeça e Pescoço - Laringe

3. AVALIAÇÃO DO RISCO DA PESQUISA:

$\begin{array}{cll}\text { RISCO MÍNIMO } & (X) & \text { RISCO MÉDIO } \\ \text { RISCO BAIXO } & \square & \text { RISCO MAIOR }\end{array}$

4. DURAÇÃO DA PESQUISA : 2 anos

Essas informações estão sendo fornecidas para sua participação voluntária neste estudo, que tem como objetivo avaliação da função pulmonar em pacientes submetidos a laringectomia total.

Para esta análise, serão realizadas avaliações no Ambulatório de Cirurgia de Cabeça e Pescoço do HCFMUSP por médico cirurgião e testes de função pulmonar no laboratório de função pulmonar.

O teste de função pulmonar será realizado por meio de espirometria simples com o paciente na posição sentada. Será solicitado ao paciente que realize uma manobra de inspiração máxima, seguida de uma expiração máxima forçada. Nos pacientes traqueostomizados, será utilizado um adaptador elaborado especificamente para esse tipo paciente.

Ainda na avaliação pulmonar será realizado um exame de pletismografia de corpo inteiro no qual o paciente entrará em uma cabine e com o adaptador fixado ao traqueostoma será instruído a respirar gentilmente e depois realizar determinadas manobras como respirar curta e rapidamente.

O (a) sr. (a) não terá benefício financeiro com sua participação nesta pesquisa, pois trata-se de estudo com objetivo de melhorar os procedimentos terapêuticos na área da respiração, bem como os instrumentos de avaliação. Somente no final do estudo poderemos concluir a presença de algum benefício que poderá ser aplicado na avaliação e tratamento de outros pacientes. É importante ressaltar que não há procedimentos alternativos que possam ser vantajosos pelos quais o (a) sr. (a) possa optar. 
Em qualquer etapa do estudo o (a) sr. (a) terá acesso aos profissionais responsáveis pela pesquisa para esclarecimento de eventuais dúvidas. O principal investigador é o Prof. Dr. Rogério Aparecido Dedivitis, que pode ser encontrado na Rua Dr. Olintho Rodrigues Dantas 343 cj 92 - Santos - SP; telefone 1332335550. Se houver a necessidade de alguma consideração ou dúvida sobre a ética da pesquisa, entre em contato com o Comitê de Ética em Pesquisa (CEP) - Rua Ovídio Pires de Campos, 225 - 5o andar - tel: 3069-6442 ramais 16, 17, 18 ou 20, FAX: 3069-6442 ramal 26 - e-mail: cappesq@hcnet.usp.br. É garantida a liberdade da retirada do seu consentimento a qualquer momento, assim como a desistência em relação à participação no estudo, sem qualquer prejuízo à continuidade de seu tratamento na Instituição.

E garantido a todos os participantes o direito de confidencialidade, uma vez que as informações obtidas serão analisadas em conjunto com as de outros pacientes e não serão divulgados dados de identificação. É garantido também o seu direito em relação ao conhecimento dos resultados da pesquisa. Não há despesas pessoais em qualquer fase do estudo, incluindo exames e consultas. Fica aqui explicitado o compromisso do pesquisador de utilizar os dados e o material coletado somente para esta pesquisa.

Acredito ter sido suficientemente informado por meio do que li, ou do que foi lido para mim, sobre o estudo AVALIAÇÃO DA FUNÇÃO PULMONAR EM PACIENTES SUBMETIDOS A LARINGECTOMIA TOTAL. Eu discuti com os pesquisadores sobre a minha decisão voluntária em participar da pesquisa e ficaram claros para mim quais são os propósitos do estudo, os procedimentos a serem realizados, seus desconfortos e riscos, as garantias de confidencialidade e de esclarecimentos permanentes. Ficou claro também que minha participação é isenta de despesas. Concordo voluntariamente em participar deste estudo e poderei retirar o meu consentimento a qualquer momento, antes ou durante o mesmo, sem penalidades ou prejuízo ou perda de qualquer benefício que eu possa ter adquirido ou em relação ao meu atendimento neste serviço.

Assinatura do participante/representante legal

Data

Assinatura da testemunha

Data

(Pacientes menores de 18 anos, analfabetos, ou portadores de deficiência auditiva ou visual)

\section{PARA O RESPONSÁVEL PELO PROJETO:}

Declaro que obtive de forma apropriada e voluntária o Consentimento Livre e Esclarecido deste participante ou de seu representante legal para a participação neste estudo. 
Anexo C - Protocolo de Avaliação.

\section{I - IDENTIFICAÇÃO - Número}

Nome:

Endereço:

Cidade: Telefone 1:

Telefone 2:

Data Nascimento: ...... /..... /..... Idade (anos) : Profissão:

Raça: (1) branca (2) negra (3) amarela $\perp_{\ldots} \perp_{1} \mid$

Tabagismo: (0) não; (1) +; (2) ++; (3) +++; (4)

Etilismo (0) não; (1) +; (2) ++; (3) +++; (4) ++++

Peso: ......... Kg Altura:

$\mathrm{m}$

Doenças respiratórias:

Escala de Dispnéia (Medical Research Council):

\begin{tabular}{|l|l|}
\hline Grau & Características definitórias \\
\hline 0 & Sem dispnéia, a não ser com exercício extenuante \\
\hline 1 & Falta de ar quando caminha depressa no plano ou sobe ladeira suave \\
\hline 2 & $\begin{array}{l}\text { Anda mais devagar que pessoa da mesma idade no plano devido à } \\
\text { falta de ar ou tem de parar para respirar }\end{array}$ \\
\hline 3 & $\begin{array}{l}\text { Pára de respirar após caminhar uma quadra (90 a } 120 \text { m) ou após } \\
\text { poucos minutos no plano }\end{array}$ \\
\hline 4 & Muito dispnéico para sair de casa ou dispnéico ao vestir-se \\
\hline
\end{tabular}

\section{II - DADOS DO TUMOR DA LARINGE}

Sítio da doença:

Supraglótico (1); Glótico (2); Infraglótico (3)

Estadiamento

$\mathrm{T}:$ (1) (2) (3) (4)

$\mathrm{N}$ : (1) N0; (2) N1; (3) N2a; (4) N2b; (5) N2c; (6) N3

$\mathrm{M}:(1) \mathrm{M0} ;(2) \mathrm{M} 1$

\section{III - DADOS DO TRATAMENTO}

Preserv órgão (1); Laring. total (2); Laring. vertical (3); Laring. horizontal (4)... __

Data do início do tratamento: ...................

\section{IV - DADOS DA REABILITAÇÃO VOCAL}

Nenhuma (1); Prótese tráqueo-esofágica (2); Voz esofágica (3). 
Anexo D - Tabelas de resultados.

\begin{tabular}{|c|c|c|c|c|c|c|c|c|c|c|c|}
\hline ID & Grupo & Idade & Sexo & Raça & Tabag. & Peso & Altura & IMC & E. Disp. & TempoLT & CVF_prev \\
\hline 1 & Caso & 67 & 1 & 1 & 4 & 57 & 1,63 & 21,45 & 0 & 18 & 3,860 \\
\hline 2 & Caso & 53 & 2 & 1 & 4 & 65 & 1,58 & 26,04 & 1 & 32 & 3,114 \\
\hline 3 & Caso & 70 & 1 & 1 & 4 & 47 & 1,73 & 15,70 & 3 & 70 & 4,315 \\
\hline 4 & Caso & 62 & 1 & 1 & 2 & 75 & 1,65 & 27,55 & 1 & 52 & 4,067 \\
\hline 5 & Caso & 68 & 1 & 1 & 2 & 47 & 1,56 & 19,31 & 1 & 116 & 3,478 \\
\hline 6 & Caso & 67 & 1 & 1 & 4 & 78 & 1,73 & 26,06 & 1 & 43 & 4,377 \\
\hline 7 & Caso & 76 & 1 & 1 & 2 & 80 & 1,70 & 27,68 & 1 & 185 & 4,036 \\
\hline 8 & Caso & 69 & 1 & 2 & 4 & 80 & 1,79 & 24,97 & 1 & 60 & 4,646 \\
\hline 9 & Caso & 66 & 1 & 1 & 4 & 73 & 1,73 & 24,39 & 0 & 20 & 4,398 \\
\hline 10 & Caso & 87 & 1 & 1 & 4 & 80 & $\begin{array}{l}1,67 \\
\end{array}$ & 28,69 & 1 & 121 & 3,653 \\
\hline 11 & Caso & 67 & 2 & 1 & 1 & 72 & 1,61 & 27,78 & 0 & 30 & 2,981 \\
\hline 12 & Caso & 63 & 1 & 1 & 2 & 92 & 1,77 & 29,37 & 0 & 68 & 4,667 \\
\hline 13 & Caso & 62 & 1 & 1 & 2 & 78 & 1,68 & 27,64 & 0 & 17 & 4,222 \\
\hline 14 & Caso & 81 & 2 & 1 & 0 & 71 & 1,48 & 32,41 & 1 & 78 & 2,142 \\
\hline 15 & Caso & 68 & 1 & 1 & 4 & 84 & 1,66 & 30,48 & 0 & 42 & 3,995 \\
\hline 16 & Caso & 62 & 1 & 1 & 3 & 76 & 1,69 & 26,61 & 0 & 49 & 4,274 \\
\hline 17 & Caso & 54 & 1 & 2 & 7 & 75 & 1,65 & 27,55 & 0 & 76 & 4,233 \\
\hline 18 & Caso & 60 & 1 & 1 & 2 & 61 & 1,60 & 23,83 & 1 & 52 & 3,850 \\
\hline 19 & Caso & 47 & 1 & 2 & 4 & 70 & 1,82 & 21,13 & 1 & 110 & 5,257 \\
\hline 20 & Caso & 68 & 1 & 1 & 2 & 68 & 1,67 & 24,38 & 0 & 61 & 4,046 \\
\hline 21 & Caso & 72 & 1 & 1 & 0 & 62 & 1,67 & 22,23 & 0 & 13 & 3,964 \\
\hline 22 & Caso & 57 & 2 & 2 & 4 & 66 & 1,45 & 31,39 & 1 & 131 & 2,465 \\
\hline 23 & Caso & 58 & 1 & 2 & 4 & 63 & 1,54 & 26,56 & 0 & 13 & 3,581 \\
\hline 24 & Caso & 42 & 1 & 2 & 4 & 68 & 1,68 & 24,09 & 1 & 16 & 4,636 \\
\hline 25 & Caso & 74 & 1 & 1 & 4 & 65 & 1,65 & 23,88 & 2 & 50 & 3.819 \\
\hline 26 & Caso & 51 & 1 & 1 & 4 & 89 & 1,74 & 29,23 & 0 & 140 & 4,760 \\
\hline 27 & Caso & 65 & 1 & 1 & 4 & 65 & 1,60 & 25,39 & 2 & 167 & 3,747 \\
\hline 28 & Caso & 41 & 1 & 1 & 1 & 60 & 1,67 & 21,51 & 0 & 53 & 4,605 \\
\hline 29 & Caso & 68 & 1 & 1 & 3 & 76 & 1,70 & 26,30 & 0 & 51 & 4,201 \\
\hline 30 & Caso & 58 & 1 & 1 & 4 & 70 & 1,72 & 23,66 & 0 & 55 & 4,512 \\
\hline 31 & Caso & 83 & 1 & 1 & 4 & 65 & 1,67 & 23,31 & 0 & 172 & 3,736 \\
\hline 32 & Caso & 64 & 1 & 1 & 4 & 100 & 1,75 & 32,65 & 0 & 33 & 4,543 \\
\hline 33 & Caso & 73 & 2 & 2 & 4 & 50 & 1,59 & 19,78 & 1 & 159 & 2,779 \\
\hline 34 & Caso & 58 & 1 & 1 & 4 & 50 & 1,60 & 19,53 & 1 & 12 & 3,891 \\
\hline 35 & Caso & 75 & 1 & 1 & 4 & 67 & 1,65 & 24,61 & 1 & 53 & 3,798 \\
\hline 36 & Caso & 62 & 1 & 1 & 0 & 55 & 1,55 & 22,89 & 1 & 37 & 3,550 \\
\hline 37 & Caso & 66 & 1 & 1 & 4 & 65 & 1,65 & 23,88 & 0 & 149 & 3,984 \\
\hline 38 & Caso & 65 & 1 & 1 & 0 & 63 & 1,72 & 21,30 & 0 & 38 & 4,367 \\
\hline 39 & Caso & 71 & 1 & 1 & 4 & 65 & 1,89 & 18,20 & 0 & 228 & 5,122 \\
\hline 40 & Caso & 63 & 1 & 2 & 4 & 66 & 1,69 & 23,11 & 0 & 107 & 4,253 \\
\hline 41 & Caso & 44 & 1 & 2 & 3 & 56 & 1,70 & 19,38 & 0 & 40 & 4,698 \\
\hline 42 & Caso & 62 & 1 & 2 & 4 & 50 & 1,55 & 20,81 & 0 & 132 & 3,550 \\
\hline 43 & Caso & 69 & 1 & 2 & 3 & 73 & 1,68 & 25,86 & 0 & 60 & 4,077 \\
\hline 44 & Caso & 42 & 1 & 3 & 0 & 66 & 1,72 & 22,31 & 0 & 61 & 4,843 \\
\hline 45 & Caso & 78 & 1 & $\overline{1}$ & 0 & 67 & 1,57 & 27,18 & 1 & 98 & 3,322 \\
\hline 46 & Caso & 64 & 1 & 2 & 4 & 70 & 1,74 & 23,12 & 0 & 59 & 4,491 \\
\hline 47 & Caso & 61 & 2 & 1 & 1 & 57 & 1,52 & 24,67 & 1 & 65 & 2,698 \\
\hline 48 & Caso & 63 & 1 & 1 & 4 & 62 & 1,81 & 18,92 & 1 & 59 & 4,874 \\
\hline 49 & Caso & 62 & 1 & 1 & 4 & 60 & 1,79 & 18,73 & 1 & 90 & 4,791 \\
\hline 50 & Caso & 81 & 7 & 3 & 4 & 52 & 1,55 & 21,64 & 0 & 170 & 3,157 \\
\hline
\end{tabular}




\begin{tabular}{|c|c|c|c|c|c|c|c|c|c|c|c|}
\hline 51 & \begin{tabular}{|l|} 
Controle \\
\end{tabular} & 54 & 1 & 1 & 4 & 71 & 1,66 & 25,77 & ND & $\mathrm{ND}$ & 4,284 \\
\hline 52 & Controle & 61 & 1 & 1 & 1 & 75 & 1,71 & 25,65 & ND & $\mathrm{ND}$ & 4,398 \\
\hline 53 & \begin{tabular}{|l|} 
Controle \\
\end{tabular} & 73 & 1 & 1 & 3 & 85 & 1,64 & 31,60 & ND & ND & 3,788 \\
\hline 54 & Controle & 64 & 1 & 1 & 1 & 55 & 1,65 & 20,20 & ND & ND & 4,026 \\
\hline 55 & \begin{tabular}{|l|} 
Controle \\
\end{tabular} & 57 & 1 & 1 & 0 & 106 & 1,69 & 37,11 & ND & $\mathrm{ND}$ & 4,377 \\
\hline 56 & \begin{tabular}{|l|} 
Controle \\
\end{tabular} & 64 & 1 & 2 & 4 & 80 & 1,72 & 27,04 & ND & ND & 4,388 \\
\hline 57 & Controle & 59 & 1 & 1 & 0 & 60 & 1,72 & 20,28 & ND & ND & 4,491 \\
\hline 58 & Controle & 55 & 1 & 1 & 2 & 61 & 1,69 & 21,36 & ND & ND & 4,419 \\
\hline 59 & Controle & 55 & 1 & 1 & 4 & 51 & 1,57 & 20,69 & ND & ND & 3,798 \\
\hline 60 & \begin{tabular}{|l|} 
Controle \\
\end{tabular} & 63 & 1 & $\overline{1}$ & 4 & 71 & 1,80 & 21,91 & ND & ND & 4,822 \\
\hline 61 & \begin{tabular}{|l|} 
Controle \\
\end{tabular} & 55 & 1 & 1 & 2 & 65 & 1,72 & 21,97 & ND & ND & 4,574 \\
\hline 62 & \begin{tabular}{|l|} 
Controle \\
\end{tabular} & 59 & 1 & 1 & 2 & 63 & 1,62 & 24,01 & ND & ND & 3,974 \\
\hline 63 & \begin{tabular}{|l|} 
Controle \\
\end{tabular} & 61 & 1 & $\overline{1}$ & 4 & 110 & 1,64 & 40,90 & ND & ND & 4,036 \\
\hline 64 & Controle & 57 & 1 & 1 & 0 & 65 & 1,67 & 23,31 & ND & ND & 4,274 \\
\hline 65 & Controle & 66 & 1 & 1 & 4 & 84 & 1,60 & 32,81 & ND & ND & 3,726 \\
\hline 66 & \begin{tabular}{|l|} 
Controle \\
\end{tabular} & 68 & 1 & 1 & 4 & 81 & 1,80 & 25,00 & ND & ND & 4,718 \\
\hline 67 & \begin{tabular}{|l|} 
Controle \\
\end{tabular} & 66 & 1 & 1 & 4 & 49 & 1,58 & 19,63 & ND & ND & 3,622 \\
\hline 68 & \begin{tabular}{|l|} 
Controle \\
\end{tabular} & 67 & 1 & 2 & 3 & 80 & 1,72 & 27,04 & ND & ND & 4,326 \\
\hline 69 & \begin{tabular}{|l|} 
Controle \\
\end{tabular} & 74 & 1 & 1 & 1 & 41 & 1,73 & 13,70 & ND & ND & 4,232 \\
\hline 70 & \begin{tabular}{|l|} 
Controle \\
\end{tabular} & 67 & 1 & 2 & 4 & 56 & 1,70 & 19,38 & ND & ND & 4,222 \\
\hline 71 & \begin{tabular}{|l|} 
Controle \\
\end{tabular} & 56 & 1 & 1 & 4 & 80 & 1,75 & 26,12 & ND & ND & 4,708 \\
\hline 72 & \begin{tabular}{|l|} 
Controle \\
\end{tabular} & 61 & 1 & 1 & 2 & 85 & 1,70 & 29,41 & ND & ND & 4,346 \\
\hline 73 & \begin{tabular}{|l|} 
Controle \\
\end{tabular} & 74 & 1 & 1 & 0 & 70 & 1,74 & 23,12 & ND & ND & 4,284 \\
\hline 74 & \begin{tabular}{|l|} 
Controle \\
\end{tabular} & 65 & 1 & 1 & 4 & 80 & 1,72 & 27,04 & ND & ND & 4,367 \\
\hline 75 & Controle & 70 & 1 & 1 & 4 & 63 & 1,72 & 21,30 & ND & ND & 4,263 \\
\hline 76 & Controle & 64 & 1 & 1 & 4 & 109 & 1,74 & 36,00 & ND & ND & 4,491 \\
\hline 77 & \begin{tabular}{|l|} 
Controle \\
\end{tabular} & 72 & 1 & 2 & 0 & 58 & 1,70 & 20,07 & ND & ND & 4,119 \\
\hline 78 & \begin{tabular}{|l|} 
Controle \\
\end{tabular} & 74 & 1 & 1 & 4 & 84 & 1,64 & 31,23 & ND & ND & 3,767 \\
\hline 79 & \begin{tabular}{|l|} 
Controle \\
\end{tabular} & 66 & 1 & 1 & 3 & 78 & 1,69 & 27,31 & ND & ND & 4,191 \\
\hline 80 & Controle & 61 & 1 & 1 & 0 & 46 & 1,61 & 17,75 & ND & $\mathrm{ND}$ & 3,881 \\
\hline 81 & \begin{tabular}{|l|} 
Controle \\
\end{tabular} & 67 & 1 & 1 & 3 & 89 & 1,68 & 31,53 & ND & ND & 4,119 \\
\hline 82 & \begin{tabular}{|l|} 
Controle \\
\end{tabular} & 73 & 1 & 1 & 4 & 72 & 1,64 & 26,77 & ND & ND & 3,788 \\
\hline 83 & \begin{tabular}{|l|} 
Controle \\
\end{tabular} & 63 & 1 & $\overline{1}$ & 0 & 83 & 1,61 & 32,02 & ND & ND & 3,840 \\
\hline 84 & \begin{tabular}{|l|} 
Controle \\
\end{tabular} & 63 & 1 & 1 & 4 & 57 & 1,69 & 19,96 & ND & ND & 4,253 \\
\hline 85 & \begin{tabular}{|l|} 
Controle \\
\end{tabular} & 58 & 1 & $\overline{1}$ & 3 & 71 & 1,65 & 26,08 & ND & ND & 4,150 \\
\hline 86 & \begin{tabular}{|l|} 
Controle \\
\end{tabular} & 63 & 1 & 1 & 4 & 86 & 1,71 & 29,41 & ND & ND & 4,357 \\
\hline 87 & \begin{tabular}{|l|} 
Controle \\
\end{tabular} & 66 & 1 & 1 & 0 & 74 & 1,72 & 25,01 & ND & ND & 4,346 \\
\hline 88 & \begin{tabular}{|l|} 
Controle \\
\end{tabular} & 72 & 1 & 3 & 4 & 50 & 1,52 & 21,64 & ND & ND & 3,188 \\
\hline 89 & Controle & 56 & 1 & 1 & 1 & 79 & 1,76 & 25,50 & ND & ND & 4,760 \\
\hline 90 & \begin{tabular}{|l|} 
Controle \\
\end{tabular} & 57 & 1 & 1 & 4 & 90 & 1,64 & 33,46 & ND & ND & 4,119 \\
\hline 91 & Controle & 65 & 1 & 1 & 4 & 89 & 1,69 & 31,16 & ND & $\mathrm{ND}$ & 4,212 \\
\hline 92 & \begin{tabular}{|l|} 
Controle \\
\end{tabular} & 61 & 1 & 2 & 4 & 77 & 1,66 & 27,94 & ND & ND & 4,140 \\
\hline 93 & \begin{tabular}{|l|} 
Controle \\
\end{tabular} & 59 & 1 & 1 & 3 & 76 & 1,79 & 23,72 & ND & ND & 4,853 \\
\hline 94 & \begin{tabular}{|l|} 
Controle \\
\end{tabular} & 55 & 2 & 1 & 4 & 79 & 1,63 & 29,73 & ND & ND & 3,297 \\
\hline 95 & \begin{tabular}{|l|} 
Controle \\
\end{tabular} & 67 & 2 & 1 & 2 & 56 & 1,48 & 25,57 & ND & ND & 2,408 \\
\hline 96 & \begin{tabular}{|l|} 
Controle \\
\end{tabular} & 61 & 2 & 1 & 4 & 42 & 1,55 & 17,48 & ND & ND & 2,830 \\
\hline 97 & \begin{tabular}{|l|} 
Controle \\
\end{tabular} & 60 & 2 & 1 & 1 & 59 & 1,54 & 24,88 & ND & ND & 2,805 \\
\hline 98 & Controle & 63 & 2 & 1 & 2 & 82 & 1,59 & 32,44 & ND & ND & 2,969 \\
\hline 99 & Controle & 59 & 2 & 1 & 2 & 62 & 1,62 & 23,62 & ND & $\mathrm{ND}$ & 3,177 \\
\hline 100 & \begin{tabular}{|l|} 
Controle \\
\end{tabular} & 58 & 2 & 1 & 4 & 54 & 1,50 & 24,00 & ND & ND & 2,667 \\
\hline
\end{tabular}




\begin{tabular}{|c|c|c|c|c|c|c|c|}
\hline CVF_obs & CVF_\% & VEF1_prev & VEF1_obs & VEF1_\% & Tiff_prev & Tiff_obs & Tiff_\% \\
\hline 2,600 & 67,354 & 3,032 & 1,740 & 57,388 & 78,576 & 66,923 & 85,170 \\
\hline 2,040 & 65,502 & 2,532 & 1,100 & 43,439 & 81,006 & 53,922 & 66,565 \\
\hline 3,970 & 92,003 & 3,294 & 3,210 & 97,438 & 76,235 & 80,856 & 106,062 \\
\hline 3,680 & 90,482 & 3,226 & 2,510 & 77,815 & 79,211 & 68,207 & 86,107 \\
\hline 3,000 & 86,266 & 2,770 & 2,000 & 72,197 & 79,604 & 66,667 & 83,748 \\
\hline 3,600 & 82,244 & 3,370 & 2,580 & 76,558 & 76,826 & 71,667 & 93,284 \\
\hline 3,060 & 75,821 & 3,042 & 2,340 & 76,928 & 75,578 & 76,471 & 101,181 \\
\hline 3,270 & 70,383 & 3,522 & 2,060 & 58,483 & 75,382 & 62,997 & 83,570 \\
\hline 3,130 & 71,170 & 3,395 & 1,910 & 56,256 & 77,023 & 61,022 & 79,226 \\
\hline 2,070 & 56,666 & 2,663 & 1,480 & 55,572 & 73,936 & 71,498 & 96,702 \\
\hline 2,650 & 88,893 & 2,342 & 2,020 & 86,240 & 78,374 & 76,226 & 97,260 \\
\hline 4,190 & 89,783 & 3,606 & 3,140 & 87,077 & 76,914 & 74,940 & 97,434 \\
\hline 3,450 & 81,711 & 3,327 & 2,920 & 87,767 & 78,686 & 84,638 & 107,564 \\
\hline 2,110 & 98,495 & 1,650 & 1,760 & 106,673 & 77,982 & 83,412 & 106,964 \\
\hline 3,550 & 88,870 & 3,108 & 2,380 & 76,572 & 77,854 & 67,042 & 86,113 \\
\hline 3,950 & 92,421 & 3,361 & 3,400 & 101,166 & 78,511 & 86,076 & 109,636 \\
\hline 3,850 & 90,958 & 3,427 & 3,010 & 87,827 & 80,787 & 78,182 & 96,775 \\
\hline 3,200 & 83,117 & 3,107 & 2,050 & 65,980 & 80,480 & 64,063 & 79,601 \\
\hline 3,940 & 74,955 & 4,178 & 2,530 & 60,552 & 79,191 & 64,213 & 81,086 \\
\hline 3,290 & 81,309 & 3,142 & 2,510 & 79,885 & 77,679 & 76,292 & 98,214 \\
\hline 3,160 & 79,728 & 3,041 & 2,480 & 81,547 & 76,891 & 78,481 & 102,068 \\
\hline 1,790 & 72,610 & 2,043 & 1,620 & 79,299 & 82,194 & 90,503 & 110,109 \\
\hline 3,700 & 103,317 & 2,955 & 2,580 & 87,321 & 81,924 & 69,730 & 85,115 \\
\hline 3,890 & 83,905 & 3,831 & 2,700 & 70,478 & 82,626 & 69,409 & 84,004 \\
\hline 3,410 & 89,297 & 2,923 & 2,590 & 88,602 & 76,847 & 75,953 & 98,837 \\
\hline 4,010 & 84,242 & 3,807 & 2,810 & 73,811 & 79,803 & 70,075 & 87,810 \\
\hline 2,460 & 65,661 & 2,981 & 1,690 & 56,692 & 79,495 & 68,699 & 86,420 \\
\hline 4,610 & 100,104 & 3,822 & 3,630 & 94,967 & 82,998 & 78,742 & 94,872 \\
\hline 3,790 & 90,208 & 3,243 & 2,820 & 86,946 & 77,154 & 74,406 & 96,439 \\
\hline 3,630 & 80,456 & 3,563 & 3,100 & 87,005 & 78,774 & 85,399 & 108,411 \\
\hline 3,360 & 89,941 & 2,764 & 2,430 & 87,916 & 74,724 & 72,321 & 96,785 \\
\hline 3,470 & 76,386 & 3,513 & 2,700 & 76,853 & 77,067 & 77,810 & 100,964 \\
\hline 2,310 & 83,121 & 2,158 & 1,490 & 69,055 & 77,706 & 64,502 & 83,008 \\
\hline 3,560 & 91,484 & 3,157 & 2,440 & 77,279 & 80,874 & 68,539 & 84,748 \\
\hline 3,560 & 93,734 & 2,898 & 2,330 & 80,400 & 76,650 & 65,449 & 85,387 \\
\hline 3,610 & 101,687 & 2,888 & 2,700 & 93,503 & 80,961 & 74,792 & 92,381 \\
\hline 2,990 & 75,045 & 3,125 & 2,480 & 79,365 & 78,423 & 82,943 & 105,764 \\
\hline 4,880 & 111,750 & 3,387 & 3,620 & 106,892 & 77,395 & 74,180 & 95,846 \\
\hline 3,380 & 65,995 & 3,810 & 1,680 & 44,094 & 73,238 & 49,704 & 67,867 \\
\hline 4,070 & 95,693 & 3,336 & 3,220 & 96,534 & 78,314 & 79,115 & 101,023 \\
\hline 3,300 & 70,240 & 3,848 & 2,530 & 65,745 & 81,882 & 76,667 & 93,631 \\
\hline 3,390 & 95,490 & 2,888 & 2,410 & 83,460 & 80,961 & 71,091 & 87,809 \\
\hline 3,810 & 93,444 & 3,151 & 2,850 & 90,459 & 77,307 & 74,803 & 96,761 \\
\hline 3,390 & 69,998 & 3,966 & 2,460 & 62,024 & 81,926 & 72,566 & 88,576 \\
\hline 2,090 & 62,908 & 2,552 & 1,630 & 63,871 & 77,459 & 77,990 & 100,686 \\
\hline 4,920 & 109,552 & 3,479 & 3,050 & 87,659 & 77,242 & 61,992 & 80,257 \\
\hline 2,530 & 93,772 & 2,182 & 1,420 & 65,093 & 80,582 & 56,126 & 69,651 \\
\hline 4,000 & 82,075 & 3,741 & 1,970 & 52,657 & 76,214 & 49,250 & 64,621 \\
\hline 4,330 & 90,380 & 3,699 & 3,020 & 81,648 & 76,761 & 69,746 & 90,861 \\
\hline 2,330 & 73,809 & 2,409 & 1,680 & 69,744 & 77,218 & 72,103 & 93,376 \\
\hline
\end{tabular}




\begin{tabular}{|c|c|c|c|c|c|c|c|}
\hline 2,610 & 60,919 & 3,461 & 1,670 & 48,252 & 80,612 & 63,985 & 79,374 \\
\hline 2,220 & 50,477 & 3,454 & 0,940 & 27,218 & 78,358 & 42,342 & 54,037 \\
\hline 3,350 & 88,444 & 2,915 & 2,940 & 100,871 & 77,219 & 87,761 & 113,652 \\
\hline 2,490 & 61,853 & 3,175 & 0,790 & 24,880 & 78,817 & 31,727 & 40,254 \\
\hline 2,360 & 53,913 & 3,487 & 1,210 & 34,702 & 79,496 & 51,271 & 64,495 \\
\hline 2,210 & 50,369 & 3,412 & 2,040 & 59,792 & 77,592 & 92,308 & 118,965 \\
\hline 2,990 & 66,576 & 3,538 & 1,220 & 34,485 & 78,577 & 40,803 & 51,927 \\
\hline 2,350 & 53,182 & 3,537 & 2,040 & 57,673 & 79,890 & 86,809 & 108,660 \\
\hline 2,440 & 64,238 & 3,132 & 2,040 & 65,142 & 81,990 & 83,607 & 101,972 \\
\hline 4,530 & 93,946 & 3,707 & 1,670 & 45,045 & 76,389 & 36,865 & 48,260 \\
\hline 3,410 & 74,553 & 3,639 & 1,280 & 35,178 & 79,365 & 37,537 & 47,296 \\
\hline 2,050 & 51,584 & 3,200 & 0,600 & 18,751 & 80,327 & 29,268 & 36,436 \\
\hline 2,480 & 61,445 & 3,217 & 1,440 & 44,762 & 79,583 & 58,065 & 72,961 \\
\hline 1,190 & 27,843 & 3,419 & 0,340 & 9,944 & 79,846 & 28,571 & 35,783 \\
\hline 1,810 & 48,580 & 2,956 & 1,100 & 37,215 & 79,298 & 60,773 & 76,639 \\
\hline 2,590 & 54,891 & 3,581 & 1,960 & 54,727 & 75,404 & 75,676 & 100,360 \\
\hline 1,690 & 46,654 & 2,888 & 0,640 & 22,159 & 79,648 & 37,870 & 47,546 \\
\hline 2,380 & 55,023 & 3,336 & 2,050 & 61,447 & 77,001 & 86,134 & 111,861 \\
\hline 2,590 & 61,196 & 3,194 & 1,700 & 53,231 & 75,447 & 65,637 & 86,998 \\
\hline 2,470 & 58,502 & 3,269 & 0,920 & 28,147 & 77,351 & 37,247 & 48,153 \\
\hline 2,100 & 44,602 & 3,715 & 1,790 & 48,186 & 78,643 & 85,238 & 108,386 \\
\hline 2,750 & 63,272 & 3,420 & 2,170 & 63,454 & 78,533 & 78,909 & 100,479 \\
\hline 3,200 & 74,697 & 3,227 & 2,590 & 80,250 & 75,272 & 80,938 & 107,527 \\
\hline 4,170 & 95,491 & 3,387 & 3,060 & 90,356 & 77,395 & 73,381 & 94,814 \\
\hline 2,920 & 68,490 & 3,261 & 2,420 & 74,219 & 76,410 & 82,877 & 108,463 \\
\hline 2,130 & 47,428 & 3,479 & 1,530 & 43,973 & 77,242 & 71,831 & 92,995 \\
\hline 1,800 & 43,704 & 3,143 & 1,570 & 49,959 & 76,366 & 87,222 & 114,216 \\
\hline 2,360 & 62,649 & 2,889 & 1,700 & 58,836 & 77,022 & 72,034 & 93,524 \\
\hline 2,810 & 67,047 & 3,260 & 2,530 & 77,607 & 77,723 & 90,036 & 115,842 \\
\hline 2,690 & 69,312 & 3,116 & 1,500 & 48,145 & 80,108 & 55,762 & 69,609 \\
\hline 2,020 & 49,045 & 3,201 & 1,520 & 47,485 & 77,701 & 75,248 & 96,842 \\
\hline 2,860 & 75,508 & 2,915 & 2,130 & 73,080 & 77,219 & 74,476 & 96,447 \\
\hline 2,300 & 59,902 & 3,065 & 1,090 & 35,560 & 79,714 & 47,391 & 59,452 \\
\hline 2,430 & 57,133 & 3,336 & 0,940 & 28,181 & 78,314 & 38,683 & 49,395 \\
\hline 3,270 & 78,797 & 3,326 & 1,490 & 44,793 & 79,999 & 45,566 & 56,958 \\
\hline 2,870 & 65,877 & 3,403 & 2,140 & 62,882 & 77,964 & 74,564 & 95,640 \\
\hline 2,870 & 66,035 & 3,361 & 2,540 & 75,564 & 77,198 & 88,502 & 114,643 \\
\hline 2,890 & 90,652 & 2,534 & 1,490 & 58,796 & 79,516 & 51,557 & 64,839 \\
\hline 2,820 & 59,244 & 3,749 & 2,300 & 61,356 & 78,468 & 81,560 & 103,941 \\
\hline 2,480 & 60,210 & 3,318 & 1,990 & 59,980 & 80,371 & 80,242 & 99,839 \\
\hline 2,530 & 60,069 & 3,285 & 0,650 & 19,786 & 77,920 & 25,692 & 32,972 \\
\hline 2,560 & 61,843 & 3,285 & 1,260 & 38,361 & 79,233 & 49,219 & 62,119 \\
\hline 2,990 & 61,611 & 3,774 & 1,300 & 34,443 & 77,352 & 43,478 & 56,208 \\
\hline 3,240 & 98,273 & 2,649 & 2,760 & 104,202 & 79,990 & 85,185 & 106,495 \\
\hline 2,390 & 99,260 & 1,934 & 1,620 & 83,760 & 80,194 & 67,782 & 84,523 \\
\hline 1,700 & 60,064 & 2,276 & 0,720 & 31,639 & 80,162 & 42,353 & 52,834 \\
\hline 2,960 & 105,518 & 2,265 & 2,310 & 102,005 & 80,460 & 78,041 & 96,993 \\
\hline 2,340 & 78,820 & 2,361 & 1,920 & 81,332 & 79,286 & 82,051 & 103,488 \\
\hline 2,210 & 69,563 & 2,536 & 1,820 & 71,764 & 79,498 & 82,353 & 103,591 \\
\hline 1,940 & 72,748 & 2,180 & 1,080 & 49,550 & 81,336 & 55,670 & 68,445 \\
\hline
\end{tabular}




\begin{tabular}{|c|c|c|c|c|c|c|c|}
\hline F25_75_prev & F25_75_obs & F25_75_\% & PFE_prev & PFE_obs & PFE_\% & FEF50_FIF50_obs & CVL_prev \\
\hline 2,833 & 0,940 & 33,179 & 10,160 & 4,250 & 41,829 & 32,00 & 3,860 \\
\hline 2,377 & 0,410 & 17,247 & 6,966 & 3,410 & 48,955 & 11,00 & 3,114 \\
\hline 2,749 & 2,960 & 107,670 & 10,622 & 6,400 & 60,253 & 92,00 & 4,315 \\
\hline 2,988 & 1,350 & 45,178 & 10,355 & 7,170 & 69,243 & 49,00 & 4,067 \\
\hline 2,804 & 1,170 & 41,720 & 9,780 & 4,690 & 47,953 & 38,00 & 3,478 \\
\hline 2,833 & 1,650 & 58,239 & 10,675 & 7,410 & 69,414 & 73,00 & 4,377 \\
\hline 2,598 & 1,890 & 72,745 & 10,371 & 6,520 & 62,867 & 155,00 & 4,036 \\
\hline 2,776 & 0,920 & 33,136 & 10,945 & 7,210 & 65,876 & 16,00 & 4,646 \\
\hline 2,863 & 0,860 & 30,043 & 10,693 & 4,200 & 39,277 & 34,00 & 4,398 \\
\hline 2,368 & 1,050 & 44,346 & 10,063 & 3,700 & 36,769 & 37,00 & 3,653 \\
\hline 2,110 & 1,590 & 75,340 & 6,950 & 4,590 & 66,039 & 43,00 & 2,981 \\
\hline 2,956 & 2,530 & 85,603 & 10,956 & 6,080 & 55,494 & 119,00 & 4,667 \\
\hline 2,988 & 3,480 & 116,459 & 10,511 & 8,050 & 76,587 & 102,00 & 4,222 \\
\hline 1,735 & 1,960 & 112,937 & 6,012 & 4,140 & 68,867 & 62,00 & 2,142 \\
\hline 2,804 & 1,280 & 45,642 & 10,298 & 8,920 & 86,619 & 19,00 & 3,995 \\
\hline 2,988 & 4,310 & 144,235 & 10,563 & 8,110 & 76,779 & 88,00 & 4,274 \\
\hline 3,286 & 2,680 & 81,566 & 10,519 & 6,880 & 65,404 & 82,00 & 4,233 \\
\hline 3,056 & 1,040 & 34,028 & 10,132 & 4,960 & 48,956 & 27,00 & 3,850 \\
\hline 3,615 & 1,550 & 42,883 & 11,593 & 4,090 & 35,279 & 75,00 & 5,257 \\
\hline 2,804 & 1,990 & 70,959 & 10,349 & 7,200 & 69,569 & 51,00 & 4,046 \\
\hline 2,696 & 2,110 & 78,251 & 10,282 & 6,880 & 66,912 & 59,00 & 3,964 \\
\hline 2,091 & 2,390 & 114,319 & 6,099 & 5,170 & 84,772 & 98,00 & 2,465 \\
\hline 3,128 & 1,630 & 52,105 & 9,853 & 6,540 & 66,374 & 45,00 & 3,581 \\
\hline 3,905 & 1,800 & 46,096 & 10,988 & 7,020 & 63,887 & 57,00 & 4,636 \\
\hline 2,646 & 2,060 & 77,848 & 10,148 & 7,380 & 72,723 & 52,00 & 3,819 \\
\hline 3,417 & $\frac{1,750}{1,750}$ & 51,210 & 11,065 & 5,960 & 53,863 & 40,00 & 4,760 \\
\hline 2,893 & 0,950 & 32,841 & 10,040 & 5,370 & 53,489 & 28,00 & 3,747 \\
\hline 3,970 & 3,100 & 78,084 & 10,964 & 9,280 & 84,642 & 56,00 & 4,605 \\
\hline 2,804 & 2,140 & 76,307 & 10,503 & 6,700 & 63,789 & 78,00 & 4,201 \\
\hline 3,128 & 3,150 & 100,694 & 10,800 & 7,800 & 72,222 & 77,00 & 4,512 \\
\hline 2,446 & 1,600 & 65,425 & 10,117 & 7,010 & 69,290 & 61,00 & 3,736 \\
\hline 2,924 & 2,220 & 75,931 & 10,834 & 7,870 & 72,643 & 48,00 & 4,543 \\
\hline 1,982 & 0,910 & 45,919 & 6,754 & 3,260 & 48,271 & 36,00 & 2,779 \\
\hline 3,128 & 1,440 & 46,032 & 10,171 & 5,530 & 54,371 & 58,00 & 3,891 \\
\hline 2,622 & 1,140 & 43,480 & 10,133 & 7,210 & 71,157 & 27,00 & 3,798 \\
\hline 2,988 & 2,100 & 70,277 & 9,831 & 7,080 & 72,015 & 50,00 & 3,550 \\
\hline 2,863 & 2,570 & 89,780 & 10,281 & 7,270 & 70,711 & 77,00 & 3,984 \\
\hline 2,893 & 2,630 & 90,917 & 10,661 & 7,970 & 74,761 & 100,00 & 4,367 \\
\hline 2,722 & 0,570 & 20,937 & 11,413 & 5,250 & 46,002 & 15,00 & 5,122 \\
\hline 2,956 & 3,070 & 103,874 & 10,544 & 8,190 & 77,678 & 114,00 & 4,253 \\
\hline 3,782 & 2,150 & 56,847 & 11,038 & 5,560 & 50,372 & 56,00 & 4,698 \\
\hline 2,988 & 1,450 & 48,524 & 9,831 & 8,740 & 88,900 & 28,00 & 3,550 \\
\hline 2,776 & 2,270 & & 10,383 & 7,420 & 71,460 & 76,00 & 4,077 \\
\hline 3,905 & 1,790 & 45,840 & 11,205 & 5,240 & 46,766 & 61,00 & 4,843 \\
\hline 2,552 & 1,390 & 54,463 & 9,680 & 4,330 & 44,733 & 202,00 & 3,322 \\
\hline 2,924 & 1,350 & 46,174 & 10,782 & 7,210 & 66,868 & 39,00 & 4,491 \\
\hline 2,106 & 0,550 & 26,120 & 6,473 & 3,820 & 59,017 & 29,00 & 2,698 \\
\hline 2,956 & 0,880 & 29,775 & 11,161 & 5,200 & 46,590 & 20,00 & 4,874 \\
\hline 2,988 & 2,100 & 70,277 & 11,079 & 4,930 & 44,499 & 83,00 & 4,791 \\
\hline
\end{tabular}




\begin{tabular}{|c|c|c|c|c|c|c|c|}
\hline 3,286 & 0,970 & 29,522 & 10,572 & 3,350 & 31,687 & 38,00 & 4,284 \\
\hline 3,022 & 0,390 & 12,906 & 10,686 & 2,930 & 27,418 & 12,00 & 4,398 \\
\hline 2,671 & 4,470 & 167,352 & 10,113 & 8,460 & 83,657 & 176,00 & 3,788 \\
\hline 2,924 & 0,230 & 7,867 & 10,317 & 2,190 & 21,226 & 14,00 & 4,026 \\
\hline 3,166 & 0,490 & 15,478 & 10,665 & 2,260 & 21,192 & 36,00 & 4,377 \\
\hline 2,924 & 4,690 & 160,412 & 10,679 & 9,700 & 90,828 & 94,00 & 4,388 \\
\hline 3,092 & 0,370 & 11,967 & 10,779 & 3,580 & 33,213 & 12,00 & 4,491 \\
\hline 3,245 & 2,430 & 74,895 & 10,708 & 7,960 & 74,337 & 74,00 & 4,419 \\
\hline 3,245 & 2,350 & 72,430 & 10,073 & 6,370 & 63,238 & 70,00 & 3,798 \\
\hline 2,956 & 0,490 & 16,579 & 11,110 & 3,700 & 33,303 & 8,00 & 4,822 \\
\hline 3,245 & 0,410 & 12,637 & 10,866 & 2,700 & 24,849 & 7,00 & 4,574 \\
\hline 3,092 & 0,190 & 6,145 & 10,256 & 1,630 & 15,893 & 6,00 & 3,974 \\
\hline 3,022 & 0,560 & 18,532 & 10,322 & 3,950 & 38,268 & 23,00 & 4,036 \\
\hline 3,166 & 0,120 & 3,790 & 10,560 & 1,640 & 15,531 & 8,00 & 4,274 \\
\hline 2,863 & 0,450 & 15,720 & 10,022 & 3,180 & 31,730 & 20,00 & 3,726 \\
\hline 2,804 & 1,520 & 54,200 & 11,014 & 7,260 & 65,917 & 53,00 & 4,718 \\
\hline 2,863 & 0,200 & 6,987 & 9,918 & 2,410 & 24,299 & 10,00 & 3,622 \\
\hline 2,833 & 2,650 & 93,536 & 10,624 & 7,400 & 69,655 & 95,00 & 4,326 \\
\hline 2,646 & 0,930 & 35,145 & 10,555 & 3,660 & 34,676 & 75,00 & 4,232 \\
\hline 2,833 & 0,300 & 10,589 & 10,521 & 3,180 & 30,225 & 12,00 & 4,222 \\
\hline 3,205 & 2,230 & 69,587 & 11,000 & 6,090 & 55,363 & 57,00 & 4,708 \\
\hline 3,022 & 1,910 & 63,208 & 10,634 & 7,530 & 70,808 & 49,00 & 4,346 \\
\hline 2,646 & 2,620 & 99,011 & 10,605 & 7,240 & 68,267 & 117,00 & 4,284 \\
\hline 2,893 & 2,170 & 75,015 & 10,661 & 8,820 & 82,734 & 96,00 & 4,367 \\
\hline 2,749 & 2,720 & 98,940 & 10,571 & 7,480 & 70,760 & 275,00 & 4,263 \\
\hline 2,924 & 0,970 & 33,177 & 10,782 & 6,610 & 61,303 & 43,00 & 4,491 \\
\hline 2,696 & 1,570 & 58,225 & 10,435 & 3,990 & 38,236 & 55,00 & 4,119 \\
\hline 2,646 & 1,080 & 40,814 & 10,097 & 5,900 & 58,433 & 75,00 & 3,767 \\
\hline 2,863 & 3,910 & 136,591 & 10,488 & 6,400 & 61,023 & 113,00 & 4,191 \\
\hline 3,022 & 0,770 & 25,482 & 10,165 & 3,190 & 31,382 & 25,00 & 3,881 \\
\hline 2,833 & 1,070 & 37,767 & 10,418 & 3,990 & 38,298 & 79,00 & 4,119 \\
\hline 2,671 & 1,510 & 56,533 & 10,113 & 9,010 & 89,096 & 35,00 & 3,788 \\
\hline 2,956 & 0,400 & 13,534 & 10,128 & 2,550 & 25,179 & 13,00 & 3,840 \\
\hline 2,956 & 0,270 & 9,135 & 10,544 & 2,580 & 24,470 & 8,00 & 4,253 \\
\hline 3,128 & 0,590 & 18,860 & 10,434 & 3,140 & 30,094 & 15,00 & 4,150 \\
\hline 2,956 & 1,580 & 53,459 & 10,647 & 5,620 & 52,785 & 61,00 & 4,357 \\
\hline 2,863 & 4,710 & 164,538 & 10,642 & 10,710 & 100,638 & 105,00 & 4,346 \\
\hline 2,696 & 0,550 & 20,397 & 9,510 & 3,850 & 40,486 & 30,00 & 3,188 \\
\hline 3,205 & 2,430 & 75,828 & 11,052 & 7,850 & 71,027 & 54,00 & 4,760 \\
\hline 3,166 & 1,890 & 59,699 & 10,402 & 7,450 & 71,621 & 102,00 & 4,119 \\
\hline 2,893 & 0,190 & 6,568 & 10,506 & 2,180 & 20,750 & 5,00 & 4,212 \\
\hline 3,022 & 0,440 & 14,561 & 10,426 & 3,170 & 30,404 & 17,00 & 4,140 \\
\hline 3,092 & 0,390 & 12,614 & 11,142 & 3,900 & 35,003 & 9,00 & 4,853 \\
\hline 2,399 & 3,370 & 140,446 & 7,252 & 7,950 & 109,624 & 106,00 & 3,297 \\
\hline 1,940 & 0,970 & 49,991 & 6,156 & 4,230 & 68,715 & 33,00 & 2,408 \\
\hline 2,147 & 0,240 & 11,178 & 6,658 & 2,010 & 30,191 & 10,00 & 2,830 \\
\hline 2,154 & 2,060 & 95,628 & 6,609 & 6,960 & 105,303 & 47,00 & 2,805 \\
\hline 2,161 & 1,900 & 87,919 & 6,879 & 6,190 & 89,983 & 71,00 & 2,969 \\
\hline 2,288 & 1,990 & 86,962 & 7,125 & 5,660 & 79,437 & 91,00 & 3,177 \\
\hline 2,141 & 0,540 & 25,227 & 6,390 & 2,260 & 35,366 & 24,00 & 2,667 \\
\hline
\end{tabular}




\begin{tabular}{|c|c|c|c|c|c|c|c|c|}
\hline CVL_obs & CVL_\% & VR_prev & VR_obs & VR_\% & CPT_prev & CPT_obs & CPT_\% & TGV_obs \\
\hline 2,800 & 72,535 & 2,076 & 2,660 & 128,143 & 5,929 & 5,460 & 92,088 & 3,490 \\
\hline 2,270 & 72,887 & 1,425 & 3,420 & 240,084 & 4,559 & 5,690 & 124,808 & 3,860 \\
\hline 3,980 & 92,234 & 2,315 & 3,070 & 132,608 & 6,618 & 7,050 & 106,532 & 5,220 \\
\hline 3,720 & 91,466 & 2,045 & 1,800 & 88,032 & 6,105 & 5,520 & 90,419 & 2,870 \\
\hline 2,950 & 84,829 & 1,952 & 2,620 & 134,221 & 5,426 & 5,570 & 102,654 & 3,540 \\
\hline 3,580 & 81,787 & 2,273 & 2,000 & 87,997 & 6,638 & 5,580 & 84,060 & 2,970 \\
\hline 3,870 & 95,892 & 2,341 & 2,040 & 87,157 & 6,364 & 5,910 & 92,863 & 2,920 \\
\hline 3,570 & 76,840 & 2,419 & 2,560 & 105,820 & 7,050 & 6,120 & 86,810 & 3,170 \\
\hline 3,450 & 78,447 & 2,259 & 3,820 & 169,124 & 6,645 & 7,260 & 109,257 & 4,920 \\
\hline 2,160 & 59,129 & 2,437 & 3,370 & 138,307 & 6,077 & 5,530 & 91,003 & 3,670 \\
\hline 2,680 & 89,899 & 1,630 & 2,420 & 148,503 & 4,631 & 5,100 & 110,118 & 3,000 \\
\hline 4,240 & 90,855 & 2,295 & 2,520 & 109,794 & 6,949 & 6,760 & 97,282 & 3,100 \\
\hline 3,540 & 83,843 & 2,104 & 1,970 & 93,640 & 6,318 & 5,510 & 87,217 & 2,910 \\
\hline 2,260 & 105,498 & 1,420 & 2,270 & 159,825 & 3,584 & 4,530 & 126,403 & 2,310 \\
\hline 3,930 & 98,383 & 2,149 & 3,120 & $\begin{array}{l}145,184 \\
\end{array}$ & 6,135 & 7,060 & 115,077 & 3,700 \\
\hline 4,060 & 94,995 & 2,124 & 2,130 & 100,306 & 6,389 & 6,190 & 93 & 3,280 \\
\hline 4,260 & 100,645 & 932 & 1,810 & 93,690 & 6,159 & 6,070 & 550 & 2,550 \\
\hline 3,340 & 86,753 & 918 & 2,350 & 122,523 & 5,764 & 5,690 & 716 & 3,200 \\
\hline 4,060 & 77,238 & 168 & 1,880 & 86,712 & 7,412 & 5,940 & 38 & 3,600 \\
\hline 3,400 & 84,027 & 2,169 & 2,420 & 111,588 & 6,206 & 5,820 & 93,782 & 2,900 \\
\hline 3,290 & 83,007 & 2,225 & 2,280 & 102,467 & 6,179 & 5,580 & 90,310 & 3,450 \\
\hline 1,860 & 75,450 & 1,124 & 1,510 & 134,318 & 3,610 & 3,370 & 93,360 & 1,680 \\
\hline 4,060 & 113,370 & 1,772 & 2,330 & 131,520 & 5,352 & 6,390 & 119,390 & 3,520 \\
\hline 3,830 & & 1,822 & 3,1 & & 6,454 & 7,010 & 622 & 4,140 \\
\hline 3,370 & 0 & 2,214 & 2,360 & 10 & 6,023 & 5,740 & 297 & 3,530 \\
\hline 4,210 & 88,444 & 2,067 & 3,590 & 173,690 & 6,818 & 7,790 & 114,260 & 4,350 \\
\hline 2,810 & 03 & 1,989 & 2,370 & 119 & 5,730 & 5,180 & 401 & 2,680 \\
\hline 4,550 & 98,801 & 1,788 & 1,570 & 87,808 & 6,390 & 6,120 & 5,782 & 2,880 \\
\hline 3,790 & 90,208 & 2,228 & 3,140 & 140,946 & 6,419 & 6,930 & 107,967 & 4,120 \\
\hline 3,980 & 88,213 & 2,126 & 3,410 & 160,380 & 6,628 & 7,390 & 111,490 & 3,900 \\
\hline 3,610 & 96,633 & 2,380 & 2,640 & 110,915 & 6,104 & 6,250 & 102,394 & 3,400 \\
\hline 3,680 & & 2,270 & 2,870 & & 6,800 & 6,550 & 319 & 4,400 \\
\hline 2,210 & 22 & 1,632 & 2,670 & 16 & 4,432 & 4,880 & 098 & 3,460 \\
\hline 3,800 & 51 & 1,890 & 2,300 & 12 & 5,778 & 6,100 & 580 & 3,710 \\
\hline 3,960 & 104,265 & 2,228 & 2,630 & 118,043 & 6,017 & 6,590 & 109,532 & 4,030 \\
\hline 3,660 & 103,096 & 1,848 & 2,000 & 108,243 & 5,396 & 5,660 & 104,894 & 2,640 \\
\hline 2,930 & 73,539 & 2,101 & 1,820 & 86,621 & 6,078 & 4,750 & 78,155 & 2,420 \\
\hline 4,960 & 113,582 & 2,225 & 2,500 & 112,365 & 6,581 & 7,460 & 113,360 & 3,930 \\
\hline 3,690 & 72,048 & 2,644 & 2,810 & 106,262 & 7,745 & 6,490 & 83,793 & 4,470 \\
\hline 4,390 & 103,216 & 2,138 & 1,910 & & & 6,300 & 98,720 & 3,220 \\
\hline 3,480 & & & & & & 5,200 & & 2,890 \\
\hline 3,710 & & & $\overline{1,4}$ & & 5,396 & 5,170 & & 2,650 \\
\hline 4,120 & & 2,203 & 2,220 & 95 & 6,270 & 6,340 & 101,116 & 2,830 \\
\hline 3,630 & 74,954 & 1,901 & 2,240 & 117,858 & 6,737 & 5,870 & 87,128 & 3,750 \\
\hline 2,120 & 63,811 & 2,113 & 2,360 & 111,705 & 5,429 & 4,490 & 82,706 & 2,470 \\
\hline 5,160 & 114,896 & 2,250 & 1,640 & 72,882 & 6,729 & 6,800 & 101,049 & 3,160 \\
\hline 2,650 & 98,220 & 1,342 & 1,710 & 127,431 & 4,060 & 4,360 & 107,379 & 2,780 \\
\hline 4,140 & 84,947 & 2,374 & 4,010 & 168,913 & 7,233 & 8,150 & 112,686 & 5,790 \\
\hline 4,440 & 92,676 & 2,321 & 2,050 & 88,343 & 7,098 & 6,490 & 91,441 & 4,250 \\
\hline 2,420 & 76,660 & 2,116 & 1,350 & 63,812 & 5,267 & 3,770 & 71,582 & 2,590 \\
\hline
\end{tabular}




\begin{tabular}{|c|c|c|c|c|c|c|c|c|}
\hline 2,650 & 61,852 & 1,952 & 2,730 & 139,885 & 6,230 & 5,390 & 86,514 & 3,300 \\
\hline 2,900 & 65,939 & 2,149 & 4,930 & 229,430 & 6,537 & 7,830 & 119,778 & 5,900 \\
\hline 3,360 & 88,708 & 2,180 & 1,970 & 90,363 & 5,959 & 5,330 & 89,442 & 2,900 \\
\hline 2,560 & 63,591 & 2,073 & 3,690 & 178,011 & 6,091 & 6,250 & 102,605 & 4,940 \\
\hline 2,380 & 54,370 & 2,053 & 2,990 & 145,641 & 6,423 & 5,370 & 83,612 & 3,640 \\
\hline 2,180 & 49,685 & 2,211 & 1,670 & 75,538 & 6,588 & 3,850 & 58,443 & 2,500 \\
\hline 3,300 & 73,479 & 2,140 & 3,830 & 178,947 & 6,622 & 7,130 & 107,678 & 5,730 \\
\hline 2,430 & 54,992 & 2,025 & 2,000 & 98,775 & 6,436 & 4,420 & $\begin{array}{l}68,675 \\
\end{array}$ & 2,450 \\
\hline 2,470 & 65,027 & 1,788 & 1,430 & 79,960 & 5,585 & 3,890 & 69,647 & 2,250 \\
\hline 4,730 & 98,094 & 2,354 & 5,410 & 229,792 & 7,162 & 10,140 & 141,588 & 7,590 \\
\hline 3,900 & 85,266 & 2,084 & 4,140 & 198,666 & 6,649 & 8,040 & 120,924 & 5,520 \\
\hline 2,710 & 68,192 & 1,943 & 4,240 & 218,186 & 5,913 & 6,950 & 117,546 & 5,530 \\
\hline 2,820 & 69,869 & 2,011 & 4,360 & 216,818 & 6,041 & 7,180 & 118,858 & 5,030 \\
\hline 1,380 & 32,288 & 2,014 & 7,890 & 391,836 & 6,281 & 9,270 & 147,595 & 8,430 \\
\hline 1,890 & 50,727 & 2,003 & 1,860 & 92,879 & 5,723 & 3,750 & 65,523 & 2,510 \\
\hline 2,580 & 54,680 & 2,425 & 2,930 & 120,835 & 7,128 & 5,510 & 77,305 & 3,560 \\
\hline 2,250 & 62,114 & 1,963 & 6,070 & 309,189 & 5,581 & 8,320 & 149,067 & 6,980 \\
\hline 2,350 & 54,329 & 2,253 & 1,500 & 66,575 & 6,567 & 3,850 & 58,625 & 2,050 \\
\hline 2,590 & 61,196 & 2,372 & 4,380 & 184,693 & 6,591 & 6,980 & 105,910 & 5,510 \\
\hline 2,580 & 61,107 & 2,214 & 3,890 & 175,724 & 6,425 & 6,460 & 100,538 & 5,250 \\
\hline 2,230 & 47,363 & 2,157 & 1,690 & 78,346 & 6,855 & 3,920 & 57,187 & 2,240 \\
\hline 2,760 & 63,502 & 2,129 & 2,690 & 126,344 & 6,466 & 5,440 & 84,130 & 3,520 \\
\hline 3,180 & 74,230 & 2,391 & 2,110 & 88,240 & 6,661 & 5,300 & 79,563 & 3,290 \\
\hline 3,930 & 89,995 & 2,225 & 2,830 & 127,197 & 6,581 & 6,770 & 102,875 & 3,650 \\
\hline 3,130 & 73,416 & 2,295 & 2,480 & 108,042 & 6,547 & 5,610 & 85,691 & 3,700 \\
\hline 2,260 & 50,323 & 2,250 & 2,360 & 104,880 & 6,729 & 4,620 & 68,654 & 3,090 \\
\hline 1,770 & 42,976 & 2,284 & 3,770 & 165,047 & 6,391 & 5,540 & 86,679 & 4,610 \\
\hline 2,590 & 68,755 & 2,194 & 3,030 & 138,091 & 5,952 & 5,620 & 94,416 & 3,470 \\
\hline 2,550 & 60,843 & 2,180 & 1,620 & 74,315 & 6,361 & 4,170 & 65,553 & 2,620 \\
\hline 2,700 & 69,570 & 1,952 & 4,690 & 240,291 & 5,828 & 7,400 & 126,971 & 5,850 \\
\hline 2,130 & 51,715 & 2,174 & 2,760 & 126,937 & 6,284 & 4,890 & 77,822 & 3,180 \\
\hline 2,930 & 77,356 & 2,180 & 1,840 & 84,400 & 5,959 & 4,760 & 79,876 & 2,840 \\
\hline 2,410 & 62,767 & 1,980 & 4,060 & 205,051 & 5,815 & 6,480 & 111,446 & 4,440 \\
\hline 2,780 & 65,363 & 2,138 & 4,630 & 216,598 & 6,382 & 7,410 & 116,113 & 5,440 \\
\hline 3,570 & 86,026 & 1,988 & 4,770 & 239,903 & 6,132 & 8,340 & 136,006 & 5,830 \\
\hline 2,830 & 64,959 & 2,177 & 2,580 & 118,512 & 6,524 & 5,420 & 83,084 & 3,300 \\
\hline 2,920 & 67,185 & 2,239 & 1,460 & 65,208 & 6,574 & 4,380 & 666,626 & 2,520 \\
\hline 2,980 & 93,476 & 1,930 & 2,940 & 152,363 & 5,115 & 5,930 & 115,929 & 4,210 \\
\hline 3,000 & 63,025 & 2,177 & 1,480 & 67,990 & 6,926 & 4,480 & 64,688 & 2,730 \\
\hline 2,580 & 62 & 1,955 & 1,940 & 99,258 & 6,068 & 4,510 & 74,324 & 2,610 \\
\hline 2,950 & 70,041 & 2,166 & 5,220 & 241,019 & 6,368 & 8,180 & 128,453 & 6,560 \\
\hline 2,680 & 64,742 & 2,050 & 2,490 & 121,446 & 6,183 & 5,170 & 83,622 & 3,620 \\
\hline 3,050 & 62,848 & 2,278 & 4,420 & 194,013 & 7,118 & 7,470 & 104,947 & 5,650 \\
\hline 3,270 & 99,183 & 1,572 & 1,790 & 113,853 & 4,889 & 5,060 & 103,490 & 2,780 \\
\hline 2,490 & 103,413 & 1,293 & 1,590 & 122,979 & 3,721 & 4,070 & 109,368 & 2,070 \\
\hline 1,950 & 68,897 & 1,420 & 2,770 & 195,125 & 4,270 & 4,720 & 110,529 & 3,730 \\
\hline 2,950 & 105,162 & 1,385 & 1,870 & 135,057 & 4,210 & 4,820 & 114,484 & 2,620 \\
\hline 2,330 & 78,483 & 1,541 & 1,710 & 110,938 & 4,531 & 4,050 & 89,390 & 2,270 \\
\hline 2,170 & 68,304 & 1,583 & 1,660 & 104,884 & 4,780 & 3,830 & 80,125 & 2,200 \\
\hline 1,980 & 74,248 & 1,263 & 1,800 & 142,540 & 3,950 & 3,780 & 95,700 & 2,260 \\
\hline
\end{tabular}




\begin{tabular}{|c|c|c|c|c|c|c|c|c|}
\hline Cl_obs & VRE_obs & DLCO_prev & DLCO_obs & DLCO_\% & VA_obs & VA_CPT_obs & Kco & Raw_prev \\
\hline 1,970 & 0,830 & 26,450 & 14,150 & 53,497 & 3,900 & 0,714 & 3,63 & 2,50 \\
\hline 1,830 & 0,440 & 24,456 & 18,630 & 76,178 & 3,990 & 0,701 & 4,67 & 2,50 \\
\hline 2,170 & 1,810 & 29,920 & 14,080 & 47,059 & 5,960 & 0,845 & 2,36 & 2,50 \\
\hline 2,650 & 0,890 & 28,320 & 22,020 & 77,754 & 4,890 & 0,886 & 4,50 & 2,50 \\
\hline 2,020 & 0,920 & 23,370 & 14,760 & 63,158 & 4,620 & 0,829 & 3,19 & 2,50 \\
\hline 2,610 & 0,940 & 30,550 & 18,800 & 61,538 & 5,240 & 0,939 & 3,59 & 2,50 \\
\hline 2,990 & 0,720 & 27,430 & 28,680 & 104,557 & 5,620 & 0,951 & 5,10 & 2,50 \\
\hline 2,950 & 0,450 & 32,590 & 17,040 & 52,286 & 4,920 & 0,804 & 3,46 & 2,50 \\
\hline 2,340 & 1,100 & 30,760 & 12,960 & 42,133 & 5,730 & 0,789 & 2,26 & 2,50 \\
\hline 1,860 & 0,300 & 23,890 & 11,490 & 48,095 & 3,570 & 0,646 & 3,22 & 2,50 \\
\hline 2,100 & 0,570 & 23,208 & 13,780 & 59,376 & 4,130 & 0,810 & 3,34 & 2,50 \\
\hline 3,670 & 0,570 & 33,030 & 33,030 & 100,000 & 6,330 & 0,936 & 5,22 & 2,50 \\
\hline 2,600 & 0,940 & 29,550 & 22,650 & 76,650 & 4,890 & 0,887 & 4,64 & 2,50 \\
\hline 2,220 & 0,040 & 17,864 & 17,380 & 97,291 & 3,660 & 0,808 & 4,75 & 2,50 \\
\hline 3,350 & 0,580 & 27,470 & 34,300 & 124,863 & 6,020 & 0,853 & 5,69 & 2,50 \\
\hline 2,910 & 1,150 & 29,960 & 28,950 & 96,629 & 5,480 & 0,885 & 5,29 & 2,50 \\
\hline 3,520 & 0,740 & 30,000 & 24,590 & 81,967 & 5,280 & 0,870 & 4,66 & 2,50 \\
\hline 2,500 & 0,850 & 26,690 & 17,450 & 65,380 & 4,940 & 0,868 & 3,53 & 2,50 \\
\hline 2,340 & 1,720 & 38,440 & 32,670 & 84,990 & 5,750 & 0,968 & 5,68 & 2,50 \\
\hline 2,920 & 0,480 & 27,880 & 24,660 & 88,451 & 5,400 & 0,928 & 4,56 & 2,50 \\
\hline 2,130 & 1,160 & 27,040 & 22,410 & 82,877 & 4,710 & 0,844 & 4,76 & 2,50 \\
\hline 1,690 & 0,180 & 20,552 & & 50,214 & 2,640 & 0,783 & 3,91 & 2,50 \\
\hline 2,880 & & 50 & & 98,702 & 5,690 & 890 & 4,28 & 2,50 \\
\hline 2,880 & & & & & & 53 & 4,55 & 2,50 \\
\hline 2,200 & & & & & & & 3,89 & 2,50 \\
\hline 3,44 & & 34,320 & & & 5,860 & 0,752 & 5,35 & 2,50 \\
\hline 2,500 & 0,310 & 25,640 & 16 & 64,587 & 4,640 & 0,896 & 3,57 & 2,50 \\
\hline 3,240 & 1,290 & 33,550 & 25,140 & 74,933 & 5,760 & 0,941 & 4,37 & 2,50 \\
\hline 2,810 & 0,980 & 29,110 & 21,710 & 74,579 & 5,790 & 0,835 & 3,75 & 2,50 \\
\hline 3,500 & 0,490 & 32,030 & 28,530 & 89,073 & 6,230 & 0,843 & 4,58 & 2,50 \\
\hline 2,850 & 0,770 & 24,730 & 22,150 & 89,567 & 5,150 & 0,824 & 4,30 & 2,50 \\
\hline 2,150 & 1,530 & 32,000 & 30,630 & 95,719 & 6,600 & 1,008 & 4,64 & 2,50 \\
\hline 1,420 & 0,710 & 21,832 & 12,660 & 57,988 & 3,210 & 0,658 & 3,95 & 2,50 \\
\hline 2,390 & 1,410 & 27,110 & 12,820 & 47,289 & 5,780 & 0,948 & 2,22 & 2,50 \\
\hline 2,570 & 1,390 & 25,590 & 17,320 & 67,683 & 5,590 & 0,848 & 3,10 & 2,50 \\
\hline 3,020 & 40 & 24,220 & 20 & 83,278 & 4,920 & 0,869 & 4,10 & 2,50 \\
\hline 2,330 & 10 & 27,480 & & 78,930 & 4,090 & 0,861 & 5,30 & 2,50 \\
\hline 3,520 & 30 & 30 & 31 & 103,141 & 6,420 & 0,861 & 4,91 & 2,50 \\
\hline 2,020 & & 36 , & & & & 0,864 & 3,11 & 2,50 \\
\hline 3,090 & & & & & & 30 & 4,60 & 2,50 \\
\hline 2,310 & & 34,150 & & 71,157 & 3,770 & 0,725 & 6,44 & 2,50 \\
\hline 2,530 & 1,120 & 24,220 & 18,640 & 76,961 & 4,570 & 0,884 & 4,08 & 2,50 \\
\hline 3,510 & 0,510 & 28,080 & 19,160 & 68,234 & 5,970 & 0,942 & 3,21 & 2,50 \\
\hline 2,120 & 1,440 & 35,390 & 20,730 & 58,576 & 4,660 & 0,794 & 4,45 & 2,50 \\
\hline 2,020 & 0,100 & 21,680 & 18,480 & 85,240 & 3,470 & 0,773 & 5,32 & 2,50 \\
\hline 3,640 & 1,460 & 31,590 & 30,210 & 95,632 & 6,320 & 0,929 & 4,78 & 2,50 \\
\hline 1,580 & 0,980 & 21,768 & 12,210 & 56,092 & 3,500 & 0,803 & 3,49 & 2,50 \\
\hline 2,360 & 1,570 & 34,670 & 16,560 & 47,765 & 6,200 & 0,761 & 2,67 & 2,50 \\
\hline 2,240 & 1,990 & 34,060 & 24,280 & 71,286 & 5,950 & 0,917 & 4,08 & 2,50 \\
\hline 1,180 & 1,160 & 20,230 & 9,770 & 48,295 & 3,550 & 0,942 & 2,75 & 2,50 \\
\hline
\end{tabular}




\begin{tabular}{|c|c|c|c|c|c|c|c|c|}
\hline 2,090 & 0,480 & 30,410 & 22,220 & 73,068 & 4,540 & 0,842 & 4,90 & 2,50 \\
\hline 1,930 & 0,860 & 30,990 & 23,000 & 74,217 & 5,390 & 0,688 & 4,27 & 2,50 \\
\hline 2,430 & 0,910 & 25,600 & 10,280 & 40,156 & 3,930 & 0,737 & 2,61 & 2,50 \\
\hline 1,310 & 1,130 & 27,900 & 9,670 & 34,659 & 3,590 & 0,574 & 2,70 & 2,50 \\
\hline 1,730 & 0,540 & 31,010 & 20,020 & 64,560 & 3,440 & 0,641 & 5,82 & 2,50 \\
\hline 1,350 & 0,800 & 30,770 & 10,060 & 32,694 & 2,940 & 0,764 & 3,42 & 2,50 \\
\hline 1,400 & 1,860 & 31,820 & 19,140 & 60,151 & 4,560 & 0,640 & 4,20 & 2,50 \\
\hline 1,970 & 0,380 & 31,430 & 25,470 & 81,037 & 4,160 & 0,941 & 6,13 & 2,50 \\
\hline 1,650 & 0,770 & 26,510 & 15,960 & 60,204 & 3,290 & 0,846 & 4,85 & 2,50 \\
\hline 2,550 & 2,180 & 34,260 & 8,020 & 23,409 & 6,140 & 0,606 & 1,31 & 2,50 \\
\hline 2,520 & 1,220 & 32,660 & 11,420 & 34,966 & 4,600 & 0,572 & 2,48 & 2,50 \\
\hline 1,430 & 1,280 & 27,720 & 10,280 & 37,085 & 3,960 & 0,570 & 2,60 & 2,50 \\
\hline 2,150 & 0,490 & 28,120 & 15,030 & 53,450 & 4,300 & 0,599 & 3,49 & 2,50 \\
\hline 0,850 & 0,500 & 30,190 & ND & ND & ND & ND & ND & 2,50 \\
\hline 1,240 & 0,590 & 25,430 & 9,380 & 36,886 & 2,830 & 0,755 & 3,31 & 2,50 \\
\hline 1,950 & 0,540 & 33,210 & 18,810 & 56,640 & 4,380 & 0,795 & 4,30 & 2,50 \\
\hline 1,340 & 0,790 & 24,610 & 7,330 & 29,785 & 3,190 & 0,383 & 2,30 & 2,50 \\
\hline 1,790 & 0,510 & 30,140 & 7,380 & 24,486 & 2,880 & 0,748 & 2,56 & 2,50 \\
\hline 1,460 & 1,040 & 29,080 & 14,030 & 48,246 & 4,290 & 0,615 & 3,27 & 2,50 \\
\hline 1,210 & 1,340 & 29,320 & 13,100 & 44,679 & 4,180 & 0,647 & 3,13 & 2,50 \\
\hline 1,680 & 0,490 & 33,680 & 5,480 & 16,271 & 3,020 & 0,770 & $\begin{array}{l}1,82 \\
\end{array}$ & 2,50 \\
\hline 1,920 & 0,810 & 30,580 & 17,310 & 56,606 & 4,050 & 0,744 & 4,27 & 2,50 \\
\hline 2,010 & 1,060 & 29,490 & 13,760 & 46,660 & 4,260 & 0,804 & 3,23 & 2,50 \\
\hline 3,120 & 0,800 & 30,560 & 20,810 & 68,096 & 6,050 & 0,894 & 3,44 & 2,50 \\
\hline 1,900 & 1,130 & 29,510 & 8,020 & 27,177 & 4,040 & 0,720 & 1,99 & 2,50 \\
\hline 1,530 & 0,670 & 31,590 & 14,200 & 44,951 & 3,700 & 0,801 & 3,83 & 2,50 \\
\hline 0,940 & 0,830 & 28,270 & ND & ND & ND & ND & ND & 2,50 \\
\hline 2,150 & 0,400 & 25,390 & 11,030 & 43,442 & 3,960 & 0,705 & 2,79 & 2,50 \\
\hline 1,550 & 0,910 & 29,120 & 8,240 & 28,297 & 3,510 & 0,842 & 2,35 & 2,50 \\
\hline 1,550 & 1,060 & 26,890 & 21,210 & 78,877 & 4,310 & 0,582 & 4,92 & 2,50 \\
\hline 1,720 & 0,330 & 28,500 & 14,280 & 50,105 & 3,280 & 0,671 & 4,36 & 2,50 \\
\hline 1,930 & 0,990 & 25,600 & 5,190 & 20,273 & 3,620 & 0,761 & 1,43 & 2,50 \\
\hline 2,040 & 0,370 & 26,470 & 19,890 & 75,142 & 4,430 & 0,684 & 4,49 & 2,50 \\
\hline 1,970 & 0,650 & 29,750 & 8,850 & 29,748 & 4,170 & 0,563 & 2,12 & 2,50 \\
\hline 2,500 & 0,840 & 29,160 & 17,500 & 60,014 & 5,140 & 0,616 & 3,40 & 2,50 \\
\hline 2,120 & 0,660 & 30,570 & 17,980 & 58,816 & 4,110 & 0,758 & 4,37 & 2,50 \\
\hline 1.860 & 1.040 & 30,350 & 9.730 & 32.059 & 4.040 & 0.922 & 2.40 & 2.50 \\
\hline 1,710 & 1,270 & 20,890 & 10,790 & 51,652 & 4,320 & 0,728 & 2,50 & 2,50 \\
\hline 1,740 & 1,130 & 34,090 & 25,460 & 74,685 & 4,390 & 0,980 & 5,80 & 2,50 \\
\hline 1,910 & 0,570 & 28,960 & 16,490 & 56,941 & 4,030 & 0,894 & 4,09 & 2,50 \\
\hline 1,620 & 1,320 & 29,330 & 9,900 & 33,754 & 4,710 & 0,576 & 2,10 & 2,50 \\
\hline 1,550 & 1,110 & 28,940 & 5,950 & 20,560 & 3,650 & 0,706 & 1,63 & 2,50 \\
\hline 1,820 & 1,210 & 34,690 & 8,930 & 25,742 & 4,640 & 0,621 & 1,92 & 2,50 \\
\hline 2,280 & 0,950 & 25,448 & 23,440 & 92,109 & 4,270 & 0,844 & 5,48 & 2,50 \\
\hline 2,000 & 0,450 & 19,880 & 10,370 & 52,163 & 3,610 & 0,887 & 2,87 & 2,50 \\
\hline 0,980 & 0,880 & 22,536 & 6,800 & 30,174 & 2,750 & 0,583 & 2,47 & 2,50 \\
\hline 2,200 & 0,690 & 22,424 & 15,460 & 68,944 & 4,190 & 0,869 & 3,69 & 2,50 \\
\hline 1,780 & 0,490 & 23,272 & 17,440 & 74,940 & 3,650 & 0,901 & 4,77 & 2,50 \\
\hline 1,630 & 0,500 & 24,616 & 9,200 & 37,374 & 2,900 & 0,757 & 3,17 & 2,50 \\
\hline 1,530 & 0,400 & 21,688 & 11,090 & 51,134 & 2,810 & 0,743 & 3,94 & 2,50 \\
\hline
\end{tabular}




\begin{tabular}{|c|c|c|c|c|c|c|c|c|c|}
\hline Raw_obs & Raw_\% & sRaw_obs & sGaw_prev & sGaw_obs & sGaw_\% & LFE & Obst & Aprisio & Restrição \\
\hline 1,70 & 68,00 & 6,42 & 0,20 & 0,16 & 80,00 & 1 & 0 & 1 & 0 \\
\hline 2,51 & 100,40 & 9,45 & 0,20 & 0,11 & 55,00 & 0 & 0 & 0 & 0 \\
\hline 0,46 & 18,40 & 2,74 & 0,20 & 0,37 & 185,00 & 0 & 0 & 0 & 0 \\
\hline 1,72 & 68,80 & 4,99 & 0,20 & 0,21 & 105,00 & 0 & 0 & 0 & 0 \\
\hline 1,50 & 60,00 & 5,95 & 0,20 & 0,17 & 85,00 & 1 & 0 & 1 & 0 \\
\hline 0,55 & 22,00 & 2,05 & 0,20 & 0,49 & 245,00 & 1 & 0 & 0 & 0 \\
\hline 0,95 & 38,00 & 3,01 & 0,20 & 0,33 & 165,00 & 1 & 0 & 0 & 0 \\
\hline 1,26 & 50,40 & 4,17 & 0,20 & 0,24 & 120,00 & 0 & 1 & 0 & 0 \\
\hline 1,23 & 49,20 & 6,52 & 0,20 & 0,15 & 75,00 & 1 & 0 & 0 & 0 \\
\hline 2,68 & 107,20 & 10,11 & 0,20 & 0,10 & 50,00 & 1 & 0 & 0 & 0 \\
\hline 1,55 & 62,00 & 5,52 & 0,20 & 0,18 & 90,00 & 0 & 0 & 0 & 0 \\
\hline 1,67 & 66,80 & 5,51 & 0,20 & 0,18 & 90,00 & 0 & 0 & 0 & 0 \\
\hline 0,82 & 32,80 & 2,39 & 0,20 & 0,42 & 210,00 & 1 & 0 & 0 & 0 \\
\hline 1,32 & 52,80 & 3,18 & 0,20 & 0,31 & 155,00 & 1 & 0 & 1 & 0 \\
\hline 1,15 & 46,00 & 4,58 & 0,20 & 0,22 & 110,00 & 1 & 0 & 1 & 0 \\
\hline 0,52 & 20,80 & 1,94 & 0,20 & 0,51 & 255,00 & 0 & 0 & 0 & 0 \\
\hline 1,58 & 63,20 & 4,53 & 0,20 & 0,22 & 110,00 & 0 & 0 & 0 & 0 \\
\hline 1,38 & 55,20 & 5,16 & 0,20 & 0,19 & 95,00 & 1 & 0 & 1 & 0 \\
\hline 1,25 & 50,00 & 7,25 & 0,20 & 0,14 & 70,00 & 0 & 0 & 0 & 0 \\
\hline 1,51 & 60,40 & 4,64 & 0,20 & 0,22 & 110,00 & 0 & 0 & 0 & 0 \\
\hline 1,55 & 62,00 & 5,18 & 0,20 & 0,19 & 95,00 & 1 & 0 & 0 & 0 \\
\hline 1,01 & 40,40 & 1,81 & 0,20 & 0,55 & 275,00 & 1 & 1 & 0 & 0 \\
\hline 1,07 & 42,80 & 5,38 & 0,20 & 0,19 & 95,00 & 0 & 0 & 0 & 0 \\
\hline 1,37 & 54,80 & 7,71 & 0,20 & 0,13 & 65,00 & 0 & 0 & 0 & 0 \\
\hline 0,80 & 32,00 & 3,83 & 0,20 & 0,26 & 130,00 & 7 & 0 & 1 & 0 \\
\hline 0,90 & 36,00 & 5,01 & 0,20 & 0,20 & 100,00 & 7 & 0 & 1 & 0 \\
\hline 1,41 & 56,40 & 4,94 & 0,20 & 0,21 & 105,00 & 0 & 0 & 0 & 0 \\
\hline 1,11 & 44,40 & 3,59 & 0,20 & 0,28 & 140,00 & 7 & 0 & 1 & 0 \\
\hline 1,46 & 58,40 & 6,39 & 0,20 & 0,16 & 80,00 & 7 & 0 & 0 & 0 \\
\hline 1,44 & 57,60 & 5,72 & 0,20 & 0,18 & 90,00 & 0 & 0 & 0 & 0 \\
\hline 1,37 & 54,80 & 7,51 & 0,20 & 0,14 & 70,00 & 0 & 1 & 1 & 0 \\
\hline 1,08 & 43,20 & 5,50 & 0,20 & 0,18 & 90,00 & 0 & 0 & $\overline{1}$ & $\overline{0}$ \\
\hline 2,08 & 83,20 & 9,45 & 0,20 & 0,11 & 55,00 & 0 & 0 & 0 & $\overline{0}$ \\
\hline 1,02 & 40,80 & 4,07 & 0,20 & 0,25 & 125,00 & 0 & 0 & 0 & $\overline{0}$ \\
\hline 1,09 & 43,60 & 5,57 & 0,20 & 0,18 & 90,00 & 1 & 0 & 0 & 0 \\
\hline 0,96 & 38,40 & 3,02 & 0,20 & 0,33 & 165,00 & 1 & 0 & 0 & 0 \\
\hline 0,95 & 38,00 & 2,80 & 0,20 & 0,36 & 180,00 & 0 & 0 & 0 & 0 \\
\hline 1,09 & 43,60 & 5,14 & 0,20 & 0,20 & 100,00 & 0 & 0 & 0 & 0 \\
\hline 1,79 & 71,60 & 8,51 & 0,20 & 0,12 & 60,00 & 0 & 0 & 0 & 0 \\
\hline 0,90 & 36,00 & 3,48 & 0,20 & 0,29 & 145,00 & 1 & 0 & 0 & 0 \\
\hline 1,42 & 56,80 & 5,92 & 0,20 & 0,18 & 90,00 & 0 & 1 & 0 & 0 \\
\hline 0,93 & 37,20 & 2,93 & 0,20 & 0,34 & 170,00 & 0 & 0 & 0 & 1 \\
\hline 1,49 & 59,60 & 6,95 & 0,20 & 0,15 & 75,00 & 0 & 0 & 0 & 0 \\
\hline 1,33 & 53,20 & 5,62 & 0,20 & 0,18 & 90,00 & 0 & 0 & 0 & 0 \\
\hline 1,31 & 52,40 & 6,85 & 0,20 & 0,15 & 75,00 & 1 & 0 & 0 & 0 \\
\hline 1,91 & 76,40 & 8,37 & 0,20 & 0,12 & 60,00 & 0 & 0 & 0 & 1 \\
\hline 1,92 & 76,80 & 6,83 & 0,20 & 0,15 & 75,00 & 1 & 0 & 0 & 0 \\
\hline 1,13 & 45,20 & 11,54 & 0,20 & 0,09 & 45,00 & 1 & 0 & 1 & 0 \\
\hline 2,06 & 82,40 & 11,94 & 0,20 & 0,08 & 40,00 & 1 & 1 & 0 & 0 \\
\hline 1,36 & 54,40 & 4,55 & 0,20 & 0,22 & 110,00 & 1 & 0 & 0 & 1 \\
\hline
\end{tabular}




\begin{tabular}{|c|c|c|c|c|c|c|c|c|c|}
\hline 2,18 & 87,20 & 7,72 & 0,20 & 0,13 & 65,00 & 1 & 0 & 1 & 0 \\
\hline 2,90 & 116,00 & 19,45 & 0,20 & 0,05 & 25,00 & 1 & 0 & 1 & 0 \\
\hline 0,68 & 27,20 & 2,29 & 0,20 & 0,44 & 220,00 & 0 & 0 & 0 & 0 \\
\hline 5,50 & 220,00 & 28,98 & 0,20 & 0,03 & 15,00 & 1 & 0 & 1 & 0 \\
\hline 6,00 & 240,00 & 22,59 & 0,20 & 0,04 & 20,00 & 1 & 0 & 1 & 0 \\
\hline 0,75 & 30,00 & 1,80 & 0,20 & 0,62 & 310,00 & 0 & 0 & 0 & 1 \\
\hline 2,87 & 114,80 & 15,98 & 0,20 & 0,06 & 30,00 & 1 & 0 & 1 & 0 \\
\hline 1,27 & 50,80 & 3,04 & 0,20 & 0,33 & 165,00 & 0 & 0 & 0 & 1 \\
\hline 1,08 & 43,20 & 2,64 & 0,20 & 0,38 & 190,00 & 0 & 0 & 0 & 1 \\
\hline 1,38 & 55,20 & 10,77 & 0,20 & 0,09 & 45,00 & 1 & 0 & 1 & 0 \\
\hline 2,25 & 90,00 & 13,29 & 0,20 & 0,08 & 40,00 & 1 & 0 & 1 & 0 \\
\hline 6,42 & 256,80 & 36,99 & 0,20 & 0,03 & 15,00 & 1 & 0 & 1 & 0 \\
\hline 2,07 & 82,80 & 11,23 & 0,20 & 0,09 & 45,00 & 1 & 0 & 1 & 0 \\
\hline 6,64 & 265,60 & 57,02 & 0,20 & 0,02 & 10,00 & 1 & 0 & 1 & 0 \\
\hline 2,97 & 118,80 & 7,93 & 0,20 & 0,13 & 65,00 & 1 & 0 & 0 & 1 \\
\hline 1,79 & 71,60 & 7,09 & 0,20 & 0,14 & 70,00 & 0 & 0 & 0 & 1 \\
\hline 5,58 & 223,20 & 39,66 & 0,20 & 0,03 & 15,00 & 1 & 0 & 1 & $\overline{0}$ \\
\hline 0,96 & 38,40 & 2,12 & 0,20 & 0,47 & 235,00 & 0 & 0 & 0 & $\overline{1}$ \\
\hline 2,53 & 101,20 & 16,56 & 0,20 & 0,06 & 30,00 & 1 & 0 & 1 & 0 \\
\hline 3,34 & 133,60 & 19,47 & 0,20 & 0,05 & 25,00 & 1 & 0 & 1 & 0 \\
\hline 1,96 & 78,40 & 5,06 & 0,20 & 0,20 & 100,00 & 0 & 0 & 0 & 1 \\
\hline 2,15 & 86,00 & 7,63 & 0,20 & 0,13 & 65,00 & 0 & 0 & 0 & 0 \\
\hline 1,11 & 44,40 & 3,42 & 0,20 & 0,29 & 145,00 & 0 & 0 & 0 & 1 \\
\hline 1,09 & 43,60 & 4,28 & 0,20 & 0,24 & 120,00 & 0 & 0 & 0 & 0 \\
\hline 1,16 & 46,40 & 4,14 & 0,20 & 0,24 & 120,00 & 0 & 0 & 0 & 0 \\
\hline 1,38 & 55,20 & 4,44 & 0,20 & 0,23 & 115,00 & 0 & 0 & 0 & 1 \\
\hline 1,73 & 69,20 & 8,11 & 0,20 & 0,12 & 60,00 & 0 & 0 & 1 & 0 \\
\hline 1,68 & 67,20 & 5,78 & 0,20 & 0,17 & 85,00 & 0 & 0 & 1 & 0 \\
\hline 0,81 & 32,40 & 2,10 & 0,20 & 0,48 & 240,00 & 0 & 0 & 0 & 1 \\
\hline 2,36 & 94,40 & 10,38 & 0,20 & 0,10 & 50,00 & 1 & 0 & 1 & 0 \\
\hline 2,24 & 89,60 & 7,72 & 0,20 & 0,13 & 65,00 & 1 & 0 & 0 & 1 \\
\hline 1,47 & 58,80 & 4,52 & 0,20 & 0,22 & 110,00 & 0 & 0 & 0 & 0 \\
\hline 4,90 & 196,00 & 24,66 & 0,20 & 0,04 & 20,00 & 1 & 0 & 1 & 0 \\
\hline 3,75 & 150,00 & 22,16 & 0,20 & 0,05 & 25,00 & 1 & 0 & 1 & 0 \\
\hline 2,19 & 87,60 & 13,49 & 0,20 & 0,08 & 40,00 & 1 & 0 & 1 & 0 \\
\hline 0,95 & 38,00 & 3,59 & 0,20 & 0,28 & 140,00 & 0 & 0 & 0 & 1 \\
\hline 0,91 & 36,40 & 2,38 & 0,20 & 0,42 & 210,00 & 0 & 0 & 0 & 1 \\
\hline 1,58 & 63,20 & 6,40 & 0,20 & 0,16 & 80,00 & 1 & 0 & 1 & 0 \\
\hline 1,71 & 68,40 & 4,71 & 0,20 & 0,21 & 105,00 & 0 & 0 & 0 & 1 \\
\hline 1,34 & 53,60 & 3,69 & 0,20 & 0,27 & 135,00 & 0 & 0 & 0 & 1 \\
\hline 3,03 & 121,20 & 20,73 & 0,20 & 0,05 & 25,00 & 1 & 0 & 1 & 0 \\
\hline 3,44 & 137,60 & 11,99 & 0,20 & 0,08 & 40,00 & 1 & 0 & 1 & 0 \\
\hline 1,41 & 56,40 & 9,12 & 0,20 & 0,11 & 55,00 & 1 & 0 & 1 & 0 \\
\hline 1,19 & 47,60 & 3,92 & 0,20 & 0,26 & 130,00 & 0 & 0 & 0 & 0 \\
\hline 2,20 & 88,00 & 5,52 & 0,20 & 0,18 & 90,00 & 1 & 0 & 0 & 0 \\
\hline 2,72 & 108,80 & 10,88 & 0,20 & 0,09 & 45,00 & 1 & 0 & 1 & 1 \\
\hline 1,73 & 69,20 & 4,67 & 0,20 & 0,21 & 105,00 & 0 & 0 & 0 & 0 \\
\hline 1,28 & 51,20 & 3,83 & 0,20 & 0,26 & 130,00 & 0 & 0 & 0 & 0 \\
\hline 1,80 & 72,00 & 4,24 & 0,20 & 0,24 & 120,00 & 0 & 0 & 0 & 1 \\
\hline 3,60 & 144,00 & 9,98 & 0,20 & 0,10 & 50,00 & 1 & 0 & 0 & 0 \\
\hline
\end{tabular}




\begin{tabular}{|c|c|c|c|c|c|c|c|c|}
\hline Red_DLCo & V_ext_obs & V_ext_CVF_\% & Rej._Vext & T_Exp_obs & Temp $<6$ & Time PFE & Delta_CVF & Rej.CVF \\
\hline 0,00 & 0,10 & 3,85 & 0 & 7,12 & 0 & 0,105 & 0,08 & 0 \\
\hline 1,00 & 0,05 & 2,45 & 0 & 8,52 & 0 & 0,070 & 0,00 & 0 \\
\hline 0,00 & 0,19 & 4,79 & 0 & 3,47 & 1 & 0,139 & 0,03 & 0 \\
\hline 1,00 & 0,12 & 3,26 & 0 & 8,18 & 0 & 0,085 & 0,07 & 0 \\
\hline 1,00 & 0,09 & 3,00 & 0 & 7,25 & 0 & 0,067 & 0,02 & 0 \\
\hline 1,00 & 0,10 & 2,78 & 0 & 8,01 & 0 & 0,061 & 0,07 & 0 \\
\hline 1,00 & 0,19 & 6,21 & 1 & 6,78 & 0 & 0,106 & 0,14 & 0 \\
\hline 1,00 & 0,14 & 4,28 & 0 & 8,07 & 0 & 0,058 & 0,10 & 0 \\
\hline 0,00 & 0,11 & 3,51 & 0 & 7,21 & 0 & 0,121 & 0,05 & 0 \\
\hline 0,00 & 0,13 & 6,28 & 0 & 12,30 & 0 & 0,119 & 0,03 & 0 \\
\hline 1,00 & 0,10 & 3,77 & 0 & 6,94 & 0 & 0,147 & 0,03 & 0 \\
\hline 0,00 & 0,13 & 3,10 & 0 & 8,03 & 0 & 0,149 & 0,23 & 1 \\
\hline 1,00 & 0,17 & 4,93 & 0 & 5,42 & 1 & 0,149 & 0,06 & 0 \\
\hline 1,00 & 0,07 & 3,32 & 0 & 6,75 & 0 & 0,057 & 0,05 & 0 \\
\hline 1,00 & 0,13 & 3,66 & 0 & 7,48 & 0 & 0,054 & 0,04 & 0 \\
\hline 0,00 & 0,15 & 3,80 & 0 & 4,59 & 1 & 0,116 & 0,01 & 0 \\
\hline 0,00 & 0,16 & 4,16 & 0 & 8,98 & 0 & 0,128 & 0,04 & 0 \\
\hline 0,00 & 0,06 & 1,88 & 0 & 7,92 & 0 & 0,062 & 0,06 & 0 \\
\hline 0,00 & 0,14 & 3,55 & 0 & 6,25 & 0 & 0,304 & 0,02 & 0 \\
\hline 0,00 & 0,12 & 3,65 & 0 & 8,08 & 0 & 0,067 & 0,02 & 0 \\
\hline 0,00 & 0,12 & 3,80 & 0 & 5,53 & 1 & 0,069 & 0,03 & 0 \\
\hline 0,00 & 0,10 & 5,59 & 0 & 6,02 & 0 & 0,107 & 0,00 & 0 \\
\hline 0,00 & 0,16 & 4,32 & 0 & 7,69 & 0 & 0,114 & 0,02 & 0 \\
\hline 0,00 & 0,09 & 2,31 & 0 & 6,73 & 0 & 0,068 & 0,00 & 0 \\
\hline 0,00 & 0,11 & 3,23 & 0 & 5,96 & 1 & 0,067 & 0,03 & 0 \\
\hline 0,00 & 0,10 & 2,49 & 0 & 6,89 & 0 & 0,148 & 0,01 & 0 \\
\hline 0,00 & 0,14 & 5,69 & 0 & 8,58 & 0 & 0,078 & 0,02 & 0 \\
\hline 0,00 & 0,12 & 2,60 & 0 & 7,53 & 0 & 0,075 & 0,02 & 0 \\
\hline 1,00 & 0,16 & 4,22 & 0 & 6,13 & 0 & 0,133 & 0,01 & 0 \\
\hline 0,00 & 0,21 & 5,79 & 1 & 4,28 & 1 & 0,086 & 0,24 & 1 \\
\hline 0,00 & 0,12 & 3,57 & 0 & 6,83 & 0 & 0,102 & 0,05 & 0 \\
\hline 0,00 & 0,15 & 4,32 & 0 & 4,99 & 1 & 0,086 & 0,07 & 0 \\
\hline 0,00 & 0,07 & 3,03 & 0 & 7,44 & 0 & 0,059 & 0,04 & 0 \\
\hline 0,00 & 0,12 & 3,37 & 0 & 6,82 & 0 & 0,121 & 0,00 & 0 \\
\hline 1,00 & 0,17 & 4,78 & 0 & 7,92 & 0 & 0,132 & 0,01 & 0 \\
\hline 1,00 & 0,15 & 4,16 & 0 & 6,56 & 0 & 0,074 & 0,03 & 0 \\
\hline 0,00 & 0,10 & 3,34 & 0 & 6,31 & 0 & 0,072 & 0,00 & 0 \\
\hline 0,00 & 0,36 & 7,38 & 1 & 8,27 & 0 & 0,178 & 0,07 & 0 \\
\hline 0,00 & 0,08 & 2,37 & 0 & 9,09 & 0 & 0,049 & 0,04 & 0 \\
\hline 1,00 & 0,34 & 8,35 & 1 & 5,79 & 7 & 0,143 & 0,08 & 0 \\
\hline 0,00 & 0,12 & 3,64 & 0 & 6,19 & 0 & 0,104 & 0,01 & 0 \\
\hline 0,00 & 0,11 & 3,24 & 0 & 6,81 & 0 & 0,039 & 0,08 & 0 \\
\hline 0,00 & 0,15 & 3,94 & 0 & 7,85 & 0 & 0,097 & 0,02 & 0 \\
\hline 1,00 & 0,11 & 3,24 & 0 & 6,04 & 0 & 0,088 & 0,01 & 0 \\
\hline 1,00 & 0,07 & 3,35 & 0 & 5,92 & 1 & 0,137 & 0,22 & 1 \\
\hline 0,00 & 0,13 & 2,64 & 0 & 9,26 & 0 & 0,115 & 0,09 & 0 \\
\hline 0,00 & 0,05 & 1,98 & 0 & 9,03 & 0 & 0,062 & 0,09 & 0 \\
\hline 1,00 & 0,07 & 1,75 & 0 & 8,33 & 0 & 0,038 & 0,05 & 0 \\
\hline 1,00 & 0,10 & 2,31 & 0 & 5,38 & 1 & 0,099 & 0,11 & 0 \\
\hline 1,00 & 0,15 & 6,44 & 1 & 5,67 & 1 & 0,093 & 0,05 & 0 \\
\hline
\end{tabular}




\begin{tabular}{|c|c|c|c|c|c|c|c|c|}
\hline 1,00 & 0,07 & 2,68 & 0 & 8,57 & 0 & 0,059 & 0,00 & 0 \\
\hline 1,00 & 0,06 & 2,70 & 0 & 7,90 & 0 & 0,047 & 0,09 & 0 \\
\hline 1,00 & 0,20 & 5,97 & 1 & 4,90 & 1 & 0,128 & 0,00 & 0 \\
\hline 1,00 & 0,04 & 1,61 & 0 & 13,70 & 0 & 0,057 & 0,14 & 0 \\
\hline 1,00 & 0,05 & 2,12 & 0 & 9,90 & 0 & 0,083 & 0,02 & 0 \\
\hline 1,00 & 0,11 & 4,98 & 0 & 4,69 & 1 & 0,065 & 0,02 & 0 \\
\hline 1,00 & 0,04 & 1,34 & 0 & 10,50 & 0 & 0,043 & 0,04 & 0 \\
\hline 0,00 & 0,09 & 3,83 & 0 & $\begin{array}{ll}6,28 \\
\end{array}$ & 0 & 0,099 & 0,07 & 0 \\
\hline 1,00 & 0,07 & 2,87 & 0 & 6,89 & 0 & 0,044 & 0,02 & 0 \\
\hline 1,00 & 0,09 & 1,99 & 0 & 13,55 & 0 & 0,068 & 0,06 & 0 \\
\hline 1,00 & 0,04 & 1,17 & 0 & 9,87 & 0 & 0,063 & 0,03 & 0 \\
\hline 1,00 & 0,03 & 1,46 & 0 & 11,93 & 0 & 0,074 & 0,01 & 0 \\
\hline 1,00 & 0,06 & 2,42 & 0 & 10,71 & 0 & 0,093 & 0,05 & 0 \\
\hline ND & 0,04 & 3,36 & 0 & 9,90 & 0 & 0,059 & 0,05 & 0 \\
\hline 1,00 & 0,06 & 3,31 & 0 & 9,69 & 0 & 0,087 & 0,05 & 0 \\
\hline 1,00 & 0,08 & 3,09 & 0 & 7,16 & 0 & 0,050 & 0,02 & 0 \\
\hline 1,00 & 0,03 & 1,78 & 0 & 9,71 & 0 & 0,053 & 0,08 & 0 \\
\hline 1,00 & 0,14 & 5,88 & 0 & 5,30 & 1 & 0,096 & 0,02 & 0 \\
\hline 1,00 & 0,07 & 2,70 & 0 & 6,79 & 0 & 0,087 & 0,05 & 0 \\
\hline 1,00 & 0,05 & 2,02 & 0 & 10,43 & 0 & 0,091 & 0,09 & 0 \\
\hline 1,00 & 0,10 & 4,76 & 0 & 5,53 & 1 & 0,144 & 0,00 & 0 \\
\hline 1,00 & 0,07 & 2,55 & 0 & 7,26 & 0 & 0,042 & 0,02 & 0 \\
\hline 1,00 & 0,17 & 5,31 & 1 & 5,56 & 1 & 0,122 & 0,17 & 1 \\
\hline 1,00 & 0,13 & 3,12 & 0 & 8,48 & 0 & 0,069 & 0,07 & 0 \\
\hline 1,00 & 0,12 & 4,11 & 0 & 4,44 & 7 & 0,091 & 0,04 & 0 \\
\hline 1,00 & 0,08 & 3,76 & 0 & 8,34 & 0 & 0,045 & 0,00 & 0 \\
\hline ND & 0,13 & 7,22 & 0 & 3,81 & 1 & 0,096 & 0,05 & 0 \\
\hline 1,00 & 0,12 & 5,08 & 0 & 7,17 & 0 & 0,097 & 0,01 & 0 \\
\hline 1,00 & 0,24 & 8,54 & 1 & 2,47 & 1 & 0,180 & 0,18 & 1 \\
\hline 1,00 & 0,07 & 2,60 & 0 & 7,58 & 0 & 0,106 & 0,07 & 0 \\
\hline 1,00 & 0,10 & 4,95 & 0 & 7,75 & 0 & 0,109 & 0,04 & 0 \\
\hline 1,00 & 0,09 & 3,15 & 0 & 7,67 & 0 & 0,052 & 0,01 & 0 \\
\hline 0,00 & 0,07 & 3,04 & 0 & 13,65 & 0 & 0,090 & 0,01 & 0 \\
\hline 1,00 & 0,04 & 1,65 & 0 & 15,83 & 0 & 0,066 & 0,01 & 0 \\
\hline 1,00 & 0,06 & 1,83 & 0 & 10,28 & 0 & 0,068 & 0,08 & 0 \\
\hline 1,00 & 0,12 & 4,18 & 0 & 8,55 & 0 & 0,102 & 0,07 & 0 \\
\hline 1,00 & 0,15 & 5,23 & 0 & 7,96 & 0 & 0,077 & 0,03 & 0 \\
\hline 1,00 & 0,05 & 1,73 & 0 & 10,74 & 0 & 0,058 & 0,04 & 0 \\
\hline 0,00 & 0,19 & 6,74 & 1 & 9,31 & 0 & 0,105 & 0,01 & 0 \\
\hline 1,00 & 0,17 & 6,85 & 1 & 7,65 & 0 & 0,100 & 0,04 & 0 \\
\hline 1,00 & 0,06 & 2,37 & 0 & 14,74 & 0 & 0,063 & 0,11 & 0 \\
\hline 1,00 & 0,08 & 3,13 & 0 & 10,20 & 0 & 0,122 & 0,03 & 0 \\
\hline 1,00 & 0,06 & 2,01 & 0 & 13,37 & 0 & 0,066 & 0,05 & 0 \\
\hline 0,00 & 0,15 & 4,63 & 0 & 5,92 & 1 & 0,085 & 0,00 & 0 \\
\hline 1,00 & 0,07 & 2,93 & 0 & 10,44 & 0 & 0,059 & 0,06 & 0 \\
\hline 2,00 & 0,05 & 2,94 & 0 & 9,79 & 0 & 0,056 & 0,01 & 0 \\
\hline 0,00 & 0,14 & 4,73 & 0 & 6,60 & 0 & 0,069 & 0,02 & 0 \\
\hline 0,00 & 0,10 & 4,27 & 0 & 5,78 & 1 & 0,073 & 0,04 & 0 \\
\hline 1,00 & 0,13 & 5,88 & 0 & 5,97 & 1 & 0,146 & 0,01 & 0 \\
\hline 1,00 & 0,04 & 2,06 & 0 & 9,25 & 0 & 0,069 & 0,02 & 0 \\
\hline
\end{tabular}




\begin{tabular}{|c|c|c|c|c|c|c|c|c|}
\hline Delta_VEF1 & Rej.VEF1 & dif_SVC_FVC & \begin{tabular}{|l|} 
Switch-In \\
\end{tabular} & Freq_Panting & Reprod_TGV & Rej.TGV & IVC & IVC_SVC \\
\hline 0,030 & 0 & 0,200 & 44,0 & 65,000 & 0,011 & 0 & 2,60 & 0,929 \\
\hline 0,020 & 0 & 0,230 & 15,0 & 77,000 & 0,003 & 0 & 2,05 & 0,903 \\
\hline 0,040 & 0 & 0,010 & 49,0 & 63,000 & 0,004 & 0 & 3,28 & 0,824 \\
\hline 0,140 & 0 & 0,040 & 70,0 & 77,000 & 0,017 & 0 & 3,31 & 0,890 \\
\hline 0,000 & 0 & $-0,050$ & 66,0 & 88,000 & 0,020 & 0 & 2,91 & 0,986 \\
\hline 0,040 & 0 & $-0,020$ & 8,0 & 102,000 & 0,010 & 0 & 3,45 & 0,964 \\
\hline 0,100 & 0 & 0,810 & 7,0 & 71,000 & 0,034 & 0 & 3,78 & 0,977 \\
\hline 0,120 & 0 & 0,300 & 42,0 & 75,000 & 0,006 & 0 & 3,17 & 0,888 \\
\hline 0,070 & 0 & 0,320 & 79,0 & 73,000 & 0,014 & 0 & 3,32 & 0,962 \\
\hline 0,060 & 0 & 0,090 & 1,0 & 63,000 & 0,016 & 0 & 2,08 & 0,963 \\
\hline 0,010 & 0 & 0,030 & 65,0 & 80,000 & 0,033 & 0 & 2,33 & 0,869 \\
\hline 0,020 & 0 & 0,050 & 15,0 & 73,000 & 0,013 & 0 & 4,00 & 0,943 \\
\hline 0,080 & 0 & 0,090 & 23,0 & 78,000 & 0,041 & 0 & 3,38 & 0,955 \\
\hline 0,040 & 0 & 0,150 & 43,0 & 75,000 & 0,052 & 0 & 1,82 & 0,805 \\
\hline 0,060 & 0 & 0,380 & 4,0 & 61,000 & 0,011 & 0 & 3,61 & 0,919 \\
\hline 0,020 & 0 & 0,110 & 152,0 & 75,000 & 0,009 & 0 & 3,79 & 0,933 \\
\hline 0,030 & 0 & 0,410 & 7,0 & 80,000 & 0,027 & 0 & 3,81 & 0,894 \\
\hline 0,090 & 0 & 0,140 & 46,0 & 72,000 & 0,009 & 0 & 3,13 & 0,937 \\
\hline 0,050 & 0 & 0,120 & 35,0 & 64,000 & 0,019 & 0 & 4,01 & 0,988 \\
\hline 0,020 & 0 & 0,110 & 7,0 & 80,000 & 0,035 & 0 & 3,30 & 0,971 \\
\hline 0,120 & 0 & 0,130 & 8,0 & 71 , & 0,020 & 0 & 2,96 & 0,900 \\
\hline 0,090 & 0 & 0,070 & 39,0 & 84,000 & 0,018 & 0 & 1,81 & 0,973 \\
\hline 0,000 & 0 & 0,360 & 74,0 & 73,000 & 0,014 & 0 & 4,05 & 0,998 \\
\hline 0,040 & 0 & $-0,060$ & 29,0 & 89,000 & 0,010 & 0 & 3,45 & 0,901 \\
\hline 0,010 & 0 & $-0,040$ & 1,0 & 97,000 & 0,014 & 0 & 3,13 & 0,929 \\
\hline 0,030 & 0 & 0,200 & 14,0 & 68,000 & 0,051 & 0 & 3,63 & 0,862 \\
\hline 0,060 & 0 & 0,350 & 11,0 & 89 , & 52 & 0 & 2,63 & 0,936 \\
\hline 0,110 & 0 & $-0,060$ & 65,0 & 83,000 & 0,017 & 0 & 4,41 & 0,969 \\
\hline 0,060 & 0 & 0,000 & 101,0 & 69,000 & 0,005 & 0 & 3,59 & 0,947 \\
\hline 0,040 & 0 & 0,350 & 12,0 & 72,000 & 0,018 & 0 & 3,82 & 0,960 \\
\hline 0,000 & 0 & 0,250 & 84,0 & 79,000 & 0,044 & 0 & 3,36 & 0,931 \\
\hline 0,210 & 1 & 0,210 & 18,0 & 88,000 & 0,041 & 0 & 3,53 & 0,959 \\
\hline 0,050 & 0 & $-0,100$ & 16,0 & 84 & 0,064 & 0 & 1,94 & 0,878 \\
\hline 0,020 & 0 & 0,240 & 5,0 & 83,000 & 0,008 & 0 & 3,45 & 0,908 \\
\hline 0,030 & 0 & 0,400 & 79,0 & 70,000 & 0,007 & 0 & 3,48 & 0,879 \\
\hline 0,030 & 0 & 0,050 & 11,0 & 73,000 & 0,027 & 0 & 3,09 & 0,844 \\
\hline 0,030 & 0 & $-0,060$ & 2,0 & 70,000 & 0,083 & 0 & 2,70 & 0,922 \\
\hline 0,040 & 0 & 0,080 & 57,0 & 66,000 & 0,013 & 0 & 4,38 & 0,883 \\
\hline 0,040 & 0 & 0,310 & 2,0 & 79,000 & 0,025 & 0 & 3,33 & 0,902 \\
\hline 0,040 & 0 & 0,320 & 93,0 & 71,000 & 0,034 & 0 & 4,40 & 1,002 \\
\hline 0,010 & 0 & 0,180 & 32,0 & 69,000 & 0,007 & 0 & 2,44 & 0,701 \\
\hline 0,010 & 0 & 0,320 & 7,0 & 75,000 & 0,060 & 0 & 3,39 & 0,914 \\
\hline 0,140 & 0 & 0,310 & 18,0 & 69,000 & 0,078 & 0 & 3,97 & 0,964 \\
\hline 0,010 & 0 & 0,240 & 63,0 & 79,000 & 0,037 & 0 & 3,23 & 0,890 \\
\hline 0,040 & 0 & 0,030 & 5,0 & 62,000 & 0,024 & 0 & 2,00 & 0,943 \\
\hline 0,030 & 0 & 0,240 & 8,0 & 84,000 & 0,047 & 0 & 4,62 & 0,895 \\
\hline 0,070 & 0 & 0,120 & 17,0 & 75,000 & 0,022 & 0 & 2,52 & 0,951 \\
\hline 0,110 & 0 & 0,140 & 104,0 & 80,000 & 0,031 & 0 & 3,69 & 0,891 \\
\hline 0,020 & 0 & 0,110 & 9,0 & 65,000 & 0,021 & 0 & 3,76 & 0,847 \\
\hline 0,020 & 0 & 0,090 & 51,0 & 73,000 & 0,035 & 0 & 1,97 & 0,814 \\
\hline
\end{tabular}




\begin{tabular}{|c|c|c|c|c|c|c|c|c|}
\hline 0,010 & 0 & 0,040 & 40,0 & 68,000 & 0,018 & 0 & 2,58 & 0,974 \\
\hline 0,000 & 0 & 0,680 & 59,0 & 63,000 & 0,039 & 0 & 2,64 & 0,910 \\
\hline 0,000 & 0 & 0,010 & 56,0 & 80,000 & 0,028 & 0 & 2,99 & 0,890 \\
\hline 0,020 & 0 & 0,070 & 5,0 & 81,000 & 0,030 & 0 & 2,26 & 0,883 \\
\hline 0,080 & 0 & 0,020 & 17,0 & 79,000 & 0,059 & 0 & 2,21 & 0,929 \\
\hline 0,010 & 0 & $-0,030$ & 3,0 & 97,000 & 0,104 & 1 & 1,99 & 0,913 \\
\hline 0,020 & 0 & 0,310 & 18,0 & 124,000 & 0,077 & 0 & 2,79 & 0,845 \\
\hline 0,030 & 0 & 0,080 & 24,0 & 89,000 & 0,049 & 0 & 2,28 & 0,938 \\
\hline 0,010 & 0 & 0,030 & 21,0 & 81,000 & 0,098 & 0 & 2,22 & 0,899 \\
\hline 0,040 & 0 & 0,200 & 17,0 & 80,000 & 0,011 & 0 & 4,33 & 0,915 \\
\hline 0,070 & 0 & 0,490 & 38,0 & 82,000 & 0,042 & 0 & 3,18 & 0,815 \\
\hline 0,010 & 0 & 0,660 & 34,0 & 76,000 & 0,036 & 0 & 2,58 & 0,952 \\
\hline 0,060 & 0 & 0,340 & 72,0 & 81,000 & 0,012 & 0 & 2,56 & 0,908 \\
\hline 0,000 & 0 & 0,190 & 28,0 & 81,000 & 0,037 & 0 & ND & ND \\
\hline 0,010 & 0 & 0,080 & 16,0 & 66,000 & 0,056 & 0 & 1,71 & 0,905 \\
\hline 0,000 & 0 & $-0,010$ & 71,0 & 67,000 & 0,051 & 0 & 2,40 & 0,930 \\
\hline 0,000 & 0 & 0,560 & 19,0 & 66,000 & 0,032 & 0 & 1,96 & 0,871 \\
\hline 0,000 & 0 & $-0,030$ & 71,0 & 109,000 & 0,063 & 0 & 2,11 & 0,898 \\
\hline 0,010 & 0 & 0,000 & 90,0 & 84,000 & 0,024 & 0 & 1,97 & 0,761 \\
\hline 0,010 & 0 & 0,110 & 11,0 & 77,000 & 0,011 & 0 & 2,02 & 0,783 \\
\hline 0,010 & 0 & 0,130 & 64,0 & 71,000 & 0,022 & 0 & 2,10 & 0,942 \\
\hline 0,040 & 0 & 0,010 & 9,0 & 65,000 & 0,026 & 0 & 2,63 & 0,953 \\
\hline 0,110 & 0 & $-0,020$ & 43,0 & 79,000 & 0,043 & 0 & 2,73 & 0,858 \\
\hline 0,000 & 0 & $-0,240$ & 54,0 & 82,000 & 0,019 & 0 & 3,86 & 0,982 \\
\hline 0,110 & 0 & 0,210 & 59,0 & 74,000 & 0,035 & 0 & 2,64 & 0,843 \\
\hline 0,050 & 0 & 0,130 & 7,0 & 85,000 & 0,074 & 0 & 2,11 & 0,934 \\
\hline 0,020 & 0 & $-0,030$ & 61,0 & 61,000 & 0,106 & 1 & ND & ND \\
\hline 0,030 & 0 & 0,230 & 35,0 & 98,000 & 0,020 & 0 & 2,49 & 0,961 \\
\hline 0,250 & 1 & $-0,260$ & 9,0 & 68,000 & 0,050 & 0 & 2,29 & 0,898 \\
\hline 0,030 & 0 & 0,010 & 10,0 & 74,000 & 0,009 & 0 & 2,52 & 0,933 \\
\hline 0,030 & 0 & 0,110 & 83,0 & 71,000 & 0,019 & 0 & 1,94 & 0,911 \\
\hline 0,020 & 0 & 0,070 & 79,0 & 71,000 & 0,014 & 0 & 2,85 & 0,973 \\
\hline 0,030 & 0 & 0,110 & 43,0 & 69,000 & 0,038 & 0 & 2,40 & 0,996 \\
\hline 0,060 & 0 & 0,350 & 8,0 & 72,000 & 0,024 & 0 & 2,76 & 0,993 \\
\hline 0,030 & 0 & 0,300 & 11,0 & 80,000 & 0,014 & 0 & 3,25 & 0,910 \\
\hline 0,010 & 0 & $-0,040$ & 8,0 & 74,000 & 0,036 & 0 & 2,79 & 0,986 \\
\hline 0,030 & 0 & 0,050 & 22,0 & 67,000 & 0,020 & 0 & 2,81 & 0,962 \\
\hline 0,040 & 0 & 0,090 & 8,0 & 67,000 & 0,043 & 0 & 2,75 & 0,923 \\
\hline 0,040 & 0 & 0,180 & 66,0 & 73,000 & 0,022 & 0 & 2,96 & 0,987 \\
\hline 0,010 & 0 & 0,100 & 183,0 & 86,000 & 0,012 & 0 & 2,55 & 0,988 \\
\hline 0,020 & 0 & 0,420 & 30,0 & 64,000 & 0,023 & 0 & 2,80 & 0,949 \\
\hline 0,020 & 0 & 0,120 & 38,0 & 89,000 & 0,737 & 1 & 2,59 & 0,966 \\
\hline 0,020 & 0 & 0,060 & 5,0 & 72,000 & 0,018 & 0 & 2,87 & 0,941 \\
\hline 0,010 & 0 & 0,030 & 45,0 & 79,000 & 0,022 & 0 & 3,02 & 0,924 \\
\hline 0,040 & 0 & 0,100 & 4,0 & 79,000 & 0,014 & 0 & 2,38 & 0,956 \\
\hline 0,010 & 0 & 0,250 & 17,0 & 66,000 & 0,016 & 0 & 1,80 & 0,923 \\
\hline 0,080 & 0 & $-0,010$ & 5,0 & 91,000 & 0,046 & 0 & 2,84 & 0,963 \\
\hline 0,000 & 0 & $-0,010$ & 13,0 & 72,000 & 0,097 & 0 & 2,19 & 0,940 \\
\hline 0,000 & 0 & $-0,040$ & 9,0 & 75,000 & 0,027 & 0 & 2,04 & 0,940 \\
\hline 0,010 & 0 & 0,040 & 14,0 & 82,000 & 0,044 & 0 & 1,97 & 0,995 \\
\hline
\end{tabular}




\begin{tabular}{|c|c|c|c|c|c|c|}
\hline Rej.Vinsp Dif. & BHT & n_BHT_9_11 & Delta_DLCO_abs & Rej._Dlco_abs & Delta_DLCO_\% & Rej._Dlco\% \\
\hline 0 & 10,500 & 2 & 0,120 & 0 & 0,848 & 0 \\
\hline 0 & 10,150 & 2 & 2,120 & 0 & 11,379 & 1 \\
\hline 1 & 11,300 & 1 & 2,270 & 0 & 16,122 & 1 \\
\hline 0 & 10,600 & 2 & 2,320 & 0 & 10,536 & 1 \\
\hline 0 & 10,700 & 2 & 0,050 & 0 & 0,339 & 0 \\
\hline 0 & 9,540 & 2 & 0,450 & 0 & 2,394 & 0 \\
\hline 0 & 10,400 & 2 & 0,660 & 0 & 2,301 & 0 \\
\hline 0 & 9,510 & 1 & 0,350 & 0 & 2,054 & 0 \\
\hline 0 & 10,800 & 2 & 0,980 & 0 & 7,562 & 0 \\
\hline 0 & 9,550 & 1 & ND & & ND & \\
\hline 0 & 9,880 & 2 & 1,230 & 0 & 8,926 & 0 \\
\hline 0 & 10,800 & 1 & 0,010 & 0 & 0,030 & 0 \\
\hline 0 & 10,600 & 2 & 1,090 & 0 & 4,812 & 0 \\
\hline 1 & 10,900 & 1 & 1,490 & 0 & 8,573 & 0 \\
\hline 0 & 9,870 & 2 & 0,730 & 0 & 2,128 & 0 \\
\hline 0 & 10,100 & 2 & 2,030 & 0 & 7,012 & 0 \\
\hline 0 & 10,100 & 2 & 0,480 & 0 & 1,952 & 0 \\
\hline 0 & 10,800 & 2 & 0,230 & 0 & 1,318 & 0 \\
\hline 0 & 12,300 & 0 & 1,150 & 0 & 3,520 & 0 \\
\hline 0 & 11,400 & 0 & 1,470 & 0 & 5,961 & 0 \\
\hline 0 & 10,600 & 2 & 0,150 & 0 & 0,669 & 0 \\
\hline 0 & 9,500 & 2 & 1,110 & 0 & 10,756 & 1 \\
\hline 0 & 11,500 & 1 & 0,520 & 0 & 2,137 & 0 \\
\hline 0 & 11,000 & 1 & 2,320 & 0 & 9,659 & 0 \\
\hline 0 & 10,900 & 2 & 0,650 & 0 & 3,174 & 0 \\
\hline 0 & 10,100 & 2 & 0,300 & 0 & 0,958 & 0 \\
\hline 0 & 10,300 & 2 & 0,270 & 0 & 1,630 & 0 \\
\hline 0 & 11,445 & 1 & 1,080 & 0 & 4,296 & 0 \\
\hline 0 & 10,565 & 2 & 2,490 & 0 & 11,469 & 1 \\
\hline 0 & 10,665 & 2 & 2,960 & 0 & 10,375 & 1 \\
\hline 0 & 10,940 & 1 & 1,120 & 0 & 5,056 & 0 \\
\hline 0 & 10,900 & 1 & 1,530 & 0 & 4,995 & 0 \\
\hline 0 & 10,590 & 2 & 1,230 & 0 & 9,716 & 0 \\
\hline 0 & 11,365 & 0 & 0,100 & 0 & 0,780 & 0 \\
\hline 0 & 9,975 & 2 & 1,220 & 0 & 7,044 & 0 \\
\hline 1 & 11,030 & 1 & 1,140 & 0 & 5,652 & 0 \\
\hline 0 & 9,430 & 2 & 1,660 & 0 & 7,653 & 0 \\
\hline 0 & 11,075 & 1 & 2,320 & 0 & 7,360 & 0 \\
\hline 0 & 10,350 & 2 & 1,760 & 0 & 10,086 & 1 \\
\hline 0 & 10,400 & 2 & 1,800 & 0 & 6,669 & 0 \\
\hline 1 & 10,513 & 2 & 0,920 & 0 & 3,786 & 0 \\
\hline 0 & 9,985 & 2 & 0,250 & 0 & 1,341 & 0 \\
\hline 0 & 10,470 & 2 & 0,130 & 0 & 0,678 & 0 \\
\hline 0 & 10,320 & 2 & 0,200 & 0 & 0,965 & 0 \\
\hline 0 & 10,715 & 2 & 0,740 & 0 & 4,004 & 0 \\
\hline 0 & 12,900 & 0 & 1,810 & 0 & 5,991 & 0 \\
\hline 0 & 10,190 & 2 & 1,320 & 0 & 10,811 & 1 \\
\hline 0 & 11,160 & 1 & 1,380 & 0 & 8,333 & 0 \\
\hline 1 & 11,115 & 1 & 1,650 & 0 & 6,796 & 0 \\
\hline 1 & 10,230 & 2 & 0,190 & 0 & 1,945 & 0 \\
\hline
\end{tabular}




\begin{tabular}{|c|c|c|c|c|c|c|}
\hline 0 & 10,820 & 2 & 0,170 & 0 & 0,765 & 0 \\
\hline 0 & 12,290 & 0 & ND & & ND & \\
\hline 0 & 11,130 & 0 & 0,090 & 0 & 0,875 & 0 \\
\hline 0 & 11,200 & 1 & 0,970 & 0 & 10,031 & 1 \\
\hline 0 & 10,655 & 1 & 0,000 & 0 & 0,000 & 0 \\
\hline 0 & 9,790 & 2 & 1,750 & 0 & 17,396 & 1 \\
\hline 1 & 11,535 & 0 & 2,370 & 0 & 12,382 & 1 \\
\hline 0 & 10,055 & 3 & 4,590 & 1 & 18,021 & 1 \\
\hline 0 & 9,925 & 2 & 1,820 & 0 & 11,404 & 1 \\
\hline 0 & 10,125 & 2 & 0,860 & 0 & 10,723 & 1 \\
\hline 1 & 10,500 & 2 & 0,170 & 0 & 1,489 & 0 \\
\hline 0 & 11,010 & 1 & 0,560 & 0 & 5,447 & 0 \\
\hline 0 & 10,405 & 2 & 1,540 & 0 & 10,246 & 1 \\
\hline & ND & ND & ND & & ND & \\
\hline 0 & 9,923 & 3 & 2,820 & 0 & 30,064 & 1 \\
\hline 0 & 10,180 & 2 & 1,890 & 0 & 10,048 & 1 \\
\hline 0 & 10,510 & 2 & 0,220 & 0 & 3,001 & 0 \\
\hline 0 & 10,100 & 2 & 0,490 & 0 & 6,640 & 0 \\
\hline 1 & 11,305 & 0 & 1,780 & 0 & 12,687 & 1 \\
\hline 1 & 11,733 & 0 & 1,090 & 0 & 8,321 & 0 \\
\hline 0 & 9,795 & 2 & 0,370 & 0 & 6,752 & 0 \\
\hline 0 & 9,860 & 2 & 0,260 & 0 & 1,502 & 0 \\
\hline 0 & 9,700 & 2 & 0,500 & 0 & 3,634 & 0 \\
\hline 0 & 10,330 & 2 & 0,500 & 0 & 2,403 & 0 \\
\hline 1 & 9,100 & 2 & 0,270 & 0 & 3,367 & 0 \\
\hline 0 & 10,345 & 2 & 1,140 & 0 & 8,028 & 0 \\
\hline & ND & ND & $\mathrm{ND}$ & & ND & \\
\hline 0 & 9,775 & 2 & 1,270 & 0 & 11,514 & 1 \\
\hline 0 & 9,515 & 2 & 1,270 & 0 & 15,413 & 1 \\
\hline 0 & 11,835 & 0 & 2,740 & 0 & 12,918 & 1 \\
\hline 0 & 11,240 & 1 & 3,400 & 1 & 23,810 & 1 \\
\hline 0 & 9,935 & 2 & 0,580 & 0 & 11,175 & 1 \\
\hline 0 & 9,885 & 2 & 2,590 & 0 & 13,022 & 1 \\
\hline 0 & 10,770 & 1 & 1,070 & 0 & 12,090 & 1 \\
\hline 0 & 10,100 & 2 & 2,500 & 0 & 14,286 & 1 \\
\hline 0 & 10,780 & 2 & 1,710 & 0 & 9,511 & 0 \\
\hline 0 & 9,480 & 2 & 0,060 & 0 & 0,617 & 0 \\
\hline 0 & 10,570 & 3 & 2,080 & 0 & 19,277 & 1 \\
\hline 0 & 11,170 & 0 & 0,310 & 0 & 1,218 & 0 \\
\hline 0 & 10,240 & 2 & 0,350 & 0 & 2,122 & 0 \\
\hline 0 & 10,595 & 1 & 0,970 & 0 & 9,798 & 0 \\
\hline 0 & 10,590 & 2 & 0,300 & 0 & 5,042 & 0 \\
\hline 0 & 10,095 & 2 & 1,850 & 0 & 20,717 & 1 \\
\hline 0 & 10,185 & 2 & 0,010 & 0 & 0,043 & 0 \\
\hline 0 & 10,265 & 2 & 1,750 & 0 & 16,876 & 1 \\
\hline 0 & 10,635 & 2 & 1,200 & 0 & 17,647 & 1 \\
\hline 0 & 10,035 & 2 & 0,100 & 0 & 0,647 & 0 \\
\hline 0 & 9,975 & 2 & 0,720 & 0 & 4,128 & 0 \\
\hline 0 & 10,840 & 1 & 0,550 & 0 & 5,978 & 0 \\
\hline 0 & 10,085 & 2 & 0,240 & 0 & 2,164 & 0 \\
\hline
\end{tabular}


9 REFERÊNCIAS 


\section{REFERÊNCIAS}

1. Matsuura K, Ebihara S, Yoshizumi T, Asai M, Hayashi R, Shizuka T, Uchiyama K. [Changes in respiratory function before and after laryngectomy] Nippon Jibiinkoka Gakkai Kaiho. 1995;98(7):1097-103.

2. Togawa K, Konno A, Hoshino T. A physiologic study on respiratory handicap of the laryngectomized. Arch Otorhinlaryngol. 1980;229(1):69-79.

3. Hess MM, Schwenk RA, Frank W, Loddenkemper R. Pulmonary function after total laryngectomy. Laryngoscope. 1999;109(6):988-94.

4. Torjussen W. Airway obstructions in laryngectomized patients. A spirometric investigation. Acta Otolaryngol. 1968;66(1):161-70.

5. Todisco T, Maurizi M, Paludetti G, Dottorini M, Merante F. Laryngeal cancer: long-term follow-up of respiratory functions after laryngectomy. Respiration. 1984;45(3):303-15.

6. McRae D, Young $P$, Hamilton $J$, Jones A. Raising airway resistance in laryngectomees increases tissue oxygen saturation. Clin Otolaryngol Allied Sci. 1996;21(4):366-8.

7. Ackerstaff AH, Hilgers FJ, Balm AJ, Van Zandwijk N. Long-term pulmonary function after total laryngectomy. Clin Otolaryngol Allied Sci. 1995;20(6):54751.

8. Vázquez de la Iglesia F, Fernández González S. Method for the study of pulmonary function in laryngectomized patients. Acta Otorrinolaringol Esp. $2006 ; 57(6): 275-8$ 
9. Davidson RN, Hayward L, Pounsford JC, Saunders KB. Lung function and within-breath changes in resistance in patients who have had a laryngectomy. Q J Med. 1986;60(232):753-62.

10. Gardner WN, Meah MS. Respiration during exercise in conscious laryngectomized humans. J Appl Physiol. 1989;66(5):2071-8.

11. Gregor RT, Hassman E. Respiratory function in post-laryngectomy patients related to stomal size. Acta Otolaryngol. 1984;97(1-2):177-83.

12. Harris S, Jonson B. Lung function before and after laryngectomy. Acta Otolaryngol. 1974;78(3-4):287-94.

13. Heyden R. The respiratory function in laryngectomized patients. Acta Otolaryngol. 1950;85:39-59.

14. Durán Cantolla J, Sampedro Alvarez JR, Zurbano Goñi F, Agüero Balbín R, Terán Santos J, Rodríguez Asensio J, Jiménez Gómez A. Measurement of pulmonary function in laryngectomized patients. An Otorrinolaringol Ibero Am. 1989;16(4):387-400.

15. Ackerstaff AH, Souren T, van Zandwijk N, Balm AJ, Hilgers FJ. Improvements in the assessment of pulmonary function in laryngectomized patients. Laryngoscope. 1993;103(12):1391-4.

16. Tan AK. Incentive spirometry for tracheostomy and laryngectomy patients. J Otolaryngol. 1995;24(5):292-4.

17. Castro MA, Dedivitis RA, Macedo AG. Evaluation of a method for assessing pulmonary function in laryngectomees. Acta Otorhinolaryngol Ital. $2011 ; 31: 243-247$

18. Shim C, Corro P, Park SS, Williams MH Jr. Pulmonary function studies in patients with upper airway obstruction. Am Rev Respir Dis. 1972;106:233-8. 
19. Usui N. Ventilatory function in laryngectomized patients. Auris Nasus Larynx. 1979;6(2):87-96.

20. Najwer K, Latkowski B, Gielec L, Sulkowski W. [Respiratory indicators after laryngectomy]. Zachowanie sie wskazników wentylacji pluc u chorych po operacju wyciecia krtani. Med Pr. 1979;30(6): 447-50.

21. Ferri T, Capra R, Collini M, Cuomo A, Bacchi G, Gariboldi LM. Studio comparativo degli indici respiratori dinamici pre e post-operatori in soggetti sottoposti a laringectomia totale. Acta Biomed Ateneo Parmense. 1983;54(3):247-54

22. Olszewski J, Zalewski P, Pietkiewicz P. [Spirometric examinations at laryngectomized patients and healthy subjects]. Badania spirometryczne $u$ laryngektomowanych i ludzi zdrowych. Otolaryngol Pol. 1995;49(4):307-10.

23. Hyatt R, Scanlon P, Nakamura M. Interpretation of pulmonary function testing A practical guide, $3^{\text {rd }}$ Ed. Philadelphia: Lippincott-Raven; 1997.

24. Brusasco V. ATS/ERS Task Force: Standardization of lung function testing. Eur Respir J. 2005;26:153-61.

25. American Thoracic Society. Lung function testing: selection of reference values and interpretative strategies. Am Rev Respir Dis. 1991; 144:1202-18.

26. American Thoracic Society. Standardization of spirometry - 1987 Update. Am Rev Respir Dis. 1987;136:1285-98.

27. Quanjer P. Standardized lung function testing. Report of the working party for the standardization of lung function tests of the European Community for Coal and Steel. Bull Eur Physiopathol Resp. 1983;19(5):1-95. 
28. DuBois AB, Botelho SY, Bedell GN, Marshall R, Comroe JH. A rapid plethysmographic method for measuring thoracic gas volume: a comparison with a nitrogen washout method for measuring functional residual capacity in normal subjects. J Clin Invest. 1956;35(3):322-326.

29. Leith DE, Mead J. Principles of body plethismography. In: Procedures for standardized measurements of lung mechanics. Bethesda: NHLL; 1974.

30. Dubois AB, Botelho SY, Marshall R, Comroe JH. A new method for measuring airway resistance in man using a body plethysmograph: values in normal subjects and in patients with respiratory disease. J Clin Invest. 1956;35(3):327-335.

31. Hankinson JL, Bang KM. Acceptability and reproductibility criteria of the American Thoracic Society as observed in a sample of the general population. Am Rev Respir Dis. 1991;143:516-21.

32. American Thoracic Society. Standardization of spirometry - 1994 Update. Am J Respir Crit Care Med. 1995;152:1107-36.

33. Menna Barreto SS, Cavalazzi AC. Determinação dos volumes pulmonares: métodos de mensuração dos volumes pulmonares. J Pneumol. 2002;28(3):95100.

34. Pereira CAC, Viegas CAA, Alves RR. Capacidade de difusão do monóxido de carbono. J Pneumol. 2002;28(3):122-128.

35. Crapo RO. Carbon monoxide diffusing capacity (transfer factor). Sem Respir Crit Care Med. 1998;19:335-47.

36. STATACorp. 2001. Stata Statistical Software: Release 7.0. College Station, Texas : Stata Corporation 
37. Bestall JC, Paul EA, Garrod R, Garnham R, Jones PW, Wedzicha JA. Usefulness of the Medical Research Council (MRC) dyspnea scale as a measure of disability in patients with chronic obstructive pulmonary disease. Thorax. 1999;54(7):581-6.

38. Bossé R, Sparrow D, Rose CL, Weiss ST. Longitudinal effect of age and smoking cessation on pulmonary function. Am Rev Respir Dis. 1981;123(4):378-81. 


\section{APÊNDICE}

Apêndice A - Valores previstos brasileiros 2008 para o gênero masculino

Tabelas, equações, questionários e valores de referência

Sociedade Brasileira de Pneumologia e Tisiologia - www.sbpt.org.br

\section{VALORES PREVISTOS BRASILEIROS 2008 \\ SEXO MASCULINO}

\begin{tabular}{|c|c|}
\hline EQUAÇĀO & LIMITE INFERIOR \\
\hline \multicolumn{2}{|l|}{ Idade 6 a 14 anos } \\
\hline CVF $=2,7183^{(\log \text { m estanura (cm) }) \times 2,7083-12,0205)}$ & previsto $\times 0,79$ \\
\hline VEF1 $=2,7183^{(\log \text { n estatura(cm) } \times 2,5431-11,8832)}$ & previsto $\times 0,80$ \\
\hline $\mathrm{FEF}_{25-75}=2,7183^{(09 \text { ) estatura (cm) } \times 1,8308-8,9219)}$ & previsto $\times 0,78$ \\
\hline VEF $1 /$ CVF previsto $=93$ & $83 \%$ \\
\hline $\mathrm{FEF}_{25-75} / \mathrm{CVF}$ previsto $=118$ & $91 \%$ \\
\hline Idade 15 a 24 anos & \\
\hline 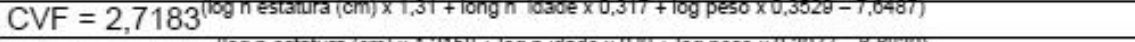 & previsto $\times 0,81$ \\
\hline 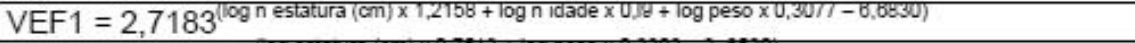 & previsto $\times 0,82$ \\
\hline 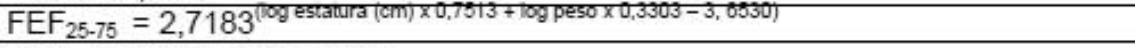 & previsto $\times 0,68$ \\
\hline VEF $_{1} /$ CVF previsto $=94 \%$ & $82 \%$ \\
\hline FEF25-75/CVF previsto $=94 \%$ & $82 \%$ \\
\hline \multicolumn{2}{|l|}{ Idade 25 a 86 anos } \\
\hline CVF $=$ estatura $\times 0,0517$ - idade $\times 0,0207-3,18$ & previsto $-0,90$ \\
\hline VEF $_{1}=$ estatura $\times 0,0338$ - idade $\times 0,0252-0,789$ & previsto $-0,76$ \\
\hline VEF1/CVF $=120,3$-estatura $\times 0,175$ - idade $\times 0,197$ & previsto $-7,6$ \\
\hline PFE $=2,7183^{(\log \text { n estatura }(\mathrm{cm}) \times 0,83-\log \text { n loade } \times 0,114-1,432)}$ & previsto $\times 0,76$ \\
\hline FEF50 $=2,7183^{(3,002-109 \text { nा }}$ & previsto $\times 0,60$ \\
\hline FEF75 $=2,7183^{(4,462-\log \text { n } 1030 \text { e } x, 0 / 1)}$ & previsto $\times 0,60$ \\
\hline $\mathrm{FEF}_{25-75}=2,7183^{(3,833-\log n \text { idadoe } \times 0,067)}$ & previsto $\times 0,59$ \\
\hline FEF75-85 $=2,7183^{(4,38-\log n \text { I I ade } \times 1,160)}$ & previsto $\times 0,58$ \\
\hline FEF50/CVF $=2,7183^{(15,17-109 \text { n estatura (cm) }) \times 1,827-109 \text { n losoe } \times 0,307)}$ & previsto $\times 0,64$ \\
\hline FEF75/CVF $=2,7183^{(13,89-\log n \text { estatura }(\mathrm{cm}) \times 1,434-\log \text { n idade } \times 0,828)}$ & previsto $\times 0,59$ \\
\hline $\mathrm{FEF}_{25-75} / \mathrm{CVF}=2,7183^{(14,387-\log \text { n estatura }(\mathrm{cm}) \times 1,600-\log \text { n idade } \times 0,454)}$ & previsto $\times 0,64$ \\
\hline FEF $_{75-85} /$ CVF $=2,7183^{(12,76-\log n \text { estatura }(\mathrm{cm}) \times 1,212-\log n \text { idade } \times 0.923)}$ & previsto $\times 0,58$ \\
\hline VVM =estatura $\times 2,15$ - idade $\times 1,06-164,6$ & previsto -39 \\
\hline \multicolumn{2}{|l|}{ Volumes pulmonares 20 a 80 anos } \\
\hline \multicolumn{2}{|l|}{ CPT $=0,0709 \times$ estatura $(\mathrm{cm})$-idade $\times 0,0068-5,172$ (CVF de Pereira + VR Neder) } \\
\hline \multicolumn{2}{|l|}{$\mathrm{Cl}=$ estatura $(\mathrm{cm}) \times 0,0646-$ idade $\times 0,011-7,05$ (Neder) } \\
\hline \multicolumn{2}{|l|}{ VR $=0,0141 \times$ idade + estatura $(\mathrm{cm}) \times 0,0197-2,08$ (Neder) } \\
\hline Difusão do CO= Estatura x 0,41-idade x 0,21-26,31 (Crapo) & previsto $-7,9$ \\
\hline \multicolumn{2}{|l|}{ Pressões respiratórias máximas (Neder) } \\
\hline Pimáx $20-80$ anos $=$ Peso $(\mathrm{Kg}) \times 0,48-$ idade $\times 0,80+120$ & previsto -27 \\
\hline Pemáx $20-80$ anos $=165,3-0,81 \times$ idade & previsto -26 \\
\hline
\end{tabular}

Obs: Todos os logs são naturais (base 2,7183 )

FONTES: 1. Pereira CA, Sato T, Rodrigues SC. New reference values for forced spirometry in white adults in Brazil. J Bras Pneumol. 2007;33:397-406 Neder JA, Andreoni S, Castelo-Filho A, Nery LE. Reference values for lung function tests.I. Static volumes. Braz J Med Biol Res 199;32:703-717. Neder JA, Andreoni S, Lerario MC, Nery LE. Reference values for lung function tests. II. Maximal respiratory pressures and voluntary ventilation. Braz J Med Biol Res. 1999;32:719-27. Duarte AA, Pereira CA, Rodrigues SC. Validation of new brazilian predicted values for forced spirometry in caucasians and comparison with predicted values obtained using other reference equations. J Bras Pneumol. $2007 ; 33: 527-35$. Mallozi MD-Espirometria em crianças e adolescentes. Equações em: J Pneumologia 1996;22:105-64. Crapo RO, Morris AH. Standardized single breath normal values for carbon monoxide diffusing capacity. Am Rev Respir Dis. $1981 ; 123: 185-9$.

Tabela enviada pelos Drs José Alberto Neder e Carlos Alberto de Castro Pereira. 
Apêndice B - Valores previstos brasileiros 2008 para o gênero feminino

Tabelas, equações, questionários e valores de referência

Sociedade Brasileira de Pneumologia e Tisiologia - www.sbpt.org.br

VALORES PREVISTOS BRASILEIROS 2008

SEXO FEMININO

\begin{tabular}{|c|c|}
\hline EQUAÇĀO & LIMITE INFERIOR \\
\hline \multicolumn{2}{|l|}{ Idade 6 a 14 anos } \\
\hline CVF $=$ estatura $(\mathrm{cm}) 0,02417+$ idade $\times 0,0561+$ peso $\times 0,010-2,2197$ & previsto $-0,477$ \\
\hline $\mathrm{VEF}_{1}=$ estatura $(\mathrm{cm}) \times 0,02336+$ idade $0,0499+$ peso $\times 0,008-2,1240$ & previsto $-0,429$ \\
\hline 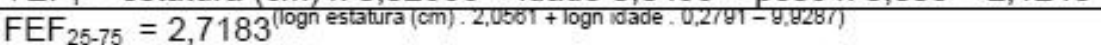 & previsto $\times 0,74$ \\
\hline $\mathrm{VEF}_{1} / \mathrm{CVF}=93(\mathrm{fixO})$ & $81 \%$ \\
\hline $\mathrm{FEF}_{25-75} / \mathrm{CVF}=120$ & $90 \%$ \\
\hline \multicolumn{2}{|l|}{ 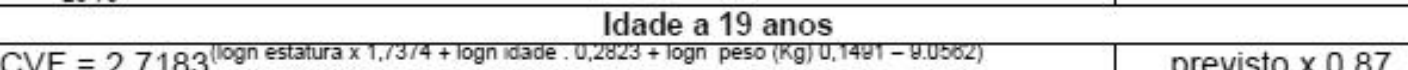 } \\
\hline $0,2823+\operatorname{loghn}$ peso $(\mathrm{kg}) 0,14 \mathrm{el}-\mathrm{g} .0502)$ & previsto $\times 0,87$ \\
\hline $\mathrm{VEF}_{1}=2,7183^{\text {(logn estatura. } 1,8283+\log \text { ldade } .0,2256+\log \text { peso }, 0,1105-8,8100)}$ & previsto $\times 0,87$ \\
\hline 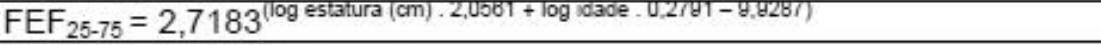 & previsto $\times 0,91$ \\
\hline $\mathrm{VEF}_{1} / \mathrm{CVF}$ previsto $=97 \%$ & $88 \%$ \\
\hline FEF/CVF previsto $=124$ & $100 \%$ \\
\hline \multicolumn{2}{|l|}{ Idade 20 a 85 anos } \\
\hline CVF $=$ estatura $\times 0,0441-$ idade $\times 0,0189-2,848$ & previsto $-0,64$ \\
\hline $\mathrm{VEF}_{1}=$ estatura $\times 0,0314-$ idade $\times 0,0203-1,353$ & previsto $-0,61$ \\
\hline VEF1/CVF $=111,5$-estatura $\times 0,14$ - idade $\times 0,158$ & previsto $-8,5$ \\
\hline $\mathrm{PFE}=2,7183^{(\log \text { n estatura }(\mathrm{cm}) \times 1,442-\log \text { n Idade } x 0,125-4,803)}$ & previsto $\times 0,75$ \\
\hline FEF $50=2,7183^{(\log \text { n estatara } \times 0,834-\log \text { n Idado } \times 0,044-1,308)}$ & previsto $\times 0,56$ \\
\hline 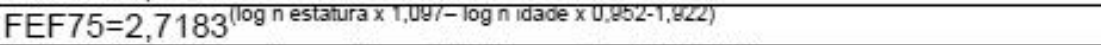 & previsto $\times 0,53$ \\
\hline $\mathrm{FEF}_{25-75}=2,7183^{(\log \text { n estatura } \times 0,808-\log \text { n Idade } \times 0,308-1,852)}$ & previsto $\times 0,57$ \\
\hline FEF75-85 $=2,7183^{(\log \text { n estatura } \times 1,382-\log \text { n idade } \times 1,088-3,27 \%)}$ & previsto $\times 0,52$ \\
\hline FEF50/CVF $=2,7183^{(13,21-\log \text { n estatura (cm) } \times 1,58-\log \text { n idade } \times 0,175)}$ & previsto $\times 0,60$ \\
\hline FEF75/CVF $=2,7183^{(12,68-\log \text { nestatura }(\mathrm{cm}) \times 1,303-\log \text { n idade } \times 0,883)}$ & previsto $\times 0,56$ \\
\hline $\mathrm{FEF}_{25-75} / \mathrm{CVF}=2,7183^{(12,73-\log \text { n estatura }(\mathrm{cm}) \times 1,401-\log \text { n idade } \times 0,319)}$ & previsto $\times 0,61$ \\
\hline $\mathrm{FEF}_{75-85} / \mathrm{CVF}=2,7183^{(11,3-\log \text { n estatura }(\mathrm{cm}) \times 1,02-\log \text { n idade } \times 0,819)}$ & previsto $\times 0,57$ \\
\hline VVM $=$ estatura $\times 2,09$ - idade $\times 0,94-162,9$ & previsto -40 \\
\hline \multicolumn{2}{|l|}{ Volumes pulmonares 20 a 80 anos } \\
\hline \multicolumn{2}{|l|}{ CPT $=$ estatura $(\mathrm{cm}) \times 0,07$ - idade $\times 0,00983-5,98$ (CVF Pereira+VR Neder) } \\
\hline \multicolumn{2}{|l|}{$\mathrm{Cl}=$ estatura $(\mathrm{cm}) \times 0,0171-$ idade $\times 0,012+$ peso $\times 0,019-1,00$ (Neder) } \\
\hline \multicolumn{2}{|l|}{$\mathrm{VR}=$ idade $\times 0,0091+$ estatura $(\mathrm{cm}) \times 0,0259-3,15$ (Neder) } \\
\hline Difusão do CO= Estatura x 0,256-idade x 0,144-8,36 (Crapo) & previsto $-5,9$ \\
\hline \multicolumn{2}{|l|}{ Pressões respiratórias máximas (Neder) } \\
\hline Pimáx $20-80$ anos $=110,5-$ idade $\times 0,49$ & previsto -15 \\
\hline PEmáx $20-80$ anos $=115,7-0,62$. idade & previsto -18 \\
\hline
\end{tabular}

Obs: Todos os logs são naturais (base $=2,7183$ )

FONTES: 1. Pereira CA, Sato T, Rodrigues SC. New reference values for forced spirometry in white adults in Brazil. J Bras Pneumol. 2007; 33:397-406. 2. Neder JA, Andreoni S, Castelo-Filho A. Nery LE. Reference values for lung function tests.I. Static volumes. Braz J Med Biol Res 199:32:703-717. 3. Neder JA, Andreoni S, Lerario MC, Nery LE. Reference values for lung function tests. II. Maximal respiratory pressures and voluntary ventilation. Braz J Med Biol Res. 1999:32:719-27. 4. Duarte AA, Pereira CA, Rodrigues SC. Validation of new brazilian predicted values for forced spirometry in caucasians and comparison with predicted values obtained using other reference equations. J Bras Pneumol. 2007; 33:527-35. 5. Mallozi MD-Espirometria em crianças e adolescentes. Equaçōes em: J Pneumologia 1996; 22:105-64. 6. Crapo RO, Morris AH. Standardized single breath normal values for carbon monoxide diffusing capacity. Am Rev Respir Dis. 1981; 123:185-9.

Tabela enviada pelos Drs José Alberto Neder e Carlos Alberto de Castro Pereira. 
Apêndice C - Evaluation of a method for assessing pulmonary function in

laryngectomees

ACTA OTORHINOLARYNGOLOGICA ITALICA 2011:31:243-247

AIrWay disease

\title{
Evaluation of a method for assessing pulmonary function in laryngectomees
}

\author{
Valutazione di un metodo per studiare la funzione polmonare nei pazienti \\ sottoposti a laringectomia totale
}

M.A. CASTRO, R.A. DEDIVITIS' A.G. MACEDO²

Department of Head and Neck Surgery of Ana Costa Hospital, Santos; Fundaçäo Lusiada UNILUS, Santos; ' Fundação Lusiada UNILUS, Santos, Postgraduate Course on Health Sciences, Hospital Heliópolis, Säo Paulo; Departments of Head and Neck Surgery of Ana Costa Hospital and Irmandade da Santa Casa da Misericórdia de Santos, Santos; ${ }^{2}$ Department of Pneumology, Federal University of Säo Paulo, São Paulo/SP, Fundação Lusiada UNILUS, Santos, Brazil

\section{SUMMARY}

In total laryngectomies the impairment of pulmonary function reflects the sum of pre- and post-operative ventilatory changes. Objective information on the respiratory condition in laryngectomees, as assessed in the pulmonary function laboratory is somewhat limited, perhaps because of difficulties related to methodology. The aim of our study was to evaluate the reproducibility of a method employed to assess the pulmonary function in laryngectomized patients. The experimental extra-tracheal device was set up with a silicone adapter through a cardboard tube to the skin around the tracheostoma. Pulmonary function tests included measurements of forced vital capacity, force expiratory volume at 1 second and Tiffeneau index in 3 consecutive evaluations, in 11 patients who underwent total laryngectomy. The control group comprised 11 patients, not laryngectomized, evaluated by conventional spirometry. Those responsible for evaluating were asked to report possible technical failures and to demonstrate the reproducibility of the curves resulting from the tests. The use of the silicone adapter and skin adhesive provided a complete, airtight seal of the system, in all cases. The presence of the tracheo-oesophageal prosthesis did not negatively affect the test results. All patients attributed a maximum value, both for comfort and acceptance, of the device. The values are comparable in both groups, thus indicating the accuracy of the proposed methodology. All examinations were reproducible. After total laryngectomy, pulmonary function testing, with an extra-tracheal device, is not only reliable but also easy to perform in a routine out-patient setting. The methodology did not present air leaks and was, therefore, well accepted by all patients tested.

KEY WORDS: Total laryngectomy $\bullet$ Respiratory function tests $\bullet$ Spirometry $•$ Tracheotomy $\bullet$ Laryngeal neoplasms $\bullet$ Respiration

\section{RIASSUNTO}

Le alterazione della funzionalità polmonare osservate nei pazienti sottoposti a laringectomia totale dipendono dalle modificazioni della ventilazione polmonare dovute all'intervento chirurgico. I dati oggettivi che si possono ottenere da una valutazione ambulatoriale dei pazienti laringectomizzati sono limitati dalle difficoltà della metodica stessa. Lo scopo del nostro studio è stato quello di valutare la riproducibilità dì un metodo utilizzato per studiare la funzionalità respiratoria nei pazienti laringectomizzati. Per tale motivo è stato allestito un sistema sperimentale extratracheale costituito da un tubo di cartone connesso ad un adattatore in silicone per la cute circostante il tracheostoma. Durante i test di funzionalità respiratoria sono state registrate la capacità vitale, il volume espiratorio forzato ad l secondo e l'indice di Tiffeneau, in 3 valutazioni consecutive di 11 pazienti sottoposti ad intervento di laringectomia totale. Il gruppo di controllo, costituito da II pazienti non laringectonizzati, è stato studiato con spirometria convenzionale. All'esecutore dell'esame è stato richiesto di segnalare le possibili cause tecniche di insuccesso e dimostrare la riproducibilità delle curve degli esami eseguiti. L'uso degli adattatori peristomali in silicone $\varepsilon$ degli adesivi cutanei ha evitato qualsiasi passibilità di dispersione del flusso aereo. La presenza di un'eventuale protesi fonatoria tracheo-esofagea non ha modificato negativamente i risultati dell' esame. Tutti $i$ pazienti hanno accettato il sistema senza problemi con giudizio positivo in termini di confort. I valori registrati erano sovrapponibili in entrambi $i$ gruppi, confermando l'accuratezza della metodica in esame. In conclusione, grazie al sistema di ventilazione extratracheale messo a punto, le prove di funzionalità polmonare offrono risultati affidabili, sono facilmente eseguibili nella normale routine ambulatoriale e ben tollerate dalla totalità dei pazienti.

PAROLE CHIAVE: Laringectomia totale - Test di funzionalità respiratoria - Spirometria - Tracheotomia - Tumori laringei • Respirazione

Acta Otorhinolaryngol Ital 2011;31:243-247 


\section{Introduction}

Many patients with head and neck cancer have a history of smoking and the pulmonary complications frequently lead to postoperative death. Spirometric pulmonary function tests are rarely performed in patients submitted to laryngectomy due to technical problems ${ }^{1}$. Many of these patients also suffer from chronic obstructive lung disease $^{2}$. Pulmonary airway obstruction was found in $81 \%$ of laryngectomized patients ${ }^{3}$.

In the post-laryngectomy state, the impairment of pulmonary function reflects the sum of ventilatory changes, mostly caused by pre-laryngectomy smoking habits and other negative effects, as well as changes due to non-physiological post-laryngectomy airway conditions. As breathing through the tracheostoma, after total laryng-ectomy, bypasses the natural air-conditioning function of the upper respiratory tract, a reduced filtering of solid air-borne particles and aerosols and inhalation of unhumidified and unheated air occurs. Compared with breathing through the upper airways, tracheostoma reduces, aerodynamically, the airflow resistance during inspiration and expiration, which may have a negative effect on peripheral lung ventilation (alveolar collapse) by shifting the equal-pressure-point ${ }^{47}$. There are various disadvantages, for the respiratory system, in post-laryngectomy status, regardless of possible tumour disease-related symptoms. One of the most important prognostic factors regarding the survival of laryngectomized patients is the progressive deterioration of pulmonary function ${ }^{58}$. Objective information on the respiratory condition in laryngectomees, as assessed in the pulmonary function laboratory, is somewhat limited $25 \%$.11.

The influence of the removal of the larynx itself and the consequent decrease in dead space ventilation can only be assessed, when pre- and post-operative spirometric values are available. Data on this topic are controversial ${ }^{12-14}$. A reliable estimate of pulmonary function is mandatory in laryngectomized patients in order to avoid complications in surgical interventions to assess the effects of therapy and even for preventive purposes ${ }^{15}$.

Traditionally, the assessment of pulmonary function, in these patients, has been performed by means of a cuffed trachea cannula connected to a pulmonary-function analyzer ${ }^{51216}$. However, the use of a cannula is troublesome for several reasons. First of all, its insertion is often an unpleasant experience for the patient, and leads to uncomfortable coughing, sometimes lasting for several minutes ${ }^{15}$. Furthermore, the use of a cuffed cannula is considered a negative influence on the results of forced expiration and inspiration tests due to a decrease in the actual diameter of the trachea. Trachea masks, manually placed over the stoma, have also been used for this reason but sometimes allow air leaks ${ }^{2}$. Extra-tracheal devices have been reported to be used by some Authors in order to avoid such problems ${ }^{\text {g-11 }}$.
A standardized, simple and inexpensive method for the assessment of pulmonary function, in laryngectomized patients, would be very useful, but it is necessary to evaluate this method in order to determine its accuracy. The aim of this study was to evaluate the reproducibility of a method developed to assess pulmonary function in larygectomized patients.

\section{Material and methods}

Overall, 11 patients ( 9 male, 2 female), underwent total laryngectomy in the Head and Neck Surgery of Ana Costa Hospital and Santa Casa da Misericórdia de Santos, Brazil. The median age was 66.5 years (ranging from 45 to 84). All patients were informed about the aims of the study and all volunteered to take part in the study. Exclusion criterion was presentation of any respiratory infection during the 2 weeks preceding the study. The Guilherme Alvaro Hospital Institutional Review Board approved this study (Registration no. 025/09).

Laryngectomees were asked to complete a questionnaire to obtain their clinical history. Details were requested concerning previous and current data referring to lung diseases, allergies, other diseases related to pulmonary function, previous smoking and drinking habits, date of laryngectomy and voice rehabilitation modality and the Medical Research Council Dyspnoea Index was applied ${ }^{17}$. Both height and weight of patients were measured before the test.

The experimental extra-tracheal device was set up with the Regular Provox Adhesive base plate (Provox ${ }^{\infty}$, Atos Medical, Hörby, Sweden) and the adapter with an inner diameter of $2.5 \mathrm{~cm}$ and a circumferential $2.5 \mathrm{~cm}$ elastic flange to connect the mouthpiece of the spirometer through a cardboard tube to the skin around the tracheostoma. The length of the cardboard was the minimum necessary to connect it to the mouth-piece of the spirometer in order to avoid the dead space increase $(4.5 \mathrm{~cm})$ (Fig. 1). When the stoma was connected to the tubing of the spirometer, via

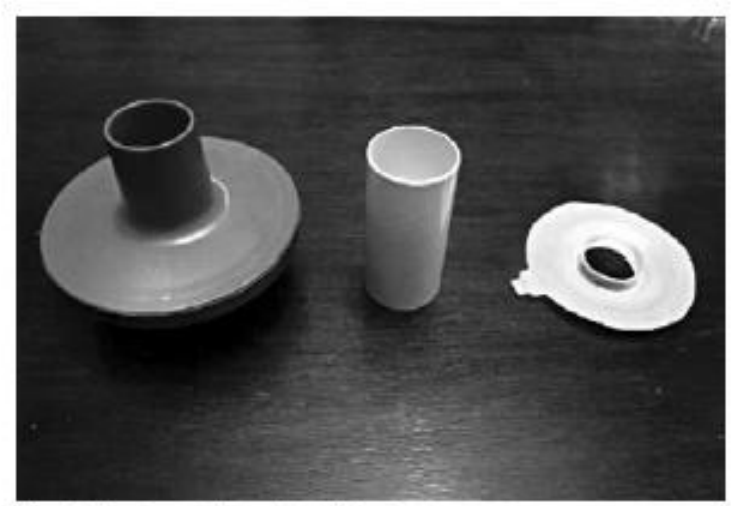

Fig. 1. Experimental extratracheal device. 


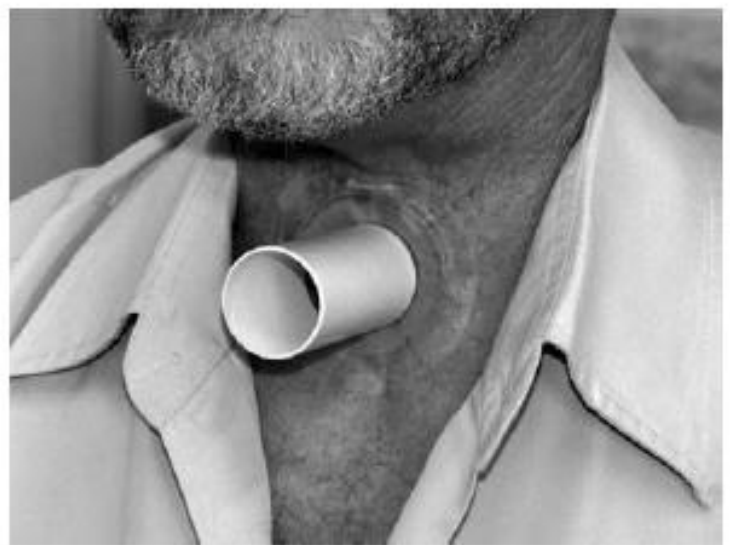

Fig. 2. Experimental extratracheal device connected to the patient.

the adapter, movements of the participants, as, for example, in forced respiratory manoeuvres, could still be tolerated, maintaining a complete airway seal (Fig. 2). After pulmonary function testing the adhesive was removed and the skin was examined for irritation or allergic reactions. The patients were asked to rate comfort and acceptance of the device, and adverse skin reactions were also evaluated.

After the adjustment of the silicone adapter and insertion of a filtre into the tubing system, participants were assessed by means of spirometric measurements (KOKO D201017 - PDS Instrumentation) (Fig. 3). Pulmonary function tests included standard measurements of forced vital capacity (FVC), force expiratory volume at 1 second $\left(\mathrm{FEV}_{1}\right.$ ) and Tiffeneau index (FEV /FVC).

After the correct calibration of the equipment, each participant underwent three consecutive evaluations according to the international protocols and techniques, previously validated in the literature ${ }^{18}$. Test results were displayed on a monitor, stored on hard drive, and data were thereafter listed in Tables and presented as Graphs (flow-volume loops and pressure-flow Graphs). All tests were performed by a pneumologist specialized in spirometry. The test results were independently evaluated by two pneumologists, with expertise in spirometry, that did not participate in the study. The 11 tests related to the group of laryngectomized patients (Group I) were evaluated together with 11 tests from patients, not laryngectomized (Group II), performed by conventional spirometry. It was decided to use a control group of patients, not laryngectomized, in order to assess the reproducibility and accuracy of the method used for laryngectomees. The 22 tests were mixed and those evaluating were not told which group belonged to each exam. They were asked to diagnose the exams, report possible technical failures, in each of the tests, and to check the reproducibility of the curves from the tests.

The tests were separated again later and the percentage of

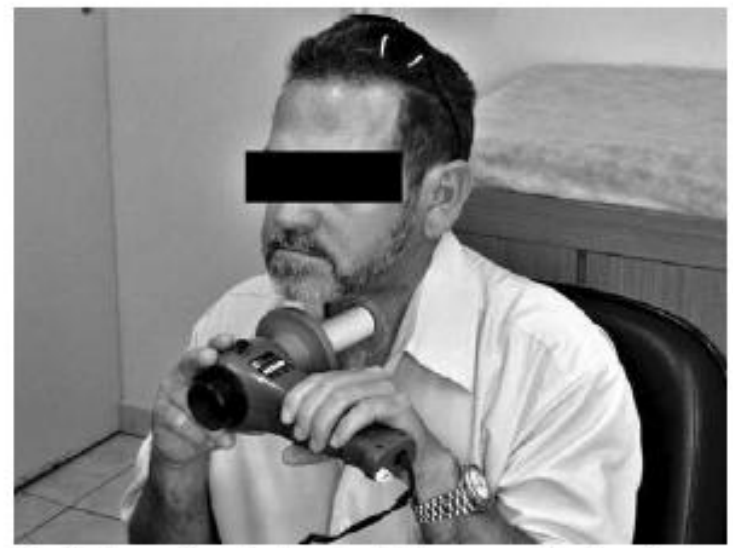

Fig. 3. The experimental extratracheal devioe connected to the spirometer,

possible technical errors, in the exams and reproducibility, were assessed for each group of tests.

\section{Results}

The mean interval between laryngectomy and pulmonary function test was 74.3 months and ranged from 6 months to 124 months. Prior to laryngectomy, 6 participants $(54 \%)$ had been cigarette smokers and $9(82 \%)$ had been alcohol drinkers. Three participants did not report previous smoking and 2 prior alcohol drinking (Table I).

Eight patients $(73 \%)$ were rehabilitated with a tracheooesophageal prosthesis (Provox ${ }^{\infty}$, Atos Medical, Hörby, Sweden) and $3(27 \%)$ with oesophageal voice.

Six participants $(54 \%)$ had a Dyspnoea Index (MRC) of 0, three $(28 \%)$ of 1 , one $(9 \%)$ of 2 and one $(9 \%)$ of 3 .

After the assessment had been made in each group, a comparison was made. In Group I, 7 patients had their exams diagnosed as normal and in the control group 8 tests were normal. In both groups, there were 3 patients with obstructive ventilatory disturbances, only one participant from Group I presented a restrictive ventilatory disorder, this patient had diaphragmatic paralysis before the examination (Table I).

The use of the adapter caused no problems in any of the 11 participants. It could easily be attached to the stoma and the lung function analyzer in all patients. The use of the silicone adapter and skin adhesive provided a complete, air-tight seal of the system throughout pulmonary function testing, in all cases. The tests usually lasted for 15 minutes. The silicone adapter was also well sealed with its very flexible flanges in those cases where the skin surface of the peristomal area was uneven because of scar formation or uneven anatomical morphology. The presence of tracheo-oesophageal prosthesis (Provox ${ }^{\infty}$, Atos Medical, Hörby, Sweden) did not affect the test results in any way. No subject showed signs of discomfort at any 
Table I. Comparative results Group I x Group |l

\begin{tabular}{lcc} 
& Group I & Group II \\
Age (media) & 64 & 48 \\
Tobacco (+) & 5 & 6 \\
Normal (n) & 7 & 8 \\
OVD (n) & 3 & 3 \\
RVD (n) & $1^{*}$ & 0 \\
\hline
\end{tabular}

OWD: Oostructive ventilatory disorder; $F W$ : Restrictive ventilatory alsorder; - Patient with ofaphragmatic paraysis.

time during the procedure. No adverse skin reactions were observed after use of the skin adhesive. All patients expressed a maximum value for comfort and acceptance of the device.

The pneumologists who evaluated independently the tests found low levels of technical failure in examinations. Only one exam was rejected in the Group I, thus indicating the accuracy of the methodology proposed.

\section{Discussion}

Relatively little attention has been paid to assessment of pulmonary function in patients who have undergone total laryngectomy, in the literature. One of the reasons for this lack of information could be the present difficulties in performing standard lung function tests in those patients ${ }^{15}$. However, there are numerous studies reporting that a large percentage of laryngectomees have obstructed the airways and many of these might benefit from medical treatment ${ }^{358}$.

Due to the probability of dying from a second cancer, lung diseases are the second leading cause of mortality in laryngectomized patients, which suggests the need to perform spirometry periodically".

The lack of performing studies on pulmonary function in laryngectomized patients is not so much because of the absence of indication, but the lack of technical means to carry out the tests ${ }^{8}$. Some authors describe the use of cuffed cannulas ${ }^{512}$ or trachea masks placed manually over the stoma to connect the patient to the lung function analyzer $^{21}$. However, the introduction of a trachea cannula is often uncomfortable for the patient and the seal of the trachea mask generally present air leaks.

The presence of indwelling voice prosthesis with a wide diameter, i.e. the Provox ${ }^{\infty}$ valve, does not seem to negatively affect the test results ${ }^{7}$. It is thought to be crucial not to reduce the diameter of the tracheal lumen during measurements (e.g., with cuffed cannulas) in order to obtain more representative data ${ }^{3}$, a fact that has also been emphasized in other studies ${ }^{27}$. Some studies describe the use of extra-tracheal devices, constructed with a plastic tube and a latex balloon cuff to obtain an airtight seal to avoid such problems?
In all cases in our study, an air-tight seal was maintained throughout the entire procedure, including also those cases in which forced expiration manoeuvres were associated with involuntary tilting movements of the thorax and neck or pulsed, high-pressure loadings during coughing. No adverse skin reaction was observed after use of the skin adhesive.

Besides the convenience of an extra-tracheal device, data in some studies show unequivocally that the values of lung volumes and functions, determined with the use of extra-tracheal devices, are more reliable ${ }^{15}$.

The findings presented herewith are in agreement with those reported in the study performed by Hess et al. ${ }^{3}$ indicating the need to re-evaluate the role of pulmonary function screening within follow-up of post-laryngectomy patients, and, particularly, in view of the availability, accuracy and easy use of pulmonary function screening equipment.

\section{Conclusions}

The pneumologists who independently evaluated the tests found low levels of technical failure in the examinations. They concluded that all examinations except one were reproducible.

\section{Acknowledgements}

Authors thank MZ Medical, São Paulo, Brazil, for providing the Regular Provox Adhesive base plates.

\section{References}

1 Matsuura K, Ebihara S, Yoshizumi T, et al. Changes in respiratory function before and after laryngectomy. Nippon Jibiinkoka Gakkai Kaiho. 1995;98:1097-103.

2 Togawa K, Konno A, Hoshino T. A physiologic study on respiratory handicap of the laryngectomized. Arch Otorhinolaryngol 1980;229:69-79.

3 Hess MM, Schwenk RA, Frank W, et al. Pulmonary function after total laryngectomy. Laryngoscope 1999;109:988-94.

4 Torjussen W. Airway obstructions in lanyngectomized patients. A spirometric investigation. Acta Otolaryngol $1968 ; 66: 161-70$

5 Todisco T, Maurizi M, Paludetti G, et al. Laryngeal cancer: long-term follow-up of respiratory functions after laryngectomy. Respiration 1984;45:303-15.

6 McRae D, Young P, Hamilton J, et al. Raising airway resistance in laryngectomees increases tissue oxygen saturation. Clin Otolaryngol Allied Sci 1996;21:366-8.

7 Ackerstaff AH, Hilgers FJ, Balm AJ, et al. Long-term pulmonary function after total laryngectomy. Clin Otolaryngol Allied Sci 1995;20:547-51.

8 Vázquez de la Iglesia F, Fernández González S. Method for the study of pulmonary function in laryngectomized patients. Acta Otorrinolaringol Esp 2006;57:275-8.

? Davidson RN, Hayward L, Pounsford JC, et al. Lung func- 
tion and within-breath changes in resistance in patients who have had a laryngectomy. Q J Med 1986;60:753-62.

10 Gardner WN, Meah MS. Respiration during exercise in conscious laryngectomized humans. J Appl Physiol 1989;66:2071-8.

11 Gregor RT, Hassman E. Respiratory function in post-lanyngectomy patients related to stomal size. Acta Otolaryngo 1984;97:177-83.

12 Harris S, Jonson B. Lung function before and after lanyngectomy. Acta Otolaryngol 1974;78:287-94.

${ }^{13}$ Heyden $\mathrm{R}$. The respiratory function in laryngectomized patients. Acta Otolaryngol 1950;85:39-59.

34 Durán Cantolla J, Sampedro Alvarez JR, Zurbano Gonì F, et al. Measurement of pulmonary function in laryngectomized patients. An Otorrinolaringol Ibero Am 1989;16:387-400.

15 Ackerstaff AH, Souren T, van Zandwijk N, et al. Improvements in the assessment of pulmonary function in laryngectomized patients. Laryngoscope 1993;103:1391-4.

16 Tan AK. Incentive spirometny for tracheostomy and lanyngectomy patients. J Otolaryngol 1995;24:292-4.

17 Sociedade Brasileira de Pneumologia e Tisiologia. II Consenso Brasileiro de Doenca Pulmonar Obstrutiva Cronica (DPOC) - 2004. J Pneumol 2004;30:1-42.

18 American Thoracic Society. Standardization of spirometry, 1994 Update. Am J Respir Crit Care Med 1995;152:1107-36.

Received: January 20, 2011 - Accepted: April 3, 2011

Address for correspondence: Dr. Mario A. Castro, Rua Dr. Olinto Rodrigues Dantas, 343 conj. 92, 11050-220 Santos, Sāo Paulo, Brazil. E.mail: mafc@uol.com.br 